\title{
Estudos Laboratoriais da Contaminação do Solo por Gasolina com o Uso de Detetor de Fotoionização
}

\section{Giovanni Chaves Penner}

Dissertação apresentada à Escola de Engenharia de São Carlos da Universidade de São Paulo, como parte dos requisitos para obtenção do Título de Mestre em Hidráulica e Saneamento.

ORIENTADOR: Prof. Dr. Dante Contin Neto

São Carlos 
A minha mãe, que fez de seus dias, dias de seus filhos. 


\section{AGRADECIMENTOS}

Desejo a princípio agradecer a Deus por sempre iluminar meus caminhos e pela proteção nos momentos difíceis.

A minha mãe Gilda Helena Chaves Penner e ao meu pai Guilherme Penner, aos meus irmãos Gerson, Gisele, Gilvandro e Gustavo, a minha prima irmã Lilia, e a todos os demais parentes que direta ou indiretamente contribuíram para essa caminhada.

Ao meu orientador Professor Dr. Dante Contin Neto, pela orientação, incentivo e amizade, aos Professores Harry e Fernanda pelos incentivos e contribuições, e a todos os demais Professores do Departamento de Hidráulica e Saneamento que de alguma forma contribuíram para a realização desta pesquisa.

Aos técnicos do Laboratório de Hidráulica Edson, Luiz Muzzeti e Oswaldo (Vadinho), pelo auxílio na montagem dos experimentos e assistência concedida durante a fase experimental. A todos os demais técnicos do Departamento de Hidráulica e Saneamento que colaboraram para com essa pesquisa.

Aos conterrâneos e amigos Aurélio, Hélio, Márcio e Neyson que conhecem as dificuldades encontradas pelos estudantes do norte do País em participar de um programa de pós-graduação em uma Universidade de qualidade, aos amigos Roberto Gadêlha, Rosana Patrícia e Gracione Ribeiro pelo companheirismo e pelos bons momentos que compartilhamos, e a todos os demais colegas que fiz na cidade de São Carlos. 
Ao amigo e Professor Alírio César de Oliveira Júnior pelo incentivo fornecido no início desta caminhada, e aos demais Professores da Universidade Federal do Pará que direta ou indiretamente colaboraram para com este momento.

A minha namorada Josiele de Souza Araújo, pelos ótimos momentos que passamos juntos e pelos que ainda virão.

Ao CNPq - Conselho Nacional de Desenvolvimento Científico e Tecnológico, pela bolsa de estudo concedida.

A todos que contribuíram para que essa pesquisa se realizasse. 


\section{SUMÁRIO}

1 INTRODUÇÃO ........................................................................................................ 1

2 OBJETIVOS............................................... ERRO! INDICADOR NÃO DEFINIDO.

3 REVISÃO BIBLIOGRÁFICA............................................................................ 5

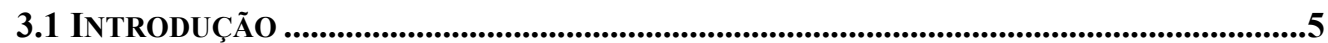

3.2 CARACTERÍSTICAS DO CONTAMINANTE (GASOLINA)_..............................................5

3.3 FASES DOS HIDROCARBONETOS .........................................................................................9

3.3.1 Comportamento das Fases dos Hidrocarbonetos ..................................... Erro! Indicador não definido.

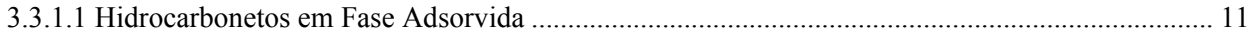

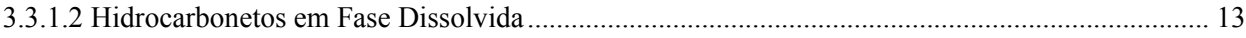

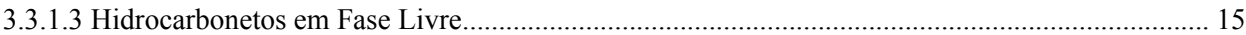

3.3.1.4 Hidrocarboneto em Fase de Vapor ................................................................................... 16

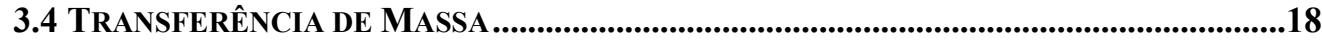

3.4.1 Movimento de Vapores na Zona Não Saturada ........................................ Erro! Indicador não definido.

3.5 MÉtodos de CAMPo PARA ANÁliSE de Hidrocarbonetos...................................22

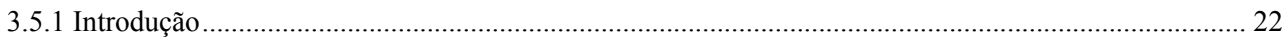

3.5.2 Nível de Qualidade de Dados.................................................................. Erro! Indicador não definido.

3.5.2.1 Nível de Qualidade de Dados 1: Seleção .............................................. Erro! Indicador não definido.

3.5.2.2 Nível de Qualidade de Dados 2: Delineação Quantitativa................ Erro! Indicador não definido.

3.5.2.3 Nível de Qualidade de Dados 3: Zona de Limpeza Quantitativa ........

3.5.3 Métodos Analíticos para Vapores Orgânicos Totais: Ionização por Chama e Detetores de

Fotoionização .

Erro! Indicador não definido.

3.5.3.1 Princípios de Operação ....................................................................... Erro! Indicador não definido.

3.5.3.2 Detetores de Ionização por Chama.................................................... Erro! Indicador não definido.

3.5.3.3 Detetores de Fotoionização ....................................................................................................... 28

3.5.3.4 Comparação entre Detetores de Ionização por Chama e Detetores de Fotoionização........................... Indicador não definido.

3.5.3.5 Descrição do Método. .

Erro! Indicador não definido.

3.5.3.6 Capacidades do Método e Considerações Práticas Erro! Indicador não definido.

\section{MATERIAL E MÉTODOS.} ERRO! INDICADOR NÃO DEFINIDO.

4.1 INTRODUÇÃO

ERRO! INDICADOR NÃO DEFINIDO.

4.2 ENSAios PRELiminares

4.2.1 Características da Gasolina

ERRO! INDICADOR NÃO DEFINIDO.

4.2.2 Caracterização do Solo... Erro! Indicador não definido. Erro! Indicador não definido.

4.3 ANÁliSE COM DETETOR DE FOTOIONIZADOR.........ERRO! INDICADOR NÃO DEFINIDO.

4.3.1 Fundamentação Teórica da Fotoionização Erro! Indicador não definido.

4.3.2 Princípios de Funcionamento do Detetor de Fotoionização. Erro! Indicador não definido.

4.4 DESCRIÇÃO DOS ENSAIOS EXPERIMENTAIS .............ERRO! INDICADOR NÃO DEFINIDO.

4.4.1 Ensaios de Difusão do Contaminante Livre para a Atmosfera ............... Erro! Indicador não definido. 4.4.1.1 Preparação dos Experimentos........................................................... Erro! Indicador não definido. 4.4.1.2 Ensaios Preliminares..................................................................... Erro! Indicador não definido.

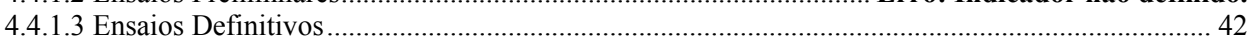

4.4.2 Ensaios de Difusão de Contaminante em Solos Não Saturado ............................................................ 44

4.4.2.1 Ensaios de Difusão de Gasolina em Solo Não Saturado em Provetas............................................. 44

4.4.2.2 Ensaios de Difusão de Gasolina em Solo Não Saturado em Escala Maior ..................................... 46

4.5 Software APIDSS (InStituto AMERiCANo do Petróleo Sistema de APOIO A

DECISÃO - AMERICAN PETROLEUM INSTITUTE DECISION SUPPORT SYSTEM) .............48

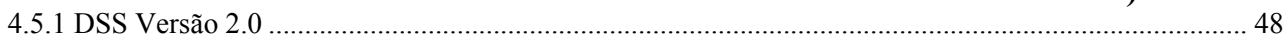

4.5.1.1 Propriedades de transporte e destino ............................................... Erro! Indicador não definido.

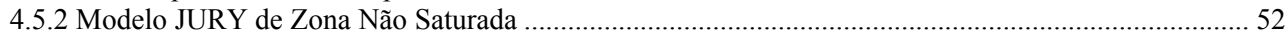

4.6 AnÁlise de ERro: CRITÉrio de CHAUVENET ..................................................56 


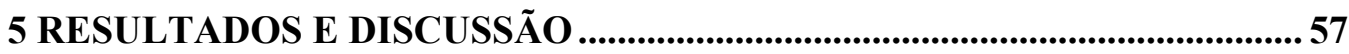

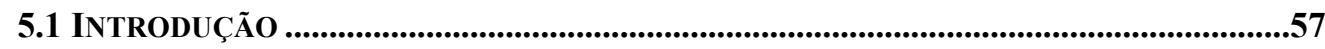

5.2 CARACTERÍSTICAS DA GASOLINA ........................................................................................57

5.3 CARACTERIZAÇÃO DO SOLO........................................................................................................58

5.4 ENSAIOS DE DIFUSÃo do CONTAMINANTE LIVRE PARA A ATMOSFERA.....................58

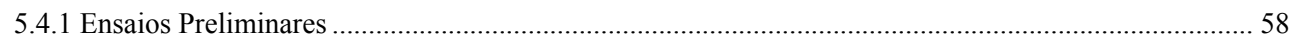

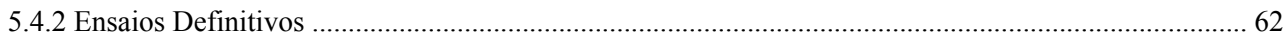

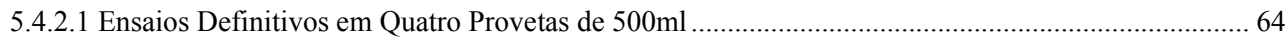

5.5 ENSAIOS DE DIFUSÃo EM SOLO NÃO SATURAdo ...............................................................79

5.5.1 Ensaios de Difusão em Solo Não Saturado em Provetas.............................................79

5.5.2 Ensaios de Difusão em Solo Não Saturado em Escala Maior ....................................93

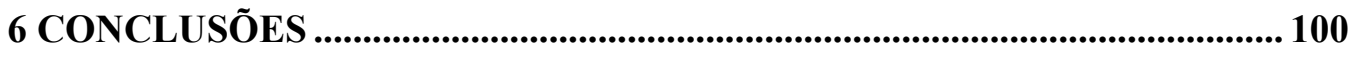

7 REFERÊNCIAS BIBLIOGRÁFICAS .......................................................... 102

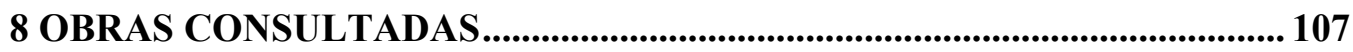




\section{LISTA DE FIGURAS}

Figura 4.1 - Composição da gasolina utilizada no Brasil......................................................35

Figura 4.2- Comparação entre o solo comum e o solo sem a fração orgânica.........................37

Figura 4.3- Exemplo esquemático princípio do processo de fotoionização.............................38

Figura 4.4- A ilustração mostra kit que compõem o detetor de fotoionização. À esquerda está localizado o balão de calibração, na região central está localizado o datalogger e à direita, conectada ao datalogger, a sonda utilizada para realizar as

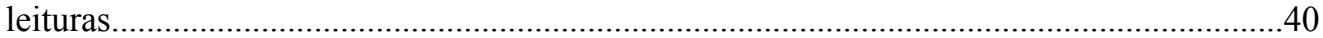

Figura 4.5- A ilustração mostra uma comparação entre as diversas fases de ensaio. a) mostra o desenvolvimento do ensaio com aproximadamente 95 dias; b) mostra o desenvolvimento do ensaio com aproximadamente 220 dias. .43

Figura 4.6- Esta ilustração mostra como procederam-se as leituras em ensaios utilizando provetas. .43

Figura 4.7- A ilustração mostra como procedeu-se o ensaio de difusão em solo utilizando cinco provetas (há uma pequena diferença na ordem das provetas, sendo que a proveta 5 dessa foto deveria estar na posição 3, isso ocorreu devido a curta duração do experimento)......

Figura 4.8- Ilustra como procedeu-se o ensaio de difusão em solo utilizando duas

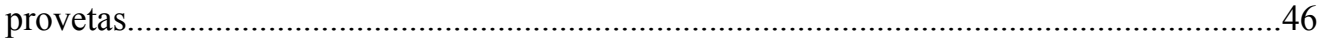

Figura 4. 9- Ilustração do ensaio utilizando colunas de acrílico. a) representa o experimento em andamento; b) representa uma visão geral do experimento. .47

Figura 4.10- A ilustra mostra como procedeu-se o ensaio com cinco recipientes cilíndricos (vale ressaltar que a princípio os recipientes foram totalmente preenchidos com solo e o solo acomodado por agitação manual, porém com a introdução de gasolina e após decorrem 120 dias de ensaio o solo compactou-se aproximadamente $3 \mathrm{~cm}$ ).... .48

Figura 4. 11- Esquema dos modelos incluídos no DSS (AMERICAN PETROLEUM INSTITUTE, 1999).

Figura 5. 1- A figura representa graficamente os valores de massa em função do

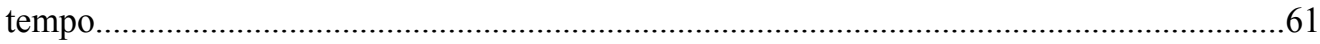

Figura 5. 2- Representação gráfica dos resultados de fluxo de massa em função do

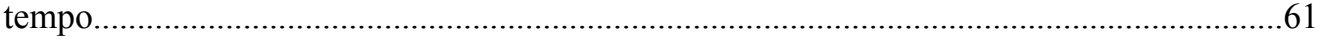

Figura 5. 3- A figura representa graficamente os valores de massa em função do tempo................................................................................................................6

Figura 5. 4- A figura representa graficamente os valores de concentração (obtidos com detetor de fotoionização) em função do tempo...............................................................63

Figura 5. 5- Representação gráfica do fluxo de massa em função do tempo ........................63 Figura 5. 6- A figura representa graficamente os valores de massa em função do tempo. ..67

Figura 5. 7- A figura representa graficamente os valores de massa volatilizada em função do tempo. 67

Figura 5. 8(a)- A figura representa graficamente os valores de concentração em função do tempo..........................................................................................................6

Figura5. 8(b)- A figura representa graficamente os valores de concentração em função do tempo até 34 dias. .68 Figura5. 8(c)- A figura representa graficamente os valores de concentração em função do tempo para tempo superior a 34 dias 69 Figura 5. 9- Representação gráfica dos resultados de fluxo de massa em função do tempo. 69

Figura 5.10- Representação gráfica do fluxo adimensionalizado em função do

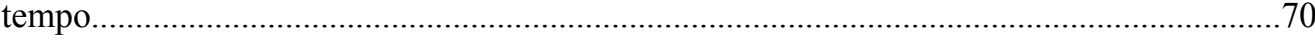


Figura 5. 11- Representação gráfica dos resultados de massa adimensionalizados em função dos resultados de tempo adimensionalizados.

Figura 5. 12- Representação esquemática das dimensões adotadas para equacionar o ensaio com quatro provetas.

Figura 5. 13- Representação gráfica dos resultados experimentais para um ajuste linear..

Figura 5. 14- Representação gráfica dos resultados experimentais comparados com um modelo com $\mathrm{C}_{\mathrm{a}}$ variável.

Figura 5. 15- Representação gráfica dos resultados de concentração obtidos com o detetor comparados com o modelo empírico

Figura 5. 16- Representação gráfica dos resultados obtidos comparando-se os dois lados da equação proposta. . .77

Figura 5. 17- Representação gráfica dos resultados para a Proveta02 (a e b).........................77

Figura 5. 18- Representação gráfica dos resultados para a Proveta03 (a e b)..........................78

Figura 5. 19- Representação gráfica dos resultados para a Proveta04 (a e b).........................78

Figura 5. 20- Representação gráfica dos resultados de massa em função do tempo................81

Figura 5. 21- Representação gráfica dos resultados de concentração em função do

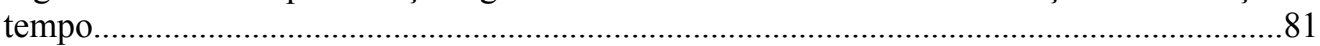

Figura 5. 22- Representação gráfica da massa volatilizada em função do tempo.....................82

Figura 5. 23- Representação gráfica dos resultados de fluxo de massa em função do tempo..... . .82

Figura 5. 24- Representação gráfica dos resultados de massa em função do tempo................85

Figura 5. 25- Representação gráfica dos resultados de concentração em função do

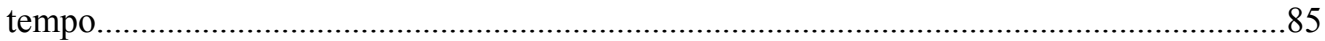

Figura 5. 26- Representação gráfica de fluxo de massa em função do tempo.........................86

Figura 5. 27- Representação gráfica do percentual de massa acumulada volatilizada e função do tempo.

Figura 5.28- Diferença entre os percentuais de massas volatilizadas para as Provetas 01 e 02.

Figura 5. 29- Ilustração dos experimentos utilizando solo contaminado por gasolina em provetas de $250 \mathrm{ml}$. Vale ressaltar que para a Proveta01, no primeiro momento, a distância " $\mathrm{e}_{2}$ " não existe.

Figura 5. 30- Ajuste de modelo exponencial aos resultados de concentração obtidos com fotoionizador. .89

Figura 5. 31- Ajuste das constantes e comparação entre os dois lados do modelo proposto (Proveta01) .90

Figura 5. 32- Representação gráfica da variação do desvio percentual em função do tempo para a Proveta01.. 90

Figura 5. 33- Ajuste das constantes e comparação entre os dois lados do modelo proposto (Proveta02) 92

Figura 5. 34- Representação gráfica da variação do desvio percentual em função do tempo para a Proveta02 .92

Figura 5. 35- Representação gráfica dos resultados obtidos simulando-se o modelo JURY para as condições do experimento. (a) para a Proveta sem Recobrimento e b) para a Proveta com Recobrimento . . .93

Figura 5. 36- Representação gráfica dos resultados de concentração ao longo do

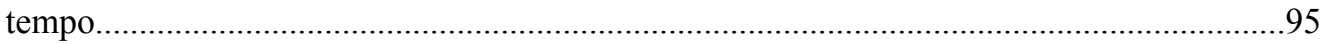

Figura 5. 37- Representação gráfica dos resultados de concentração medidos ao longo do tempo para a Coluna sem Recobrimento..

Figura 5. 38- Representação gráfica dos resultados de concentração medidos ao longo do tempo para o experimento que utilizou cinco recipientes cilíndricos.

Figura 5. 39- Representação gráfica das diferenças entre as concentrações, tomando-se como referência o Recipiente01 


\section{LISTA DE TABELAS}

Tabela 3.1 - Composição de uma gasolina regular (JOHNSON et al., 1990). .........................6

Tabela 3.2 - Propriedades dos oxigenados, gasolina e diesel $\mathrm{N}^{\mathrm{o}} 2$ (API, 1993).......................8

Tabela 3.3 - Distribuição das Fases do Contaminante (GROUNDWATER TECHNOLOGY INC. $*^{2}$ apud OLIVEIRA 1992).

.10

Tabela 3.4 - Valores Típicos da Concentração de Gasolina Residual na Zona Não Saturada (API, 1993) 12

Tabela 3.5.1 - Resumo dos Métodos de Campo para Análise de Hidrocarbonetos do Petróleo .24

Tabela 3.5.2 - Resumo dos Níveis de Qualidade de Dados..................................................2.

Tabela 3.5.3.1 - Comparação entre FIDs e PIDs......................................................................29

Tabela 3.5.3.2 - Resumo da Capacidade do Método e Considerações Práticas para Vapor Orgânico Total 32

Tabela 4.1 - Composição da gasolina utilizada no Brasil (PETROBRAS,

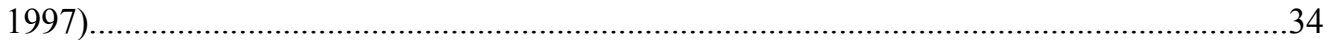

Tabela 4.2 - Modelos de Transporte e Destino nos tipos de Modelos do DSS. AMERICAN PETROLEUM INSTITUTE (1999).

Tabela 4.3 - Base de dados das propriedades químicas (API, 1999)...................................52

Tabela 5.1 - Valores de umidade $(w)$, porosidade $(\eta)$, massa específica dos sólidos $\left(\rho_{\mathrm{s}}\right)$, composição e fração de carbono orgânico $\left(f_{o c}\right)$ obtidos em ensaios realizados em amostras deformadas.

Tabela 5.2 - Valores de massa medidos em função do tempo para os diversos ensaios preliminares. .60

Tabela 5.3 - Valores de massa e concentração medidos ao longo do tempo...........................62

Tabela 5.4 - Valores de massa e concentração medidos ao longo do tempo............................64

Tabela 5.5 - Valores de massa, concentração e temperatura medidos ao longo do tempo para o experimento com cinco provetas.

Tabela 5.6 - Valores de massa, concentração e temperatura medidos ao longo do tempo para o experimento com duas provetas com solo.

Tabela 5.7 - Resultados de concentração e temperatura medidos ao longo do tempo............93

Tabela 5.8 - Valores de concentração e temperatura medidos ao longo do tempo para o experimento utilizando cinco recipientes cilíndricos. 


\section{LISTA DE ABREVIATURAS E SIGLAS}

DQL - Data Quality Level - Nível de Qualidade de Dados.

ESA - Expedited Site Assessments - Fácil Avaliação do Local.

UST - Underground Store Tank - Tanque de Armazenamento Subterrâneo.

EPA - Evironmental Protection Agency - Agência de Proteção Ambiental.

API - American Petroleum Institute - Instituto Americano do Petróleo.

TOV - Total Organic Vapor - Vapor Orgânico Total.

BTEX - Benzeno, Tolueno, Etilbenzeno e Xileno.

TPH - Total Petroleum Hydrocarbon - Total de Hidrocarbonetos do Petróleo.

ev - Elétron Volt.

VOC - Volatile Organic Compound - Composto Orgânico Volátil.

LNAPLs - Light Nonaqueous Phase Liquid - Líquido com Fase Não Aquosa mais Leve que a Água.

NAPL - Nonaqueous Phase Liquid - Líquido com Fase Não Aquosa.

Contru - Departamento de Controle e Uso de Imóveis.

CNPq - Conselho Nacional de Desenvolvimento Científico e Tecnológico.

ANP - Agência Nacional do Petróleo.

APIDSS - American Petroleum Institute Decision Support System - Instituto Americano do Petróleo Sistema de Apoio à Decisão.

PID - Photoionization Detector - Detetor de Fotoionização.

FID - Flame Ionization Detector - Detetor de Ionização por Chama.

CRHEA - Centro de Recursos Hídricos e Ecologia Aplicada.

ABNT - Associação Brasileira de Normas Técnicas. 


\section{LISTA DE SÍMBOLOS}

$\mathrm{F}_{\mathrm{x}}-$ Fluxo de massa na direção $\mathrm{x}\left[\mathrm{M} / \mathrm{L}^{2} \mathrm{~T}\right]$.

$\mathrm{D}$ - Coeficiente de difusão molecular $\left[\mathrm{L}^{2} / \mathrm{T}\right]$.

$\mathrm{dC} / \mathrm{dx}$ - Gradiente de concentração $\left[\mathrm{M} / \mathrm{L}^{2}\right]$.

$\dot{M}$ - Descarga de massa [M/T].

$\Delta \mathrm{M}$ - Variação de Massa [M].

$\Delta \mathrm{t}$ - Intervalo de tempo [T].

$\mathrm{M}$ - Massa de gasolina [M].

$\rho$ - Massa específica $\left[\mathrm{M} / \mathrm{L}^{3}\right]$.

Vol. - Volume de gasolina $\left[\mathrm{L}^{3}\right]$.

$\eta$-porosidade [-].

$\mathrm{C}_{\mathrm{T}}-$ Concentração total no solo $\left[\mathrm{M} / \mathrm{L}^{3}\right]$.

$\mathrm{t}$ - Tempo [T].

$\mu$ - Constante de proporção de decaimento de primeira ordem $\left[\mathrm{T}^{-1}\right]$.

$\mathrm{D}_{\mathrm{E}}$ - Coeficiente de difusão [ $\left.\mathrm{L}^{2} / \mathrm{T}\right]$.

$\mathrm{z}$ - Profundidade medida da superfície do solo [L].

$\mathrm{V}_{\mathrm{E}}-$ Velocidade efetiva do contaminante [L/T].

$\mathrm{C}_{0}$ - Concentração total inicial de contaminante no solo $\left[\mathrm{M} / \mathrm{L}^{3}\right]$.

L - Profundidade inicial da concentração de contaminante [L].

$\mathrm{H}_{\mathrm{E}}-$ Coeficiente de transferência de massa $[\mathrm{L} / \mathrm{T}]$.

$\rho_{\mathrm{b}}$ - Densidade do volume de solo $\left[\mathrm{M} / \mathrm{L}^{3}\right]$.

$\mathrm{C}_{\mathrm{S}}-$ Concentração da fase sorvida [-].

$\theta_{\mathrm{w}}-$ Conteúdo volumétrico de água [-].

$\mathrm{C}_{\mathrm{w}}$ - Concentração da fase dissolvida [-].

$\theta_{\mathrm{a}}-$ Conteúdo volumétrico de ar [-].

$\mathrm{C}_{\mathrm{v}}$ - Concentração da fase de vapor [-].

$\mathrm{K}_{\mathrm{d}}$ - Coeficiente de partição solo-água específico para cada substância $\left[\mathrm{L}^{3} / \mathrm{M}\right]$. 
$\mathrm{K}_{\mathrm{oc}}$ - Coeficiente de partição do carbono orgânico [ $\left[\mathrm{L}^{3} / \mathrm{M}\right]$.

$\mathrm{H}$ - Constante da Lei de Henry [-].

$\mathrm{D}_{\mathrm{g}}{ }^{\mathrm{a}}$ - Coeficiente de difusão gasosa específico para cada substância no ar $\left[\mathrm{L}^{2} / \mathrm{T}\right]$.

$\mathrm{D}_{1}{ }^{\mathrm{W}}$ - Coeficiente de difusão líquida específico para cada substância na água $\left[\mathrm{L}^{2} / \mathrm{T}\right]$.

$\mathrm{f}_{\mathrm{oc}}$ - Fração de carbono orgânico no solo [-].

$\mathrm{J}_{\mathrm{w}}-$ Fluxo volumétrico solo-água $[\mathrm{L} / \mathrm{T}]$.

$\mathrm{h}$ - Coeficiente de transferência da camada limite [L/T].

D - Espessura de ar estagnado na camada limite [L].

$\mathrm{M}_{\mathrm{WT}}$ - massa anual preenchendo a superfície de água [M/T].

$\mathrm{V}$ - proporção de infiltração [L/T].

$\mathrm{A}$ - área da fonte $\left[\mathrm{L}^{2}\right]$.

$\mathrm{C}_{\mathrm{w}}$ - concentração da fase dissolvida na superfície de água $\left[\mathrm{M} / \mathrm{L}^{3}\right]$.

$\mathrm{D}$ - coeficiente de dispersão hidrodinâmica $\left[\mathrm{L}^{2} / \mathrm{T}\right]$.

$\Delta \mathrm{C} / \Delta \mathrm{z}$ - gradiente de concentração na superfície de água $\left[\mathrm{M} / \mathrm{L}^{2}\right]$.

$\mathrm{V}_{\mathrm{R}}$ - Volume de produto retido pelos poros $\left[\mathrm{L}^{3}\right]$.

d - Distância vertical percorrida pelo produto até atingir o nível de água [L].

$\mathrm{S}_{\mathrm{R}}$ - Retenção específica do material geológico para o produto[-].

$\mathrm{dC} / \mathrm{dt}$ - Variação da concentração em função tempo $\left[\mathrm{M} / \mathrm{L}^{3} \mathrm{~T}\right]$.

$\mathrm{w}$ - Umidade [-].

$\rho_{\mathrm{s}}-$ Massa específica dos sólidos $\left[\mathrm{M} / \mathrm{L}^{3}\right]$.

$\mathrm{m}_{0}$ - Massa inicial $[\mathrm{M}]$.

$\mathrm{m}_{\mathrm{k}}$ - Massa no tempo $\mathrm{k}[\mathrm{M}]$. 


\section{RESUMO}

PENNER, G.C. (2000). Estudos Laboratoriais da Contaminação do Solo por Gasolina com o Uso de Detetor de Fotoionização. São Carlos, 2000. 109p. Dissertação (Mestrado) Escola de Engenharia de São Carlos, Universidade de São Paulo.

A presente pesquisa trata de calibrar, aferir e utilizar em laboratório um detetor de fotoionização (método de campo) proveitoso na caracterização de áreas contaminadas por vazamentos de gasolina; comparar as informações do detetor com os resultados obtidos com balança analítica; comparar os resultados de fluxo de massa medido com o previsto pelo modelo JURY contido no software APIDSS 2.0. O detetor mostrou-se útil como primeira ferramenta na caracterização de áreas contaminadas recentemente (até 100 dias). Para áreas onde a contaminação esteja em uma fase mais avançada o aparelho mostrou-se útil na detecção de alterações; os modelos desenvolvidos com base nos resultados obtidos com balança e com o detetor de fotoionização apresentaram resultados satisfatórios para o período de ensaio; as comparações realizadas com o software APIDSS 2.0 serviram para a confirmação dos resultados obtidos.

Palavras-chave: gasolina, laboratório, detetor de fotoionização, contaminação. 


\section{ABSTRACT}

PENNER, G.C. (2000). Laboratory Studies of the Contamination of Soil by Gasoline through the Measure of Vapor Concentration by Photoionization Detector. São Carlos, 2000. 109p. Dissertação (Mestrado) - Escola de Engenharia de São Carlos, Universidade de São Paulo.

The present research aims at gauging, checking and using a photoionization detector (field method) in laboratory advantageous to the characterization of areas polluted by leaks of gasoline; to compare the information of the detector with the results obtained in the analytic scale; to compare the results of the measured mass flow with those foreseen by the model JURY of the software APIDSS 2.0. The detector showed to be useful as a first tool in the characterization of areas recently contaminated (up to 100 days). To areas where the contamination is in a more advanced phase, the apparel showed to be useful in the detection of alterations; the development of models based on the results obtained with a scale and with the photoionization detector presented satisfactory results for the rehearsal period; the comparisons accomplished by the software APIDSS 2.0 confirmed the obtained results.

Key words: gasoline, laboratory, photoionization detector, contamination. 


\section{INTRODUÇÃO}

As indústrias de petróleo lidam diariamente com problemas decorrentes de vazamentos, derramamentos e acidentes durante a exploração, refinamento, transporte, e operações de armazenamento de petróleo e seus derivados. Para se ter uma idéia da magnitude do problema, segundo dados de 1997 da U.S. ENVIRONMENTAL PROTECTION AGENCY (1997) estimava-se que existiam mais de 1,1 milhões de tanques subterrâneos de armazenamento de gasolina nos Estados Unidos. Destes, 400.000 a 500.000 deveriam ser substituídos ou adaptados às legislações federais que entrariam em vigor no final de 1998. Ainda em função destas legislações, aproximadamente 300.000 tanques de armazenamento deveriam ser desativados, mais de 100.000 casos de vazamento foram comunicados e mais de 96.000 remediações foram completadas. Ainda referindo-se aos dados anteriores, semanalmente mais de 1.000 novos vazamentos estavam sendo encontrados em todo o território norte-americano e provavelmente 360.000 casos necessitariam de avaliação nos próximos anos.

Segundo a AGÊNCIA NACIONAL DO PETRÓLEO - ANP (2000), no Brasil existem 13 refinarias, 19 terminais marítimos e 20 terminais terrestres, 100 bases de distribuição, 179 distribuidoras, 25.680 postos de revenda e um consumo de $1.600 \mathrm{mil}$ barris/dia de produtos derivados de petróleo. As preocupações relacionadas ao potencial de contaminação de água subterrânea por derramamento de combustíveis vem crescendo em São Paulo e em diversas outras cidades do país, como Curitiba, que já possui legislação sobre o assunto, e Joinville (SC). Em São Paulo, dos 2.098 postos de combustíveis mapeados pelo Contru, $56 \%$ apresentaram irregularidades e de $20 \%$ a $25 \%$ apresentaram risco de explosão por causa de vazamento. Pelo levantamento do referido órgão, $70 \%$ dos tanques instalados nos postos têm mais de dez anos e já estariam precisando ser substituídos (REGGIANI, L. 1999). Em Joinville, a Prefeitura local realizou estudos com 65 postos da cidade e constatou que somente um não apresentou problema de contaminação do lençol freático (CADORIN ${ }^{1}$ apud FINOTTI \& CORSEUIL, 1997). Como na década de 70 houve um grande incentivo no aumento do número de postos de gasolina no país, é de supor que a

*11 CADORIN, M. (1996). Presidente da Fundação de Meio Ambiente de Joinville, SC Comunicação pessoal a CORSEUIL, H.X. apud FINOTTI, A.R.; CORSEUIL, H.X. (1997). Uso da Ação Corretiva Baseada no Risco - RBCA - Nos Casos de Contaminação de Solos e Águas Subterrâneas por Gasolina no Brasil. In: CONGRESSO BRASILEIRO DE ENGENHARIA SANITÁRIA E AMBIENTAL, 19. Foz do Iguaçu, 1997. Anais. CD-ROM. p. 2454. 
vida útil dos tanques de armazenamento, que no passado era estimada entre 20 e 25 anos, se extinguiu, o que conseqüentemente pode aumentar o ocorrência de vazamentos nos postos do país.

Quando ocorre um derramamento de contaminantes orgânicos em subsuperfície pode ser observada a formação de cinco fases, classificadas como: livre, residual, vapor, dissolvida e adsorvida. As duas primeiras correspondem ao produto puro em subsuperfície, com a diferença de que na fase livre o produto apresenta mobilidade, podendo fluir e ser retirado por bombeamento, ao passo que a fase residual corresponde a gotas ou agrupamento de várias gotas isoladas no meio poroso, não móveis. A fase de vapor é representada pelo produto volatilizado e presente na zona não saturada do aqüífero. A fase dissolvida corresponde ao produto dissolvido na água subterrânea e por ela transportado. E finalmente, a fase adsorvida corresponde às moléculas de produto que se aderem às partículas sólidas do aqǘfero, preferencialmente matéria orgânica e argilas, nessa ordem. Alguns autores consideram também que as fases adsorvida, residual e de vapor formam uma única fase denominada adsorvida (que será abordada mais a frente neste trabalho). Os contaminantes transitam de uma fase para outra, e a sua permanência em cada fase é regida por propriedades físico-químicas.

Em um derramamento e/ou vazamento de gasolina, uma das principais preocupações é a contaminação dos aqüíferos que são usados como fonte de abastecimento de água para consumo humano. Por ser muito pouco solúvel em água, a gasolina derramada, contendo mais de uma centena de componentes, inicialmente estará presente no subsolo como líquido em fase não aquosa (NAPL), comportando-se como uma fonte contínua de contaminação, além de apresentar risco de explosões e incêndios. Finalmente, quando em contato com a água subterrânea, a gasolina se dissolve parcialmente. Os hidrocarbonetos monoaromáticos, benzeno, tolueno, etilbenzeno, e os três xilenos orto, meta e para, chamados compostos BTEX, são os constituintes da gasolina que têm maior solubilidade em água e, portanto, são os contaminantes que primeiro poluem o lençol freático. Dentre os BTEX, o benzeno é considerado o mais tóxico, com padrão de potabilidade de $10 \mu \mathrm{g} / 1$ (BRASIL, LEIS, etc. 1990), podendo em exposições crônicas causar leucopenia, câncer, vertigens, tremores e afetar o sistema nervoso central.

Os custos da recuperação segundo U.S. ENVIRONMENTAL PROTECTION AGENCY (1999), para a extração do combustível e o tratamento do solo na área do posto de serviço e nas proximidades são de aproximadamente US\$ 125 mil. Considerando vazamento em $20 \%$ dos postos do país (cerca de 5.000), o valor alcança a quantia de US\$ 625 milhões. 
Se houver contaminação da água subterrânea, o tratamento custará em torno de US\$100 mil a US\$ 1 milhão por posto de serviço (REGGIANI, 1999).

De imediato percebe-se que se faz necessário compreender os mecanismos de transferência de massa entre as diversas fases e para isso é fundamental a utilização de técnicas apropriadas de laboratório como também métodos de campo modernos, para em seguida partir-se para a escolha da tecnologia mais apropriada para a recuperação do solo, lençol freático, ambiente, enfim, os elementos atingidos pela contaminação.

Espera-se que esta pesquisa contribua para o enriquecimento do conhecimento nessa área de estudo. 


\section{OBJETIVOS}

Esta pesquisa visa contribuir com uma linha de pesquisa em desenvolvimento no Departamento de Hidráulica e Saneamento da Escola de Engenharia de São Carlos da Universidade de São Paulo, que procura abordar problemas de contaminação de solo e águas subterrâneas por compostos orgânicos, problemas estes que pertencem à área de Hidrogeologia Ambiental.

Os objetivos específicos desta pesquisa são:

- Contribuir para o entendimento do fenômeno da volatilização da gasolina em recipientes abertos para a atmosfera através de experimentação e modelagem matemática;

- Avaliar o efeito de colunas de recobrimento em solo saturado por gasolina, simulando vazamento;

- Avaliar o desempenho do modelo JURY, contido no programa computacional APIDSS, versão 2.0, utilizado na área de avaliação de riscos provocados por contaminação por derivados de petróleo;

- Avaliar o desempenho de um detetor de fotoionização na inspeção de áreas contaminadas por gasolina;

- Contribuir para o estudo, em laboratório, da volatilização da gasolina em casos de derramamento superficial. 


\section{REVISÃO BIBLIOGRÁFICA}

\subsection{Introdução}

Nesta seção são abordados os conceitos referentes ao contaminante (gasolina), como também os comportamentos de suas fases quando em contato com o solo. Adicionalmente, são tecidos comentários sobre os princípios da transferência de massa com ênfase para o movimento de vapor no solo. Para finalizar a seção são mostrados os métodos de campo comumente utilizados com destaque para a fotoionização (PID) e a ionização por chama (FID).

\subsection{Características do Contaminante (Gasolina)}

A gasolina é uma mistura complexa de derivados de petróleo, sendo constituída por uma extensa composição (mais de 200 componentes), com a maior parte dos seus constituintes classificados como alifáticos ou como aromáticos. Os compostos alifáticos incluem constituintes como o butano, o penteno e o octano. Os compostos aromáticos incluem constituintes como o benzeno, o tolueno, o etilbenzeno e os xilenos (BTEX). Sua composição está relacionada com o petróleo que a originou, com o processamento utilizado para seu refinamento e também com a existência ou não de aditivos para minimizar seus efeitos ao meio-ambiente, aumentar sua performance e reduzir os desgastes mecânicos. Por suas características serem muito variáveis pelos diversos fatores anteriormente citados, a gasolina automotiva utilizada no Brasil deve atender as especificações indicadas em BRASIL, LEIS, etc. (1999) para os três tipos de gasolina aqui produzidos.

Em refinarias típicas, o óleo cru é separado numa torre de destilação em diversas frações e, por meio de processos adicionais, os compostos mais leves se dividem em quatro a cinco correntes principais que são misturados fornecendo a composição final da gasolina (KREAMER \& STETZENBACH, 1990). KREAMER \& STETZENBACH (1990), acrescentam que existe ainda a possibilidade de uma mistura adicional nos terminais de distribuição, onde gasolinas de diferentes refinarias podem ser mescladas. A gasolina comercializada no Brasil é uma mistura de $76 \%$ de gasolina e $24 \%$ de etanol (BRASIL, 
LEIS, etc. 1998). A adição de etanol ocorre no momento em que a gasolina é introduzida no caminhão-tanque.

JOHNSON et al. (1990), apresentam pela Tabela 3.1 a composição de uma gasolina regular com os 58 compostos principais.

Tabela 3.1 - Composição de uma gasolina regular (JOHNSON et al., 1990).

\begin{tabular}{|c|c|c|c|c|}
\hline \multirow{2}{*}{ Componente } & Fórmula & Massa & Fração & Fração \\
\hline & Química & Molecular & Mássica & Molar \\
\hline 1. propano & $\mathrm{C}_{3} \mathrm{H}_{8}$ & 44,1 & 0,0001 & 0,0002 \\
\hline 2. isobutano & $\mathrm{C}_{4} \mathrm{H}_{10}$ & 58,1 & 0,0122 & 0,1999 \\
\hline 3. n-butano & $\mathrm{C}_{4} \mathrm{H}_{10}$ & 58,1 & 0,0629 & 0,1031 \\
\hline 4. trans-2-buteno & $\mathrm{C}_{4} \mathrm{H}_{8}$ & 56,1 & 0,0007 & 0,0012 \\
\hline 5. cis-2-buteno & $\mathrm{C}_{4} \mathrm{H}_{8}$ & 56,1 & 0,0000 & 0,0000 \\
\hline 6. 3-metil-1-buteno & $\mathrm{C}_{5} \mathrm{H}_{10}$ & 70,1 & 0,0006 & 0,0008 \\
\hline 7. isopentano & $\mathrm{C}_{5} \mathrm{H}_{12}$ & 72,2 & 0,1049 & 0,1384 \\
\hline 8. 1-pentano & $\mathrm{C}_{5} \mathrm{H}_{10}$ & 70,1 & 0,0000 & 0,0000 \\
\hline 9. 2-metil-1-butano & $\mathrm{C}_{5} \mathrm{H}_{10}$ & 70,1 & 0,0000 & 0,0000 \\
\hline 10. 2-metil-1,3-butadieno & $\mathrm{C}_{5} \mathrm{H}_{8}$ & 68,1 & 0,0000 & 0,0000 \\
\hline 11. n-pentano & $\mathrm{C}_{5} \mathrm{H}_{12}$ & 72,2 & 0,0586 & 0,0773 \\
\hline 12. trans-2-pentano & $\mathrm{C}_{5} \mathrm{H}_{10}$ & 70,1 & 0,0000 & 0,0000 \\
\hline 13. 2-metil-2-buteno & $\mathrm{C}_{5} \mathrm{H}_{10}$ & 70,1 & 0,0044 & 0,0060 \\
\hline 14. 3-metil-1,2-butadieno & $\mathrm{C}_{5} \mathrm{H}_{8}$ & 68,1 & 0,0000 & 0,0000 \\
\hline 15. 3,3-dimetil-1-buteno & $\mathrm{C}_{6} \mathrm{H}_{12}$ & 84,2 & 0,0049 & 0,0055 \\
\hline 16. ciclopentano & $\mathrm{C}_{5} \mathrm{H}_{10}$ & 70,1 & 0,0000 & 0,0000 \\
\hline 17. 3-metil-1-penteno & $\mathrm{C}_{6} \mathrm{H}_{12}$ & 84,2 & 0,0000 & 0,0000 \\
\hline 18. 2,3-dimetilbutano & $\mathrm{C}_{6} \mathrm{H}_{14}$ & 86,2 & 0,0730 & 0,0807 \\
\hline 19. 2-metilpentano & $\mathrm{C}_{6} \mathrm{H}_{14}$ & 86,2 & 0,0273 & 0,0302 \\
\hline 20. 3-metilpentano & $\mathrm{C}_{6} \mathrm{H}_{14}$ & 86,2 & 0,0000 & 0,0000 \\
\hline 21. n-hexano & $\mathrm{C}_{6} \mathrm{H}_{14}$ & 86,2 & 0,0283 & 0,0313 \\
\hline 22. metilciclopentano & $\mathrm{C}_{6} \mathrm{H}_{12}$ & 84,2 & 0,0000 & 0,0000 \\
\hline 23. 2,2-dimetilpentano & $\mathrm{C}_{7} \mathrm{H}_{16}$ & 100,2 & 0,0076 & 0,0093 \\
\hline 24. benzeno & $\mathrm{C}_{6} \mathrm{H}_{6}$ & 78,1 & 0,0076 & 0,0093 \\
\hline 25. ciclohexano & $\mathrm{C}_{6} \mathrm{H}_{12}$ & 84,2 & 0,0000 & 0,0000 \\
\hline 26. 2,3-dimetilpentano & $\mathrm{C}_{7} \mathrm{H}_{16}$ & 100,2 & 0,0390 & 0,0371 \\
\hline
\end{tabular}




\begin{tabular}{|c|c|c|c|c|}
\hline Commont & Fórmula & Massa & Fração & Fração \\
\hline 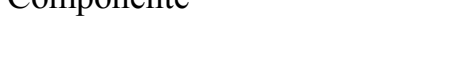 & Química & Molecular & Mássica & Molar \\
\hline 27. 3-metilhexano & $\mathrm{C}_{7} \mathrm{H}_{16}$ & 100,2 & 0,0000 & 0,0000 \\
\hline 28. 3-etilpentano & $\mathrm{C}_{7} \mathrm{H}_{16}$ & 100,2 & 0,0000 & 0,0000 \\
\hline 29. 2,2,4-trimetilpentano & $\mathrm{C}_{8} \mathrm{H}_{18}$ & 114,2 & 0,0121 & 0,0101 \\
\hline 30. n-heptano & $\mathrm{C}_{7} \mathrm{H}_{16}$ & 100,2 & 0,0063 & 0,0060 \\
\hline 31. metilciclohexano & $\mathrm{C}_{7} \mathrm{H}_{14}$ & 98,2 & 0,0000 & 0,0000 \\
\hline 32. 2,2-dimetilhexano & $\mathrm{C}_{8} \mathrm{H}_{18}$ & 114,2 & 0,0055 & 0,0046 \\
\hline 33. tolueno & $\mathrm{C}_{7} \mathrm{H}_{8}$ & 92,1 & 0,0550 & 0,0268 \\
\hline 34. 2,3,4-trimetilpentano & $\mathrm{C}_{8} \mathrm{H}_{18}$ & 114,2 & 0,0121 & 0,0101 \\
\hline 35. metilheptano & $\mathrm{C}_{8} \mathrm{H}_{18}$ & 114,2 & 0,0155 & 0,0129 \\
\hline 36. 3-metilheptano & $\mathrm{C}_{8} \mathrm{H}_{18}$ & 114,2 & 0,0000 & 0,0000 \\
\hline 37. n-ocatano & $\mathrm{C}_{8} \mathrm{H}_{18}$ & 114,2 & 0,0013 & 0,0011 \\
\hline 38. 2,4,4-trimetilhexano & $\mathrm{C}_{9} \mathrm{H}_{20}$ & 128,3 & 0,0087 & 0,0065 \\
\hline 39. 2,2-dimetilheptano & $\mathrm{C}_{9} \mathrm{H}_{20}$ & 128,3 & 0,0000 & 0,0000 \\
\hline 40. p-xileno & $\mathrm{C}_{8} \mathrm{H}_{10}$ & 106,2 & 0,0957 & 0,0858 \\
\hline 41. m-xileno & $\mathrm{C}_{8} \mathrm{H}_{10}$ & 106,2 & 0,0000 & 0,0000 \\
\hline 42. 3,3,4-trimetilhexano & $\mathrm{C}_{9} \mathrm{H}_{20}$ & 128,3 & 0,0281 & 0,0209 \\
\hline 43. o-xileno & $\mathrm{C}_{8} \mathrm{H}_{10}$ & 106,2 & 0,0000 & 0,0000 \\
\hline 44. 2,2,4-trimetilheptano & $\mathrm{C}_{10} \mathrm{H}_{22}$ & 142,3 & 0,0105 & 0,0070 \\
\hline 45. 3,3,5-trimetilheptano & $\mathrm{C}_{10} \mathrm{H}_{22}$ & 142,3 & 0,0000 & 0,0000 \\
\hline 46. n-propilbenzeno & $\mathrm{C}_{9} \mathrm{H}_{12}$ & 120,2 & 0,0841 & 0,0666 \\
\hline 47. 2,3,4-trimetilheptano & $\mathrm{C}_{10} \mathrm{H}_{22}$ & 142,3 & 0,0000 & 0,0000 \\
\hline 48. 1,3,5-trimetilbenzeno & $\mathrm{C}_{9} \mathrm{H}_{12}$ & 120,2 & 0,0411 & 0,0325 \\
\hline 49. 1,2,4-trimetilbenzeno & $\mathrm{C}_{9} \mathrm{H}_{12}$ & 120,2 & 0,0213 & 0,0169 \\
\hline 50. metilpropilbenzeno & $\mathrm{C}_{10} \mathrm{H}_{14}$ & 134,2 & 0,0351 & 0,0249 \\
\hline 51. dimetiletilbenzeno & $\mathrm{C}_{10} \mathrm{H}_{14}$ & 134,2 & 0,0307 & 0,0218 \\
\hline 52. 1,2,4,5-tetrametilbenzeno & $\mathrm{C}_{10} \mathrm{H}_{14}$ & 134,2 & 0,0133 & 0,0094 \\
\hline 53. 1,2,3,4-tetrametilbenzeno & $\mathrm{C}_{10} \mathrm{H}_{14}$ & 134,2 & 0,0129 & 0,0091 \\
\hline 54. 1,2,4-trimetil-5-etilbenzeno & $\mathrm{C}_{11} \mathrm{H}_{16}$ & 148,2 & 0,0405 & 0,0260 \\
\hline 55. n-dodecano & $\mathrm{C}_{12} \mathrm{H}_{26}$ & 170,3 & 0,0230 & 0,0129 \\
\hline 56. naftaleno & $\mathrm{C}_{10} \mathrm{H}_{8}$ & 128,2 & 0,0045 & 0,0033 \\
\hline 57. n-hexilbenzeno & $\mathrm{C}_{12} \mathrm{H}_{20}$ & 162,3 & 0,0000 & 0,0000 \\
\hline 58. metilnaftaleno & $\mathrm{C}_{11} \mathrm{H}_{10}$ & 142,2 & 0,0023 & 0,0015 \\
\hline TOTAL & & & 0,9969 & 1,0000 \\
\hline
\end{tabular}


Segundo GUIGUER (1994?), alguns dos compostos aromáticos (os quais podem ser indicadores úteis da quantidade de hidrocarbonetos resultante de vazamentos relativamente recentes) representam os compostos voláteis e solúveis encontrados na gasolina e óleo diesel. Tipicamente a gasolina é de pelo menos uma ordem de grandeza mais volátil (como indicado pela pressão de vapor) do que o óleo diesel, ver Tabela 3.2.

Tabela 3.2 - Propriedades dos oxigenados, gasolina e diesel $\mathrm{N}^{0} 2$ (API, 1993).

\begin{tabular}{|c|c|c|c|c|}
\hline Propriedades & Metanol & Etanol & Gasolina & Diesel $N^{0} 2$ \\
\hline Fórmula & $\mathrm{CH}_{3} \mathrm{OH}$ & $\mathrm{C}_{2} \mathrm{H}_{5} \mathrm{OH}$ & $\mathrm{C}_{4}$ a $\mathrm{C}_{12}$ & $\mathrm{C}_{8}$ a $\mathrm{C}_{25}$ \\
\hline Peso Molecular & 32,04 & 46,07 & $100-105$ & $\begin{array}{c}200 \\
\text { (aprox.) }\end{array}$ \\
\hline \multicolumn{5}{|l|}{ Densidade, } \\
\hline $15,5^{\circ} \mathrm{C}$ & 794 & 792 & $720-780$ & $803-887$ \\
\hline \multicolumn{5}{|l|}{ Viscosidade } \\
\hline Cetipoise a $20^{\circ} \mathrm{C}$ & 0,59 & 1,19 & $3,37-0,44$ & $2,6-4,1$ \\
\hline Cetipoise a $-20^{\circ} \mathrm{C}$ & 1,15 & 2,84 & $0,60-0,77$ & $9,7-17,6$ \\
\hline $\begin{array}{l}\text { Pressão de vapor Reid, } \\
\mathrm{mmHg}\end{array}$ & 237,82 & 118,91 & 413,775 & 10,34 \\
\hline \multicolumn{5}{|l|}{ Limite de flamabilidade, $\%$} \\
\hline \multicolumn{5}{|l|}{ De volume } \\
\hline Menor & 7,3 & 4,3 & 1,4 & 1,0 \\
\hline Maior & 36,0 & 19,0 & 7,6 & 6,0 \\
\hline Ponto de Faísca, ${ }^{\circ} \mathrm{C}$ & 11,11 & 12,78 & $-42,78$ & 73,89 \\
\hline \multicolumn{5}{|l|}{ Solubilidade em água, } \\
\hline$\%$ de volume a $21,11^{\circ} \mathrm{C}$ & 100 & 100 & Traço & Traço \\
\hline $\mathrm{mg} / \mathrm{l}$ a $20^{\circ}-25^{\circ} \mathrm{C}$ & $\infty$ & $\infty$ & $98-240$ & $2,7-3,2$ \\
\hline
\end{tabular}

GUIGUER (1994?) afirmou que a composição das misturas de gasolina varia de acordo com o local e a temporada. Como a variação global das misturas é muito grande, enxofre, compostos de oxigênio, metais-traço e constituintes voláteis (tais como BETX) variam de maneira significativa (14 a 20 por cento por peso). Dezessete distritos nos Estados Unidos são regularmente pesquisados durante o verão e o inverno, todos os anos, para comparar as 
misturas de gasolina produzidas nos diversos distritos. A aparente diferença nas temperaturas de distilação entre as localizações geográficas não é grande. Entretanto, há diferenças significativas nos níveis de enxofre, chumbo e constituintes voláteis.

OLIVEIRA et al. (1990) afirmou que para se caracterizar a gasolina ou o diesel, não é viável um teste individual para cada um dos mais de uma centena de compostos presentes. Por esta razão, uma série de hidrocarbonetos (baseada no número de átomos de carbono) foi selecionada como representativa do combustível em estudo. Para a gasolina, é geralmente a série de $\mathrm{C}_{4}$ a $\mathrm{C}_{8}$ (alguns pesquisadores usam $\mathrm{C}_{4}$ a $\mathrm{C}_{12}$ ). $\mathrm{O}$ diesel, menos volátil, tipicamente varia de $\mathrm{C}_{12}$ a $\mathrm{C}_{22}$. Os hidrocarbonetos da série de $\mathrm{C}_{1} \quad \mathrm{C}_{3}$ apresentam ponto de ebulição muito baixo o que os tornam gases sob condições normais de temperatura e pressão. Os indicadores específicos usados para se caracterizar a contaminação por gasolina para a série $\mathrm{C}_{4} \quad \mathrm{C}_{8}$ são normalmente benzeno, tolueno, etilbenzeno e xileno (BTEX). Além destes, o grupo não específico TPH (Total Petroleum Hydrocarbon) também é comumente utilizado. Ocasionalmente, impulsionadores de octanas, como éter metil-tercbutílico e metanol são usados como indicadores de contaminação por gasolina.

\subsection{Fases dos Hidrocarbonetos}

A gasolina, por apresentar uma extensa composição, afigura-se como uma grande quantidade de substâncias com características diferentes de adsorção no solo, pressão de vapor e solubilidade que, ao entrar em contato com o solo, podem situar-se em três, quatro ou até cinco fases distintas (dependendo do autor). Ao migrar pela zona não saturada o produto é parcialmente retido (adsorvido) pelas partículas do solo, formando assim a fase adsorvida (que também pode ser encontrada como fase líquida). Como dito na introdução, esta fase adsorvida pode ser subdividida em uma fase em que as moléculas do produto estão aderidas às partículas sólidas do aqüífero (denominada de adsorvida corretamente) e em outra onde pequenas quantidades do produto estão isoladas e sem mobilidade nos vazios do solo, (denominada residual). Ao entrar em contato com o lençol freático ou com uma camada de condutividade hidráulica muito baixa, a gasolina passa a fluir através do mesmo, gerando a fase livre. Uma parcela do produto que atingiu o lençol se dissolve em contato com a água subterrânea formando uma pluma de contaminação designada de fase dissolvida. Vale ressaltar que existem alguns autores, como GUIGUER, (1994?); API, (1993), que consideram a fase dissolvida como sendo os hidrocarbonetos presentes na água do solo e nas 
superfícies dos sólidos de solo como películas. Uma pequena parcela do produto pode ser encontrada como componente do vapor do solo, e com isso gerando a chamada fase de vapor. Podem haver trocas entre as fases, sendo que hidrocarbonetos que se encontram na fase de vapor podem condensar e serem adsorvidos em sólidos do solo ou a dissolvidos na água do solo, por exemplo.

Tabela 3.3 - Distribuição das Fases do Contaminante (GROUNDWATER TECHNOLOGY INC. *² apud OLIVEIRA 1992).

\begin{tabular}{lccrc}
\hline Fase & $\begin{array}{c}\text { Volume } \\
\text { Contaminado } \\
\left(\mathrm{m}^{3}\right)\end{array}$ & $\begin{array}{c}\text { Total } \\
\text { Total }\end{array}$ & $\begin{array}{c}\text { Volume de } \\
\text { Contaminante } \\
\left(\mathrm{m}^{3}\right)\end{array}$ & $\begin{array}{c}\text { Total } \\
\text { Totre }\end{array}$ \\
Adsorvida & 7.100 & 1,0 & 18.500 & 62 \\
Dissolvida & 250.000 & 20,0 & 10.000 & 33 \\
\hline
\end{tabular}

A Tabela 3.3 representa a distribuição estimada por fases para a contaminação de um solo caracterizado como areia média, com o lençol freático estando situado a uma profundidade aproximadamente de 5 metros.

Segundo OLIVEIRA (1992), os valores expostos na Tabela 3.3 deixam clara a participação de cada uma das fases na contaminação do meio ambiente subsuperficial. OLIVEIRA (1992), afirmou ainda que a quantidade do produto dissolvido na água subterrânea, é relativamente pequena (1-5\%) em comparação ao total derramado, mas é a responsável pela maior quantidade de material contaminado (79\%), uma vez que o escoamento da água subterrânea é o mecanismo de maior capacidade de espalhamento da contaminação, devido a sua alta mobilidade. A quantidade do produto retida na fase adsorvida (33\% do total derramado), embora de mobilidade baixíssima, funciona como uma fonte permanente de contaminação das águas subterrâneas pela liberação lenta e contínua de produto para a fase dissolvida.

$2 *$ GROUNDWATER TECHNOLOGY INC. (1983). Estimation of lost produtot distribution in the subsurface. Confidential Client. GTI, Chadd Ford, Pennsylvania apud OLIVEIRA, O. (1992). armazenamento subterrâneo. Instituto de Geociências - Universidade de São Paulo, São Paulo, p.20. 


\subsubsection{Comportamento das Fases dos Hidrocarbonetos}

Para se caracterizar aproximadamente um vazamento de hidrocarboneto torna-se necessário uma compreensão qualitativa sobre o comportamento das fases dos hidrocarbonetos no solo. O mesmo ocorre para selecionar e implementar uma ação corretiva mais efetiva. Assim, a seguir tratamos do comportamento geral das fases dos hidrocarbonetos no solo.

\subsubsection{Hidrocarbonetos em Fase Adsorvida}

Segundo GUIGUER (1994?), quando os combustíveis líquidos são liberados no solo, hidrocarbonetos em fase líquida migrarão descendentemente graças à gravidade e às forças capilares. Algum espalhamento horizontal ocorre enquanto hidrocarbonetos em fase líquida migram descendentemente devido também as forças capilares e às diferenças nas condutividades hidráulicas de cada camada do solo.

GUIGUER (1994?), comenta ainda que a presença de camadas de solo com condutividade hidráulica baixa também promove espalhamento horizontal dos hidrocarbonetos em fase líquida nas camadas do solo sobrejacentes com condutividade hidráulica maior. Fluídos em movimento descendente (água ou hidrocarbonetos em fase líquida) podem se acumular acima dessas camadas de condutividade baixa. Ao cessar o movimento vertical, seja pela presença de uma camada de condutividade muito baixa ou por se atingir o lençol freático, o produto que ficou retido nos poros do material geológico passa a ser denominado de fase adsorvida.

Como já mencionado, esta fase adsorvida na verdade pode ser subdividida em três fases: uma fase adsorvida nas partículas do solo, uma fase residual (líquido sem mobilidade e livre nos vazios existentes nos poros do material geológico) e uma fase de vapor (tratada em particular no item 3.3.1.4). De acordo com JURY et al. (1990), a concentração da fase adsorvida $\mathrm{C}_{\mathrm{s}}$ é expressa em microgramas por grama de solo; a concentração da fase dissolvida $C_{1}$ é expressa em microgramas por centímetro cúbico de solução de solo; e a concentração da fase gasosa $\mathrm{C}_{\mathrm{g}}$ é expressa em microgramas por centímetro cúbico de ar do solo. A concentração total $\mathrm{C}_{\mathrm{t}}$ em microgramas por centímetro cúbico de solo é expressa assim: 


$$
C_{t}=\rho_{b} C_{s}+\Theta C_{l}+a C_{g}
$$

Onde $\rho_{\mathrm{b}}\left(\mathrm{g} \mathrm{cm}^{-3}\right)$ é a densidade volumétrica do solo, $\Theta$ é conteúdo volumétrico de água, e $a$ é o teor volumétrico de ar.

A Tabela 3.4 apresenta valores da concentração aproximada de gasolina residual na zona não saturada.

Tabela 3.4 - Valores Típicos da Concentração de Gasolina Residual na Zona Não Saturada (API, 1993).

\begin{tabular}{lcc}
\hline \multicolumn{1}{c}{ MEIO } & \multicolumn{2}{c}{ Gasolina } \\
& $\left(1 / \mathrm{m}^{3}\right)$ & $(\mathrm{mg} / \mathrm{kg})^{\mathrm{a}}$ \\
\hline Cascalho grosseiro & 2,5 & 950 \\
Areia e cascalho grosseiros & 4,0 & 1.500 \\
Areia média a grosseira & 7,5 & 2.800 \\
Areia fina a média & 12,5 & 4.700 \\
Sedimento a areia fina & 20,0 & 7.600 \\
\hline
\end{tabular}

Notas:

${ }^{\mathrm{a}}=$ cálculo feito considerando a densidade do solo $1,85 \mathrm{~g} / \mathrm{cm}^{3}$ e as densidades dos combustíveis líquidos $0,7 \mathrm{~g} / \mathrm{cm}^{3}$ para a gasolina.

Segundo OLIVEIRA (1992), a quantidade de produto que irá atingir o lençol freático dependerá da sua quantidade inicial, da distância vertical que separa o ponto de vazamento ou derramamento do lençol freático e da quantidade residual do produto que ficará retida pelo solo. Esta última, sendo uma característica própria de cada tipo de material geológico, pode ser descrita de modo análogo à porosidade de retenção ou retenção específica do solo $\left(\mathrm{S}_{\mathrm{R}}\right)$. Para um volume $\mathrm{V}\left[\mathrm{L}^{3}\right]$ de produto derramado, que se infiltra na área $\mathrm{A}\left[\mathrm{L}^{2}\right]$ de solo, por uma distância vertical $d[\mathrm{~L}]$, para um material que apresente uma retenção específica para a gasolina $\mathrm{S}_{\mathrm{R}}\left[\mathrm{L}^{0}\right]$, tem-se que:

$$
V_{R}=A \cdot d \cdot S_{R}
$$

Onde:

$\mathrm{V}_{\mathrm{R}}=$ Volume de produto retido pelos poros;

$\mathrm{A}=$ Área atingida pelo vazamento;

d = Distância vertical percorrida pelo produto até atingir o nível de água (N.A.); 
$\mathrm{S}_{\mathrm{R}}=$ Retenção específica do material geológico para o produto.

OLIVEIRA (1992), menciona ainda que a conjunção dos fatores acima descritos é determinante para que o produto derramado atinja ou não a zona saturada.

As variações de nível do lençol freático promovem um espalhamento vertical de hidrocarbonetos. Hidrocarbonetos líquidos livres retidos na franja capilar se moverão descendentemente se o nível do lençol freático abaixar, deixando líquido residual na zona não saturada expandida acima da nova posição do lençol freático. Uma nova elevação subsequente do lençol freático fará com que a franja capilar e os hidrocarbonetos líquidos livres associados se movam ascendentemente. Hidrocarbonetos residuais presentes na zona não saturada podem ser remobilizados devido ao aumento de hidrocarbonetos líquidos livres, causando um espalhamento lateral numa elevação diferente. Além do que, uma fase líquida residual pode permanecer na zona saturada abaixo do lençol freático reposicionado. Apenas a quantidade móvel de hidrocarbonetos líquidos, e não a quantidade total, é que muda sob essas condições. Também, as variações de nível do lençol freático, como aquelas que foram descritas, podem afetar a quantidade de combustível passível de ser recuperada e as espessuras dos combustíveis medidas em poços de monitoramento.

\subsubsection{Hidrocarbonetos em Fase Dissolvida}

A fase dissolvida dos hidrocarbonetos resulta do contato entre e água da sub-superfície e os hidrocarbonetos líquidos, sendo que este contato pode acontecer de diversas formas, como:

- Processos de infiltração através da zona não saturada, contendo hidrocarbonetos residuais;

- Movimento da água subterrânea que se infiltra, e entra em contato com a pluma de contaminação de hidrocarbonetos livres;

- Contato direto entre a pluma de contaminação e lençol subterrâneo.

Segundo GUIGUER (1994?), as concentrações de compostos de hidrocarbonetos dissolvidos em água e as quantidades que se transferem para o sistema de água subterrânea dependem de alguns fatores, tais como:

- Profundidade do lençol freático;

- Condutividade hidráulica do solo; 
- Valores de recarga pluviométrica;

- Flutuações no lençol freático;

- Velocidade da água subterrânea;

- Solubilidade do produto;

- Temperatura da água;

- Concentração destes compostos dentro da fase de hidrocarboneto residual.

Contudo, os fatores que mais interferem no processo de dissolução são a solubilidade da substância e o grau de mistura entre as fases. As solubilidades dos hidrocarbonetos em misturas (como a gasolina) são muito reduzidas em comparação com a solubilidade do produto isolado. Segundo OLIVEIRA et al. (1990), o benzeno, numa gasolina normal sem chumbo, pode ter em água uma concentração da ordem de $30 \mathrm{mg} / \mathrm{l}$, enquanto que a substância pura apresenta uma concentração em água que ultrapassa $1.700 \mathrm{mg} / \mathrm{l}$, sendo que este fenômeno é chamado de cosolubilidade. Entretanto, com a adição de solventes hidrofílicos para aumentar o rendimento do motores e/ou reduzir o volume de compostos voláteis lançados ao meio ambiente, como acontece no Brasil com a adição de $24 \%$ de etanol à gasolina (BRASIL, LEIS, etc. 1998), origina-se o fenômeno chamado de cossolvência. Estudado por alguns autores como (BANERJEE \& YALKOWSKY, 1988; PINAL et al. 1990), o efeito da cossolvência é um elevado aumento da solubilidade dos hidrocarbonetos em contato com a água. Segundo FERNANDES et al. (1997), com a adição de 10\% de etanol à gasolina, as solubilidade dos solutos excederam a solubilidade em água pura (no sistema sem etanol) por um fator de 1,$2 ; 1,4$ e 1,5 para o benzeno, tolueno e $o$-xileno, respectivamente.

GUIGUER (1994?) afirmou que os processos de advecção e dispersão hidrodinâmica controlam o movimento dos hidrocarbonetos em fase dissolvida na água subterrânea. A dispersão hidrodinâmica causa a diluição das concentrações de hidrocarboneto dentro da pluma de contaminação de hidrocarbonetos em fase dissolvida. A dispersão hidrodinâmica é causada pela mistura mecânica dos constituintes durante a advecção e pela difusão química. A dispersão causada por difusão química (movimento dos constituintes na ausência do escoamento principal) é mínima e ocorre principalmente sob condições relativamente estáticas com condutividades hidráulicas e velocidades de escoamento muito baixas. A dispersão derivada de processos de mistura mecânica causadas pelo movimento da água no solo é o principal mecanismo de transporte. A dispersão hidrodinâmica é, conseqüentemente, o resultado de mistura mecânica. Por exemplo, um escoamento grande de água que se infiltra 
no solo e que contém combustíveis de petróleo, pode aumentar a mistura mecânica e, portanto, aumentar a dissolução e a dispersão hidrodinâmica de hidrocarbonetos no solo.

\subsubsection{Hidrocarbonetos em Fase Livre}

Em um derramamento de hidrocarbonetos no solo, quando o produto atinge a zona saturada, passa a flutuar sobre o lençol freático ou franja capilar, por possuir densidade menor que a da água e por ser, de forma global, imiscível. Como conseqüência, esta fase é designada de fase livre.

Dependendo da quantidade de produto que atinge a zona saturada e das características do lençol freático, o peso exercido pelo produto sobre o lençol subterrâneo pode deprimir o mesmo reduzindo a sua espessura.

O contaminante, quando começa a se movimentar em sua fase livre, apresenta características próprias diferentes das apresentadas pela água subterrânea. Assim, técnicas de campo geralmente utilizadas para estimar características do lençol subterrâneo tornam-se difíceis de aplicar ao contaminante, pois a espessura da camada contaminante geralmente apresenta valores insuficientes para tais técnicas.

BLAKE \& FRYBERGER ${ }^{*}$; BLAKE \& HALL $*^{4}$; HALL et al. ${ }^{5}$ apud TESTA \& PACZKOWSKI (1989), afirmam que um fator relevante a ser levado em consideração no momento em que se vai estimar a espessura da camada contaminante é que a espessura acumulada em poço de monitoramento é considerada aparente e não corresponde à real espessura da fase livre. HALL et al., (1984) apud TESTA \& PACZKOWSKI, (1989), afirmam ainda que a diferença relativa entre a espessura da camada de hidrocarbonetos

3 *BLAKE, S.B.; FRYBERGER, J.S. (1983). Containment and recovery of refined hydrocarbons from grounwater. In Proceedings of Ground Water and Petroleum Hydrocarbons - Protection, Detection, Restoration. PACE, Toronto, Ontario apud TESTA, S.M.; PACZKOWSKI M.T. (1989). Volume Determination and Recoverability of Free Hydrocarbon Groundwater Monitoring Review. p. 121.

4 *BLAKE, S.B.; HALL, R.A. (1984). Monitoring petroleum spills with wells: Some problems and solutions. In Proceedings, Fourth National Symposium on Aquifer Restoration and Ground Water Monitoring. NWWA, Dublin, Ohio apud TESTA, S.M.; PACZKOWSKI M.T. (1989). Volume Determination and Recoverability of Free Hydrocarbon Groundwater Monitoring Review. p. 121.

5 *HALL, R.A.; BLAKE, S.B.; Champlin, S.C.Jr. (1984). Determination of hydrocarbon thickness in sediments using borehole data. In Proceedings, Fourth National Symposium on Aquifer Restoration and Ground Water Monitoring. NWWA, Columbus, Ohio apud TESTA, S.M.; PACZKOWSKI M.T. (1989). Volume Determination and Recoverability of Free Hydrocarbon Groundwater Monitoring Review. p. 121. 
aparente e a real aumenta com a diminuição do tamanho dos grãos do material poroso e com o aumento do peso específico dos hidrocarbonetos.

TESTA \& PACZKOWSKI, (1989), apresentam um método de estimativa dos volumes de hidrocarbonetos em fase livre pela determinação da espessura real baseada nas características hidrogeológicas do solo e da espessura aparente do contaminante no poço de monitoramento. Segundo OLIVEIRA, (1992), o movimento vertical do lençol freático afeta a presença de produto livre e a distribuição do produto residual nas camadas saturada e não saturada. $\mathrm{O}$ movimento descendente resulta em hidrocarbonetos residuais presos ao solo na zona não saturada, enquanto que o movimento ascendente resulta em um aparente desaparecimento do produto livre, no momento em que uma nova fase residual é desenvolvida. Quando o nível d'água volta ao normal, esta fase residual pode ser remobilizada e produz novamente a fase livre. A remobilização pode ser confundida com um novo vazamento quando, na verdade, trata-se do mesmo vazamento.

\subsubsection{Hidrocarboneto em Fase de Vapor}

Os hidrocarbonetos em fase de vapor resultam principalmente da volatilização dos hidrocarbonetos em fase adsorvida presentes na zona não saturada. Os hidrocarbonetos em fase de vapor também podem se volatilizar a partir de hidrocarbonetos residuais em fase adsorvida e, numa escala menor, a partir de hidrocarbonetos em fase livre e/ou fase dissolvida presente na água do solo. A transferência de hidrocarbonetos da fase líquida para a fase de vapor é controlado pela lei de Henry. Em vapores de um vazamento recente de gasolina, os constituintes de alta pressão de vapor e de peso molecular menor (por exemplo, butano e pentano) geralmente correspondem a cerca de 75 a 85 por cento dos hidrocarbonetos em fase de vapor em equilíbrio com a gasolina mais nova. Um vazamento de hidrocarbonetos mais antigo apresentará concentrações menores de constituintes voláteis e, consequentemente, o líquido remanescente terá uma pressão de vapor menor.

Uma parcela de hidrocarbonetos em fase de vapor pode aderir ao solo ou ser adsorvida. O vapor da água e o vapor dos hidrocarbonetos disputam os mesmos espaços de adsorção nos sólidos do solo. Na maioria dos casos, a água gera uma redução drástica da capacidade de adsorção do solo para hidrocarbonetos em fase de vapor. Em solo seco ou solo com uma concentração baixa de umidade, a quantidade adsorvida está diretamente relacionada à área da superfície das partículas do solo e à quantidade de matéria orgânica. A área da superfície 
disponível para adsorção passa a ser reduzida com o aumento da quantidade de água no solo. Assim, um solo seco poroso pode adsorver hidrocarbonetos em fase de vapor mais prontamente que um solo relativamente úmido. Os hidrocarbonetos adsorvidos podem ser remobilizados como hidrocarbonetos em fase dissolvida devido ao influxo de água que se infiltra através da zona não saturada.

Segundo GUIGUER, (1994?), a migração de vapor na sub-superfície é controlada por vários parâmetros, tais como:

Propriedades físicas e químicas do produto liberado:

- Pressão de vapor;

- Solubilidade ;

- Concentração;

- Densidade;

- Viscosidade.

Propriedades hidrogeológicas:

- Condutividade hidráulica;

- Profundidade da água subterrânea;

- Direção do escoamento da água subterrânea;

- Temperatura da água;

- Porosidade;

- Conteúdo de água.

Outros:

- Pressão barométrica;

- Duração e intensidade de precipitação pluviométrica;

- Estruturas feitas pelo homem.

$\mathrm{Na}$ maioria dos casos, os hidrocarbonetos em fase de vapor tendem a seguir caminhos preferenciais e a migrar das áreas de grande pressão para áreas de pressão menor. Os vapores dos hidrocarbonetos são mais densos que o ar; consequentemente, eles podem se acumular em prédios, drenagem, caixas telefônicas subterrâneas e outras estruturas abertas para a 
atmosfera. Devido aos hidrocarbonetos em fase de vapor geralmente terem potencial de se mover rapidamente, eles podem ser usados para detectar a ocorrência de um vazamento e devem ser monitorados em relação à concentração de vapores explosivos.

Em resumo, um vazamento de combustíveis líquidos no solo consiste, inicialmente, em uma pluma de contaminação de hidrocarbonetos em fase líquida livre. Com o passar do tempo, os constituintes na fase adsorvida se volatilizarão para a fase de vapor, se dissolverão em água e permanecerão adsorvidos no solo.

Por conseguinte, hidrocarbonetos móveis em fase adsorvida, dissolvida, livre ou de vapor, tendem a se tornar mais distintos e a se separarem com o tempo. Em muitos casos, essas fases estão posicionadas como corpos distintos ou plumas de contaminação que podem migrar para direções diferentes. Na avaliação de um local onde aconteceu um vazamento, essas plumas de contaminação de hidrocarbonetos em fases diferentes no solo devem ser identificadas em relação ao potencial de afetar a água subterrânea. Os hidrocarbonetos em fase adsorvida, em fase livre e em fase dissolvida representam a maior ameaça para qualidade da água subterrânea, enquanto os hidrocarbonetos em fase de vapor próximos à superfície apresentam riscos à segurança de pessoas e instalações, devido à possibilidade de explosão. Como exemplo desta periculosidade, REGGIANI (1999) apresenta um histórico de casos onde houveram explosões decorrentes de vazamentos.

\subsection{Transferência de Massa}

Em um trabalho que envolva a contaminação do solo, a compreensão da teoria que envolve o movimento do contaminante nesta região é de fundamental importância. Segundo FETTER (1993), existem dois mecanismos básicos que atuam no transporte do contaminante em solo: difusão e advecção.

Como o contaminante quando em contato com o solo não se distribui uniformemente entre os vazios do solo, devido a presença de outras substâncias, irá ocorrer a formação de gradiente de concentração, ocasionando a formação de um processo denominado de difusão. Difusão é o processo pelo qual íons e moléculas dissolvidas se movem de áreas de maior concentração para áreas de menor concentração. Esse processo é também denominado de difusão molecular. A difusão ocorre sempre que seja formado um gradiente de concentração. A massa difundida é proporcional ao gradiente de concentração (FETTER, 1993; SCHWARZENBACH et al., 1993). 
A difusão na maioria dos casos é descrita pela $1^{\circ}$ Lei de Fick que descreve o fluxo de uma substância sob condições de estado estacionário e unidimensional.

$$
F=-D \frac{d C}{d X}
$$

Onde:

$\mathrm{F}=$ Fluxo de massa;

$\mathrm{D}=$ Coeficiente de difusão $\left(\mathrm{L}^{2} / \mathrm{T}\right)$;

$$
\frac{d C}{d X}=\text { Gradiente de concentração }\left(\mathrm{M} / \mathrm{L}^{3} \cdot \mathrm{L}\right) .
$$

Sendo que o sinal negativo indica que o movimento está se propagando da maior para a menor concentração.

Para sistemas unidimensionais onde a concentração varia com o tempo, se aplica a $2^{\mathrm{a}}$ Lei de Fick (FREEZE \& CHERRY, 1979; SCHWARZENBACH et al., 1993).

$$
\frac{d C}{d t}=D \frac{d^{2} C}{d X^{2}}
$$

Onde:

$$
\frac{d C}{d t}=\text { Variação da concentração em função tempo. }
$$

A advecção pode ser denominada como processo primário responsável pela migração do contaminante através do meio poroso. A advecção também conhecida como convecção é o processo pelo qual o poluente é transferido devido a um movimento preferencial do fluido. Sendo assim, o fluido funciona como dispersor diminuindo a concentração do contaminante. Os contaminantes que estão sendo influenciados pelo processo de advecção caminham com a mesma taxa que a velocidade linear média da água subterrânea.

\subsubsection{Movimento de Vapores na Zona Não Saturada}


A zona não saturada, é um termo que se refere ao perfil do terreno em que a água não preenche todos os espaços vazios. Esta zona é constituída de três fases: sólida (matéria mineral e orgânica), líquida (solução de sais minerais e componentes orgânicos) e gasosa (gases com diversas composições). Estas fases formam um conjunto onde ocorrem variadas reações físico-químicas.

Segundo HIRATA (1990), a distribuição do tamanho das partículas varia amplamente e define diferente texturas, com distintas características hidráulicas, relacionadas intimamente com os espaços vazios inter-grãos. Dois tipos de poros individuais podem ocorrer: os macro e os microporos. Os primeiros definem movimentos rápidos de fluidos, também denominados de fluxo não-darcianos, e os segundos, o movimento de gases é dificultado e o da água é restrito, principalmente, a movimentos capilares. É certo também, que o preenchimento dos espaços intergranulares pela água reduz a passagem de gases no material.

Segundo SCHWILLE (1984, 1988), a zona não saturada do solo possui uma importante função na retenção e dispersão de vários contaminantes. A princípio o mecanismo de transporte do contaminante em sub-superfície é o escoamento líquido. Uma vez que o escoamento líquido extingue-se, uma região de saturação residual de compostos orgânicos voláteis (VOC) líquidos permanecem no solo. Na zona não saturada uma fase descontínua de líquidos essencialmente imóveis na fase não aquosa (NAPL) é preservada por forças capilares (BAEHR \& CORAPCIOGLU, 1987). Segundo VAN DER WAARDEN et al. (1971, 1977), a região de saturação residual funciona como uma fonte na qual ocorrerão futuras dissoluções de contaminantes na água de infiltração e vaporização de gases nos vazios do solo. GRATHWOHL ${ }^{*}$ apud FERREIRA (2000), afirmou que como o coeficiente de difusão em um líquido é cerca de 10.000 vezes menor do que o coeficiente de difusão em um gás, o fluxo difusivo na zona não saturada depende principalmente dos espaços vazios preenchidos por ar, o que é uma função do conteúdo de água. Para as espécies contaminantes com alta pressão de vapor ou baixo coeficiente de partição ar-água, existe um acréscimo potencial da migração do vapor (que altera as características da água subterrânea e do solo adjacente as fases aquosa e não aquosa) dos compostos orgânicos voláteis, imóveis (SCHWILLE, 1984, 1988). SLEER \& SYKES (1989) afirmaram que a contaminação da água subterrânea por difusão gasosa (distante da fonte de contaminação líquida, residual) pode se tornar um problema muito maior de contaminação do que pelo líquido residual. CORAPCIOGLU \& BAEHR (1987), BAHER \& CORAPCIOGLU (1987) modelaram o

\footnotetext{
${ }^{6}$ GRATHWHOL, P. (1998). Diffusion in natural porous media: Contaminant transport, sorption/desorption and dissolution kinetics. University of Tübinger, Germany apud FERREIRA, S.B. (2000). Estudos laboratoriais para avaliação do potencial de contaminação de água e solo por gasolina oxigenada. Escola de Engenharia de São Carlos - Universidade de São Paulo, São Carlos, p. 33.
} 
transporte de hidrocarbonetos derivados de petróleo em solos como um líquido imiscível com transporte tanto na fase líquida quanto na fase de vapor. Pelo modelo concluíram que o transporte difusivo na fase de vapor é predominante em relação ao transporte difusivo e dispersivo na fase aquosa quando a fase imiscível estava imóvel. Segundo JOHNSON et al. (1990), nos sistemas de extração de vapor, que são freqüentemente usados para remediar locais contaminados com produtos químicos voláteis, a taxa de remoção é regida pela difusão na fase de vapor de zonas de baixa permeabilidade para zonas de maior permeabilidade.

A difusão de vapores contaminantes na zona não saturada é muitas vezes modelada pela adequação da primeira e segunda lei de Fick. A primeira lei assume que o fluxo de massa de qualquer espécie é proporcional ao seu gradiente de concentração. Sendo aplicável a sistemas onde o fluxo de uma espécie pode ser considerado independente em relação ao fluxo de outras e inerentemente, assume uma baixa concentração para demais espécies na fase gasosa específica. Isto foi considerado por ROLSTON et al. (1969), BROWN \& ROLSTON (1980), JURY et. al. (1990), entre outros autores, para caracterizar o transporte gasoso difusivo. Entretanto, misturas orgânicas líquidas como compostos de altas pressões de vapor podem ocupar uma porção significante dos vazios do solo ao serem derramadas (BAEHR \& BRUELL, 1990; HULING \& WEAVER, 1991). Por apresentarem altas pressões de vapor o fluxo de cada espécie é dependente do fluxo de outras espécies.

HIRSCHFELDER et al. (1964), MASON \& MALINAUSKAS (1983), afirmaram que, para relacionar o fluxo independente da difusão de espécies, equações de difusão geral de multicomponentes advindas da teoria da cinética de gás podem ser utilizadas. JAYNES \& ROGOWSKI (1983), concluíram que a utilização das leis de Fick resultariam em estimativas incorretas das distribuições e fluxos de massa para sistemas contendo mais do que dois componentes na fase de vapor, quando as concentrações das espécies que se difundem não é negligenciada, comparada às concentrações na fase gasosa específica. Os autores concluíram teoricamente que em sistemas ternários o coeficiente de difusão Fickano depende não só do coeficiente binário de difusão e relações de fluxo, mas também da fração molar das espécies difundidas. LEFFELAAR (1987), simulou o processo de desnitrificação transiente em solos utilizando as formulações de multicomponentes e concluiu que quando os coeficientes de difusão binária são diferentes por um fator de 2, a difusão de gases em misturas gasosas múltiplas não é exatamente modelada com a lei de Fick. Recomendando nestes casos que equações com multicomponentes devam ser utilizadas. 
BAEHR \& BRUELL (1990), não observaram nenhum desvio considerável das leis de Fick em sistemas ternários contendo vários compostos orgânicos voláteis (VOCs) quando estes compostos se difundem em misturas estagnantes de $\mathrm{O}_{2}$ e $\mathrm{N}_{2}$.

THORSTENSON \& POLLOCK (1989), explicam detalhadamente os vários modos de transporte de vapor em uma mistura multicomponentes. Os autores concluíram que se um gás não atmosférico forma uma fração significativa dos gases em uma zona não saturada, formulações do transporte de multicomponentes deveriam ser utilizadas. Entretanto, não foi especificado qual a fração da fase de vapor do solo poderia ser ocupada por vapores dos compostos orgânicos voláteis para exigir o uso de formulações de multicomponentes.

JURY et al. (1991), garantiram que em condições naturais só gradientes de menor pressão existem em sub-superfície e apenas $0,5 \%, 1 \%, 0,1 \%, 7 \%$ a $8 \%$ de toda a troca gasosa é causada respectivamente pelo efeito da temperatura, mudanças na pressão barométrica, vento e precipitação. Assim, a transferência de compostos gasosos é geralmente governada pela difusão na fase de vapor.

\subsection{Métodos de Campo para Análise de Hidrocarbonetos}

\subsubsection{Introdução}

Este item foi extraído em parte de UNITED STATE ENVIRONMENTAL PROTECTION AGENCY, (1997).

Análises de solo, solo-gás e amostragem de águas subterrâneas no campo são elementos essenciais para facilitar a avaliação do local (ESAs). Um gerenciamento de campo necessita fornecer resultados "in loco" hierarquicamente para uma completa avaliação do local em uma única mobilização (se possível). Nos últimos anos muitos métodos de campo para analisar hidrocarbonetos do petróleo estão sendo desenvolvidos e melhorados. Essas tecnologias melhoradas podem mudar a maneira de avaliação do local sendo conduzidas por dados seguros obtidos no campo que podem então ser usados para subsequente seleção do local de amostragem.

Historicamente, as análises de contaminação efetuadas para avaliação de tanques de armazenamento subterrâneos (USTs) eram realizadas fora da área atingida, em laboratórios fixos que usavam métodos analíticos certificados. Enquanto esses métodos forneciam nível de qualidade de dados (DQL) muito alto, seus resultados poderiam tomar dias ou semanas e 
seus custos eram relativamente elevados. Por outro lado, muitos estudos têm mostrado que as amostras podem sofrer significativa degradação durante o transporte e tempo decorrido antes da análise.

O desenvolvimento e melhorias de muitos métodos de campo tem permitido avaliação "in situ" por serem executados mais rapidamente e inteiramente no local. Por combinação de métodos de campo diferentes, com diferentes níveis de qualidade DQLs, ESAs podem melhorar a resolução da distribuição da contaminação e minimizar custos com análises. Métodos de baixos DQL (isto é, seleção) podem ser usados para prover uma grande quantidade de resultados para determinar a área de origem (isto é, zonas de líquido com fase não aquosa (NAPL) contaminada). Métodos de altos DQL podem ser usados para identificar baixas concentrações ou substâncias específicas de interesse em local especificado (ex., principal extremidade da pluma de contaminação). Resultados de métodos de alto DQL podem também ser usados como parte de um controle de qualidade supervisionado por um programa analítico de campo.

A Tabela 3.5.1 mostra um sumário de uma seleção primária de critérios para oito métodos de avaliação de campo freqüentemente aplicados para analisar hidrocarbonetos do petróleo. Ela é composta por uma breve discussão do sistema DQL utilizado. 
Tabela 3.5.1 - Resumo dos Métodos de Campo para Análise de Hidrocarbonetos do Petróleo.

\begin{tabular}{|c|c|c|c|c|c|c|c|c|c|}
\hline \multirow{3}{*}{ Método } & \multicolumn{8}{|c|}{ Nível de } & \multirow{3}{*}{ Limitações } \\
\hline & \multicolumn{2}{|c|}{ Material $^{1}$} & & \multirow{2}{*}{ Substâncias Detectadas } & Qualidade de & Tempo de & Custo por & Nível de & \\
\hline & $\mathrm{S}$ & $\mathrm{SG}$ & A & & & & & & \\
\hline Tubos Detetores & & $\mathrm{X}$ & $\mathrm{X}$ & $>100$ compostos específicos & $1 \mathrm{~A} / 1 \mathrm{~B}$ & 5 a $10 \mathrm{~min}$ & $\$ 8$ a $\$ 27$ & Baixo & $\begin{array}{l}\text { Alto grau de reações } \\
\text { cruzadas }\end{array}$ \\
\hline $\begin{array}{l}\text { Sensor Químico de Fibra } \\
\text { Óptica }\end{array}$ & & $\mathrm{X}$ & $\mathrm{X}$ & VOCs e $\mathrm{SVOCs} \geq \mathrm{C}_{6}$ & $1 \mathrm{~A} / 1 \mathrm{~B}$ & 3 a $5 \mathrm{~min}$ & $\begin{array}{c}<\$ 1 \text { a } \$ \\
10\end{array}$ & Baixo & $\begin{array}{l}\text { Não mede constituintes } \\
\text { específicos }\end{array}$ \\
\hline $\begin{array}{ll}\text { Kits de } & \text { Teste } \\
\text { Colorimétrico } & \end{array}$ & $\mathrm{X}$ & & $\mathrm{X}$ & Hidrocarbonetos Aromáticos & $1 \mathrm{~A} / 1 \mathrm{~B}$ & 10 a $20 \mathrm{~min}$ & $\begin{array}{c}\$ 17 \text { a } \$ \\
42\end{array}$ & Baixo - Médio & $\begin{array}{l}\text { As cores podem ser difíceis } \\
\text { de distinguir }\end{array}$ \\
\hline $\begin{array}{l}\text { Métodos } \quad \text { TOV com } \\
\text { FID/PID }\end{array}$ & $\mathrm{X}$ & $\mathrm{X}$ & $\mathrm{X}$ & VOCs Total & $1 \mathrm{~A} / 1 \mathrm{~B}$ & 1 a $30 \mathrm{~min}$ & $\begin{array}{c}<\$ 1 \text { a } \$ \\
10\end{array}$ & Baixo - Médio & $\begin{array}{l}\text { Não mede constituintes } \\
\text { específicos }\end{array}$ \\
\hline $\begin{array}{lll}\text { Kit } \quad \text { de } & \text { Teste } \\
\text { Turbidimétrico } & \end{array}$ & $\mathrm{X}$ & & & $\begin{array}{l}\text { TPH de médio-alcance } \\
\text { hidrocarbonetos } \\
\text { (ex., óleo diesel) }\end{array}$ & 1B & $\begin{array}{l}15 \text { a } 20 \text { min } \\
(25 \text { por hora })^{4}\end{array}$ & $\begin{array}{c}\$ 10 \mathrm{a} \\
\$ 15\end{array}$ & Baixo - Médio & Não útil para gasolina \\
\hline $\begin{array}{l}\text { Kits de Teste de } \\
\text { Imunização }\end{array}$ & $\mathrm{X}$ & & $\mathrm{X}$ & $\begin{array}{l}\text { TEX/PAHs/ } \\
\text { TPH }\end{array}$ & 1B & $\begin{array}{c}30 \text { a } 45 \text { min } \\
(5 \text { a } 8 \text { por hora })^{4}\end{array}$ & $\begin{array}{c}\$ 20 \text { a } \$ \\
60\end{array}$ & Médio & $\begin{array}{l}\text { Reações cruzadas podem } \\
\text { afetar a interpretação }\end{array}$ \\
\hline $\begin{array}{l}\text { Detetores Infravermelho } \\
\text { Portáteis }\end{array}$ & $\mathrm{x}$ & & $X$ & $\begin{array}{c}\text { TPH de hidrocarbonetos } \mathrm{C}_{6} \\
\text { para } \mathrm{C}_{26}\end{array}$ & 2 & 5 a $20 \min$ & $\$ 5$ a $\$ 30$ & Médio & $\begin{array}{l}\text { VOCs não são } \\
\text { acuradamente analisados }\end{array}$ \\
\hline GC para Campo & $\mathrm{X}$ & $\mathrm{X}$ & $\mathrm{X}$ & Específicos VOCs e SVOCs & $2 / 3$ & 10 a $60 \min ^{5}$ & $\begin{array}{c}\$ 20 \text { a } \$ \\
70\end{array}$ & Médio - Alto & $\begin{array}{l}\text { Requer uma habilidade } \\
\text { técnica }\end{array}$ \\
\hline
\end{tabular}

'Solo (S), Solo-Gás (SG), Água (A).

${ }^{2}$ Nível de qualidade de dados são discutidos em detalhe no texto seguinte.

${ }^{3}$ Incluidos estimativa de principal custo e disponibilidade - excluídos operários.

${ }^{4}$ Quando acontece em grupo.

${ }^{5}$ Resulta em grande tempo quando métodos preparados com alta qualidade são executados. 


\subsubsection{Nível de Qualidade de Dados}

Um sistema de classificação de métodos analíticos pelo nível de qualidade dos dados que eles fornecem é denominado de nível de qualidade de dados DQL. DQL é um dentre vários critérios que podem ser usados para selecionar um método analítico apropriado. A Tabela 3.5.2 apresenta um resumo do sistema de classificação DQL usado pela EPA, o qual foi adaptado do sistema de classificação desenvolvido pelo "New Jersey Department of Environmental Protection”. Os níveis são organizados em qualidade de dados hierárquica no qual DQL 1 provem informações de seleção, DQL 2 provem dados quantitativos, e DQL 3 provem os mais rigorosos dados quantitativos. Vale acrescentar que nos EUA cada Estado apresenta seus próprios valores de QA/QC (técnica utilizada para padronizar a qualidade dos resultados obtidos com um método de campo específico).

Tabela 3.5.2 - Resumo dos Níveis de Qualidade de Dados

\begin{tabular}{ll}
\hline Nível de Qualidade de Dados & Aplicações Gerais de Campo \\
\hline 1A: Seleção quantitativa & $\begin{array}{l}\text { Presença geral de contaminação (ex., "sim/não", } \\
\text { "baixa/média/alta"); saúde e segurança. }\end{array}$ \\
1B: Seleção semi-quantitativa & $\begin{array}{l}\text { Aproximação da zona de contaminação; fornece } \\
\text { ordens de magnitude estimada. }\end{array}$ \\
2: Delineação quantitativa & Delineação de contaminantes específicos. \\
3: Zona de limpeza Quantitativa & Monitoramento regulador, determinação de amostras \\
& em branco (limpas). \\
\hline
\end{tabular}

\subsubsection{Nível de Qualidade de Dados 1: Seleção}

O método de seleção DQL 1 é dividido em dois subgrupos 1A e 1B. Ambos são usados para uma seleção inicial de amostragem ou para avaliação de saúde e segurança. DQL 1A fornece uma indicação geral da presença de contaminantes, DQL 1B fornece valores numéricos relativos. Todos os métodos DQL 1:

- Podem requerer confirmação com método DQL mais eficiente;

- Detectam a presença de classes ou grupos de constituintes. 


\subsection{Nível de Qualidade de Dados 1A: Seleção Qualitativa}

DQL 1A é indicado para seleção inicial do solo, solo-gás, e água subterrânea fornecendo um "sim/não" para indicação de contaminação. Medidas feitas com estes métodos não são consistentes por causa da falta de controle de amostras e variabilidade de métodos inerentes. Como resultado, amostras brancas (limpas) (isto é, com baixa concentração) não podem ser determinadas por este nível. Como exemplos de método DQL 1A podemos citar a análise de ar ambiente ou mistura de vapor formada sobre um sólido ou líquido em um recipiente selado hermeticamente usando detetor de chama-ionizada FIDs e detetor de fotoionização PIDs.

\subsection{Nível de Qualidade de Dados 1B: Seleção Semi-Quantitativa}

DQL 1B fornece uma ordem de magnitude aproximada para a estimativa da contaminação. Ela pode ser usada para definir a localização de formas conhecidas de contaminação. Procedimentos de QA/QC incluem uma curva de calibração gerada usando-se como padrão uma matriz de perfuração, conferem regularmente a calibração e amostras de campo em branco. Exemplos de DQL 1B são os dados de alguns métodos do kit de teste Imunização.

\subsubsection{Nível de Qualidade de Dados 2: Delineação Quantitativa}

Os métodos DQL 2 fornecem dados seguros para a delineação do contaminante durante a avaliação do local. Tipicamente, eles são métodos de laboratório adaptados para o campo (ex., método de cromatografia gasosa portátil). Um método DQL 2 tem como características:

- Medir constituintes individuais (ex., benzeno) ou grupo de constituintes (ex., BTEX, alcance orgânico gasolina/diesel);

- Fornecer resultados que são altamente reproduzidos e acurados quando procedimento apropriados QA/QC são usados;

- Realizar delineamento do contaminante, o qual pode ser correlacionado com um altíssimo método DQL.

\subsubsection{Nível de Qualidade de Dados 3: Zona de Limpeza Quantitativa}


Métodos DQL 3 são métodos de laboratório aprovados (ex., método de laboratório U.S. EPA SW-846) e são planejados para prover a maior qualidade de dados praticáveis. Estes métodos podem ser usados para confirmar amostras "limpas" e para monitoramento regulador. DQL 3 podem ser executados fora do local em um laboratório fixo ou no local em um laboratório móvel.

\subsubsection{Métodos Analíticos para Vapores Orgânicos Totais: Ionização por Chama e Detetores de Fotoionização}

Métodos analíticos para vapores orgânicos totais (TOV) detectam compostos orgânicos voláteis totais em uma amostra. Embora, eles forneçam informações sobre a magnitude relativa da contaminação, métodos TOV são incapazes de distinguir compostos específicos.

\subsubsection{Princípios de Operação}

Existem dois tipos de instrumentos comumente usados em análises TOV - detetor de ionização por chama (FIDs) e detetor de fotoionização (PIDs).

\subsubsection{Detetores de Ionização por Chama}

FIDs usam uma chama de hidrogênio para ionizar vapores orgânicos. A medida da corrente elétrica que é gerada pelos ions livres, emite ao instrumento uma resposta, que por conseguinte é relacionada com a concentração de compostos voláteis presentes na amostra. Enquanto FIDs fornecem resposta significativa para a maior parte dos vapores orgânicos, eles apresentam maior sensibilidade para hidrocarbonetos alifáticos (ou cadeia) porque estes compostos queimam com mais eficiência do que hidrocarbonetos aromáticos (ou anel). FIDs são tipicamente calibrados com metano.

\subsubsection{Detetores de Fotoionização}


PIDs utilizam uma lâmpada ultravioleta (UV) para ionizar vapores orgânicos. Como no caso anterior, a resposta é relacionada à corrente elétrica gerada pelo composto ionizado. Compostos com alto potencial de ionização (ex., alifáticos) exigem mais energia para ionizar; portanto, a energia da lâmpada UV determina os compostos que são ionizados. O alcance das lâmpadas UV em energia varia desde 8,4 a 11,7 eV. O gás de calibração tipicamente usado para PIDs é o isobutileno. Estes instrumentos são mais sensíveis para hidrocarbonetos aromáticos (ex., BTEX), mas alguns alifáticos podem também ser detectados com as lâmpadas de alta energia.

\subsubsection{Comparação entre Detetores de Ionização por Chama e Detetores de Fotoionização}

Com relação às medições para hidrocarbonetos alifáticos e aromáticos, devem ser considerados outros fatores na seleção de um FID ou PID como os seguintes:

- Fator de resposta para constituintes específicos. Este fator difere entre os tipos de instrumentos e entre fabricantes. São importantes para saber quando calcular a concentração real. Por exemplo, um FID calibrado com metano pode oferecer resultados $150 \%$ maiores do que quando exposto a mesma concentração de benzeno, mas a resposta pode somente ser $25 \%$ para etanol.

- FIDs permanecem lineares desde 1 a 1.000 ppm $_{\mathrm{V}}$ (partes por milhão por volume), e alguns podem até mesmo alcançar $10.000 \mathrm{ppm}_{\mathrm{V}}$; PIDs permanecem lineares desde 1 a $300 \mathrm{ppm}_{\mathrm{V}}$, com alguns alcançando $750 \mathrm{ppm}_{\mathrm{V}}$ sob condições ideais.

- Muitos PIDs são afetados por altas correntes elétricas (ex., linhas de força).

- PIDs podem operar em condições de alta umidade relativa e baixo $\mathrm{O}_{2}$, mas eles requerem o gás de calibração apropriado para aproximar as condições de teste. FIDs podem operar em condições úmidas, baixo $\mathrm{O}_{2}$, alto $\mathrm{CO}_{2}$ (os ventos ambientes podem extinguir a chama FID).

- FIDs requerem mais treinamento que PIDs.

- FIDs requerem uma fonte de hidrogênio ultra - puro que pode não estar sempre disponível e requer especial manipulação e transporte. 
- PIDs estão sujeitos a valores baixos falsos quando concentrações de metano $\left(\mathrm{CH}_{4}\right)$ são maiores do que $1 \%$; FIDs têm o problema oposto, por ser sensível ao metano e fornecendo valores positivos falsos.

- Ambos os instrumentos são adversamente afetados por baixos escoamento de ar, embora FIDs sejam mais sensíveis para ambiente ligeiramente contaminado com gasolina (por causa da presença de vários alifáticos), nenhum é eficaz para determinação de ambiente altamente contaminado por gasolina, nem nenhum instrumento é acurado quando as temperaturas do ar ambiente estão abaixo de $32^{0} \mathrm{~F}\left(0^{0} \mathrm{C}\right)$.

A Tabela 3.5.3.1 apresenta um resumo da comparação entre FIDs e PIDs.

Tabela 3.5.3.1 - Comparação de FIDs e PIDs.

\begin{tabular}{|c|c|c|}
\hline & FIDs & PIDs \\
\hline Compostos Detectados & $\begin{array}{l}\text { Hidrocarbonetos alifáticos (ex., } \\
\text { butano, hexano), menos sensível } \\
\text { (embora resposta significante) a } \\
\text { aromáticos (ex., BTEX). }\end{array}$ & $\begin{array}{l}\text { Hidrocarbonetos aromáticos e } \\
\text { alguns alifáticos. }\end{array}$ \\
\hline $\begin{array}{l}\text { Alcance Linear de } \\
\text { Detecção }\end{array}$ & $1 \mathrm{a}$ mais de $1.000 \mathrm{ppm}_{\mathrm{V}}$ & 1 a menos de 300 ppm $_{V}$ \\
\hline $\begin{array}{l}\text { Condições Ambientais } \\
\text { Desfavoráveis }\end{array}$ & $\begin{array}{l}\text { Alto } \mathrm{CO}_{2} \text {, baixo } \mathrm{O}_{2} \text { (menos de } \\
15 \% \text { ventos fortes, } \\
\text { temperatura abaixo de } 0^{0} \mathrm{C} .\end{array}$ & $\begin{array}{l}\text { Umidade alta (ex., } 90 \% \text { ), } \\
\text { metano }\left(\mathrm{CH}_{4}\right) \text { abaixo de } 1 \% \text {, } \\
\text { baixo } \mathrm{O}_{2}(\text { menor do que } 15 \% \text { ), } \\
\text { temperatura abaixo de } 0^{0} \mathrm{C} .\end{array}$ \\
\hline Assuntos Variados & $\begin{array}{l}\text { Requer uma fonte de } \\
\text { hidrogênio. } \\
\text { Requer mais treinamento do que } \\
\text { PIDs. } \\
\text { Altos níveis de metano podem } \\
\text { ser interpretados como } \\
\text { contaminação. }\end{array}$ & $\begin{array}{l}\text { Adversamente afetado por } \\
\text { fontes força elétrica (ex., linhas } \\
\text { de força e transformadores). } \\
\text { Metano pode deprimir as } \\
\text { leituras. }\end{array}$ \\
\hline
\end{tabular}




\subsubsection{Descrição do Método}

Métodos analíticos de vapores orgânicos totais (TOV) fornecem uma indicação indireta das concentrações de contaminação do solo e água subterrânea por medida de constituintes orgânicos que se separam dentro de recipiente selado. Existem três tipos gerais de métodos usados com FIDs e PIDs: medida do ar ambiente, seleção em headspace, e análises de headspace. Cada um fornece um nível variado de qualidade de dados.

Observação: headspace é o espaço livre que fica entre a parte superior da amostra e superfície do recipiente, sendo preenchido por ar e vapores volatilizados da amostra.

\subsection{Medida do Ar Ambiente}

Medidas do ar ambiente são executadas por leituras tomadas diretas com qualquer FID ou PID no ar imediatamente acima da amostra de solo ou água subterrânea. Ele é comumente usado como um método de seleção para determinar qual amostra solo ou água deve ser analisada com um método de alta qualidade de dados. Ele é também usado para ajudar a determinar futuros locais de amostragem.

\subsection{Seleção em Headspace}

Com a finalidade de executar uma seleção em headspace, uma amostra de solo ou água subterrânea é colocada em um recipiente selado, freqüentemente um frasco de vidro ou saco de polietileno, deixando $1 / 2$ a 1/3 vazio. O frasco é então ou agitado e aquecido, ou deixado em repouso por um período de tempo no qual ocorre a partição dos hidrocarbonetos dentro do espaço vazio (isto é, o espaço de ar acima da amostra). O vapor formado no espaço vazio é então medido com um FID ou PID. O uso de um saco de polietileno permite ao instrumento fluxo de amostra a taxa constante, contudo, partições de hidrocarbonetos do saco podem afetar a análise, assim uma amostra em branco deve ser testada e o resultado fatorado dentro das análises.

Este método envolve uma análise mais precisa de amostras do que a medida do ar ambiente. Como resultado, a seleção em headspace fornece leituras mas consistentes que podem ser usadas para estimar concentrações relativas. Porém, as leituras permanecem relativamente imprecisas, porque a volatilização de contaminantes é afetada por: 
- Tipo de solo;

- Umidade contida no solo;

- Diluição de ar ambiente dentro do frasco;

- Variações de temperatura;

- Tempo de preparo e análise das amostras.

\subsection{Análises de Headspace}

Análise de headspace é similar à seleção em headspace mas os procedimentos são mais controlados e os resultados mais acurados. Uma quantidade moderada de uma amostra de solo ou água subterrânea é colocada em um saco de polietileno. Para amostras de solo, um volume específico de água deionizada é também colocada dentro do saco para facilitar uma partição mais consistente dos vapores orgânicos. O saco é então inflado e a amostra é agitada. Depois de um tempo especificado, um FID ou PID é usado para medir os vapores formados no espaço livre. Procedimentos para calibragem incluem o desenvolvimento de uma curva de calibração usando padrão de campo. Estes padrões ajudam na interpretação dos instrumentos de resposta e fornecem uma comparação com amostras de concentrações conhecidas.

\subsubsection{Capacidades do Método e Considerações Práticas}

Medidas do ar ambiente são classificadas como análises DQL 1A porque estas leituras são altamente variáveis ou pequenas e um curva de calibração não é usada nesta técnica. $O$ menor limite de detecção é geralmente em torno de $100 \quad \mathrm{ppm}_{\mathrm{V}}$ mas pode ser significativamente mais baixo sob condições ideais (ex., sem vento, sem umidade, alto nível de $\mathrm{O}_{2}$ ). Seleções em headspace são análises qualitativas e enquadram-se dentro do alcance DQL 1A, contudo, seus limites de deteç̧ão são geralmente entre 10 e 100 ppm. Análise de headspace é classificado como DQL 1B, método semi-quantitativo, porque fornece uma ordem de magnitude em indicação de contaminação, mas não fornecem informações sobre a concentração de constituintes específicos. Os limites mínimos de detecção com este método pode ser tão baixo quanto $0,1 \mathrm{ppm}$ para gasolina em água, mas é geralmente de $1 \mathrm{ppm}$. 
Todos os três métodos, quando usados para amostras de solo que são ricas em argila ou contém alto conteúdo orgânico podem apresentar resultados inconsistentes. Finalmente a gasolina deve ser relativamente "fresca" para fornecer resultados úteis.

Análises de vapores orgânicos totais (TOV) são um dos mais baratos métodos analíticos disponíveis. Um resumo das capacidades e considerações práticas destes três métodos analíticos usando um FID ou PID é resumido na Tabela 3.5.3.2.

Tabela 3.5.3.2 - Resumo da Capacidade do Método e Considerações Práticas para Vapores Orgânicos Totais

\begin{tabular}{|c|c|c|c|}
\hline & Ar Ambiente & Seleção em Recipiente Selado & Análises em Recipiente Selado \\
\hline Compostos & \multicolumn{3}{|c|}{ (FIDs): Alifáticos (ex., butano), menos sensível para aromáticos (ex., BTEX) } \\
\hline Detectados & \multicolumn{3}{|c|}{ (PIDs): Aromáticos, alguns alifáticos } \\
\hline \multicolumn{4}{|l|}{ Limites de Baixas } \\
\hline \multicolumn{4}{|l|}{ Detecção: } \\
\hline Gasolina na Água & $>100 \mathrm{ppm}$ & $10 \mathrm{~s}$ a $100 \mathrm{~s} \mathrm{ppm}$ & 0,1 a $1 \mathrm{ppm}$ \\
\hline Gasolina no Solo & $>100 \mathrm{ppm}$ & $10 \mathrm{~s}$ a $100 \mathrm{~s} \mathrm{ppm}$ & 1 a $10 \mathrm{ppm}$ \\
\hline Diesel no Solo & $>100 \mathrm{ppm}$ & $100 \mathrm{~s} \mathrm{ppm}$ & $10 \mathrm{~s}$ a $100 \mathrm{~s} \mathrm{ppm}$ \\
\hline Limitações & \multicolumn{3}{|c|}{$\begin{array}{l}\text { Argila ricas ou alto conteúdo orgânico pode fornecer resultados inconsistentes. } \\
\text { Melhor usado com gasolina relativamente recente. }\end{array}$} \\
\hline Tempo para Análise & 2 minutos & 10 a 30 minutos & 10 a 30 minutos \\
\hline Dificuldade de & & & \\
\hline Procedimentos & Baixo & Baixo & Médio \\
\hline Nível de Qualidade & & & \\
\hline de Dados & $1 \mathrm{~A}$ & $1 \mathrm{~A}$ & $1 \mathrm{~B}^{1}$ \\
\hline Custo por Amostra ${ }^{2}$ & $<\$ 1$ & $\$ 1$ a $\$ 5$ & $\$ 10$ \\
\hline
\end{tabular}

${ }^{1}$ Somente se os constituintes forem predeterminados.

${ }^{2}$ Custo de equipamentos são tipicamente entre $\$ 4.000$ a $\$ 8.000$. 


\section{MATERIAL E MÉTODOS}

\subsection{Introdução}

O estudo da contaminação do solo por gasolina foi realizado através de três etapas experimentais:

a) A princípio desejou-se o entendimento e a quantificação do fenômeno da volatilização da gasolina livre. Para tanto utilizou-se placa de Petri e provetas. Variou-se as dimensões dos recipientes e a quantidade de gasolina introduzida em cada recipiente. As quantidades volatilizadas foram medidas com balança analítica e detetor de fotoionização;

b) Em seguida foi estudada a volatilização em colunas de solo contaminado. Para tanto utilizou-se provetas, colunas de acrílico e recipientes cilíndricos com capacidade de 20 litros. Variou-se a quantidade de gasolina e a quantidade de solo introduzidas em cada recipiente. Nos ensaios utilizando provetas as quantidades volatilizadas foram medidas com balança analítica e detetor de fotoionização, para os ensaios restantes as quantidades volatilizadas foram medidas somente com detetor de fotoionização;

c) Para finalizar comparou-se os resultados experimentais com os resultados fornecidos pelo modelo JURY para zona não saturada que é parte integrante do software APIDSS, versão 2.0, pertencente ao Departamento de Hidráulica e Saneamento da Escola de Engenharia de São Carlos.

O solo utilizado nos experimentos foi obtido junto ao Departamento de Geotecnia da Escola de Engenharia de São Carlos. Trata-se de material devidamente caracterizado pelo referido Departamento, através de ensaios padronizados. 


\subsection{Ensaios Preliminares}

\subsubsection{Características da Gasolina}

Antes do início dos ensaios propriamente ditos, obteve-se da PETROBRAS uma caracterização da gasolina comum utilizada no Brasil e nos ensaios. A média da quantidade de etanol presente nas amostras utilizadas foi medida nessa fase da pesquisa.

Como pode se ver na Tabela 4.1 e Figura 4.1, a gasolina utilizada no Brasil apresenta 19,6\% de compostos aromáticos, sendo que neste grupo estão incluídos os BTEX, que são hidrocarbonetos que apresentam alta pressão de vapor e que podem ser medidos através de fotoionização.

Tabela 4.1 - Composição da gasolina utilizada no Brasil (PETROBRAS, 1997).

\begin{tabular}{|c|c|c|c|c|}
\hline Hidrocarbonetos & $\begin{array}{l}\text { Número de } \\
\text { Carbonos }\end{array}$ & $\begin{array}{l}\text { Peso Molecular } \\
\qquad(\mathrm{g} / \mathrm{mol})\end{array}$ & $\begin{array}{c}\text { Solubilidade Aquosa } \\
{\left[25^{\circ} \mathrm{C}\right](\mathrm{mg} / \mathrm{l})}\end{array}$ & $\begin{array}{c}\text { Composição Gasolina } \\
\text { Brasileira (Peso \%) }\end{array}$ \\
\hline \multicolumn{5}{|l|}{ Alcano } \\
\hline Propano & 3 & 44,09 & 62,4 & 1,0 \\
\hline i-Butano / n-Butano & 4 & 58,14 & 61,4 & 14,1 \\
\hline i-Pentano / n-Pentano & 5 & 72,15 & 39,0 & 17,5 \\
\hline i-Hexano / n-Hexano & 6 & 86,17 & 9,5 & 3,0 \\
\hline i-Heptano / n-Heptano & 7 & 100,2 & 2,9 & 8,7 \\
\hline i-Octano / n-Octano & 8 & 114,23 & 0,66 & 1,2 \\
\hline Nonano & 9 & 128,25 & 0,22 & 3,1 \\
\hline Decano & 10 & 142,28 & 0,052 & 1,0 \\
\hline Soma de Alcanos & & & ----- & 49,6 \\
\hline \multicolumn{5}{|l|}{ Alcenos } \\
\hline Buteno & 4 & 56,1 & 222 & 0 \\
\hline Penteno & 5 & 70,13 & 148 & 0,3 \\
\hline Hexeno & 6 & 84,17 & 50 & 0,3 \\
\hline Hepteno & 7 & 98,19 & 14,1 & 2,0 \\
\hline Octeno & 8 & 112,22 & 2,7 & 1,3 \\
\hline Noneno & 9 & 126,24 & 0,63 & 0,2 \\
\hline Deceno & 10 & 140,19 & 0,1 & 0,2 \\
\hline Soma de Alcenos & נינו & & 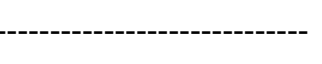 & 4,3 \\
\hline \multicolumn{5}{|l|}{ Aromáticos } \\
\hline Benzeno & 6 & 78,11 & 1780 & 1,0 \\
\hline Tolueno & 7 & 92,10 & 534,8 & 3,0 \\
\hline
\end{tabular}




\begin{tabular}{lcccc}
\hline Hidrocarbonetos & $\begin{array}{c}\text { Número de } \\
\text { Carbonos }\end{array}$ & $\begin{array}{c}\text { Peso Molecular } \\
(\mathrm{g} / \mathrm{mol})\end{array}$ & $\begin{array}{c}\text { Solubilidade Aquosa } \\
{\left[25^{\circ} \mathrm{C}\right](\mathrm{mg} / \mathrm{l})}\end{array}$ & $\begin{array}{c}\text { Composição Gasolina } \\
\text { Brasileira (Peso \%) }\end{array}$ \\
\hline o-, m-, p-xileno & 8 & 106,17 & Ca. 157 & 5,7 \\
Etilbenzeno & 8 & 106,20 & 161,2 & 1,3 \\
C9-Aromáticos & 9 & 120,19 & Ca. 55 & 5,6 \\
C10-Aromáticos & 10 & 134,21 & Ca. 10 & 3,0 \\
Naftaleno & 10 & 128,16 & 111,1 & - \\
Soma de Aromáticos & ---------------------------- & 19,6 \\
Etanol & 2 & 46,10 & c.m. & 22,0 \\
Metanol & 1 & 32,00 & c.m. & 2,4 \\
MTBE & 5 & 88,15 & 48000 & 0,1 \\
\hline
\end{tabular}
c.m. = Completamente miscível.

Composição da Gasolina Brasileira

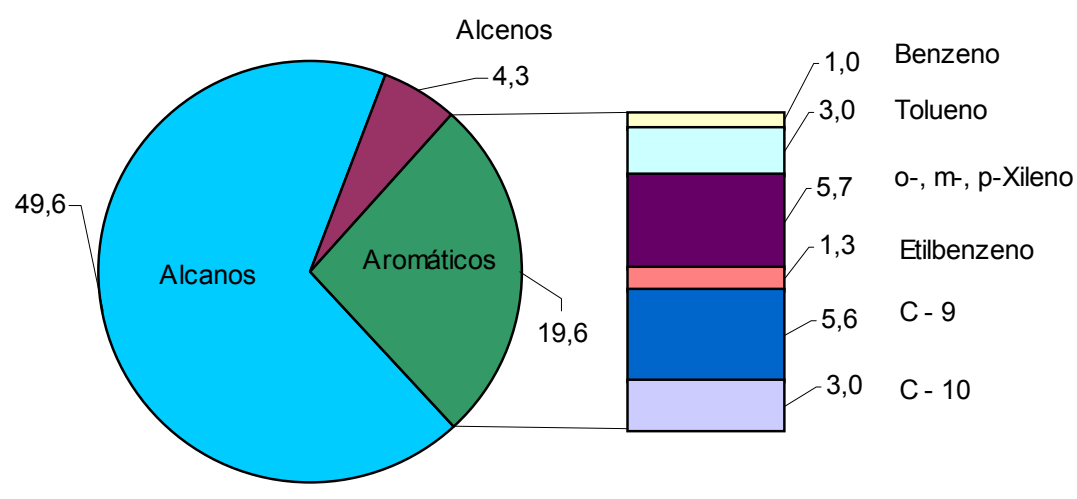

Figura 4. 1- Composição da gasolina utilizada no Brasil (PETROBRAS, 1997).

Para iniciar os ensaios de laboratório adquiriu-se 5 litros de gasolina comum de um posto de distribuição e armazenou-se em laboratório em recipiente adequado. Posteriormente, na medida do necessário, foram efetuadas novas aquisições de gasolina.

Todos os teste feitos para medir a quantidade de etanol na gasolina utilizada não apresentaram valores acima de $22 \%$. Os testes utilizados são similares aos testes sugeridos pelas distribuidoras de derivados de petróleo aos proprietários de postos de serviços para a determinação da quantidade desse produto na gasolina. O teste consiste em adicionar-se $500 \mathrm{ml}$ de gasolina a $500 \mathrm{ml}$ de água numa proveta de capacidade de $1.000 \mathrm{ml}$ e misturá-las, por agitação manual. O acréscimo de volume da fase aquosa multiplicado por dois 
corresponderá ao volume de álcool etílico presente em 1 litro de gasolina, que deve corresponder às especificações do produto (BRASIL, LEIS, etc. 1998), que é de no máximo $24 \%$ ou $240 \mathrm{ml}$.

\subsubsection{Caracterização do Solo}

A caracterização do solo consiste na desagregação manual das amostras deformadas, seguida de peneiramento em sistema vibratório e homogeneização.

Pelo programa básico de caracterização do solo realizado no Departamento de Geotecnia as amostras foram coletadas da região denominada Santa Felícia, localizada na cidade de São Carlos, e em seguida procedeu-se a análise granulométrica conjunta (Norma ABNT: MB-32) e massa específica dos sólidos (Norma ABNT: MB-28).

Nos experimentos que utilizaram solo em provetas (realizados no Departamento de Hidráulica e Saneamento), a fração orgânica do solo foi eliminada através de método utilizado no CRHEA (Centro de Recursos Hídricos e Ecologia Aplicada) e recomendado pelo Prof. Bohdan Matvienko Sikar. Esse método consiste em tomar-se as amostras devidamente pesadas de tal forma que não forme camada superior a $1 \mathrm{~cm}$; em seguida levase à estufa a $103^{\circ} \mathrm{C}$ durante aproximadamente $30 \mathrm{mim}$; em seguida retira-se as amostras da estufa e leva-se ao dessecador para esfriar a amostra e evitar que a mesma absorva umidade do ambiente. Pesa-se novamente e em seguida leva-se as amostras à mufla a aproximadamente $650{ }^{\circ} \mathrm{C}$ durante aproximadamente 1 hora para que seja eliminada toda a fração de carbono orgânico presente na amostra. Em seguida deixa-se as amostras esfriarem durante 10 min aproximadamente ao ambiente levando-se novamente ao dessecador para que sejam esfriadas sem a presença de umidade e em seguida pesam-se as amostras novamente. Os resultados comparativos entre o solo comum (coloração marrom) e o solo sem a fração orgânica (coloração avermelhada) podem ser visualizados na Figura 4.2. 


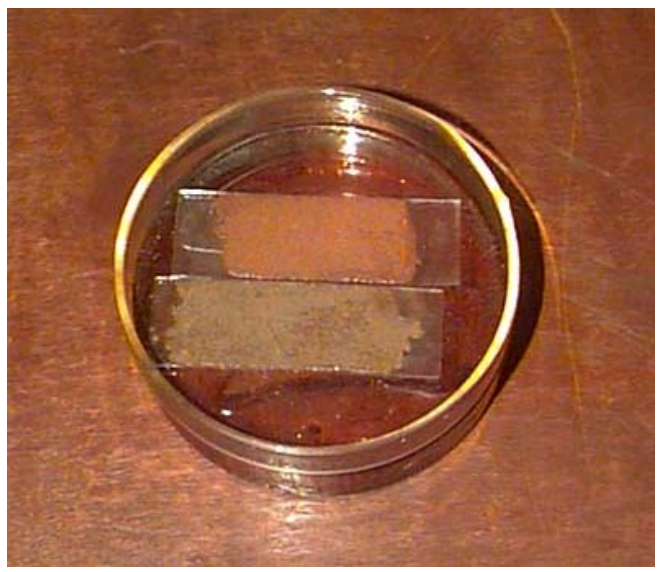

Figura 4. 2- Comparação entre o solo comum e o solo sem a fração orgânica.

\subsection{Análise com Detetor de Fotoionização}

A técnica analítica utilizada neste trabalho, para análise da concentração dos compostos orgânicos voláteis liberados da gasolina pura e do solo, foi a fotoionização por ser uma técnica de simples utilização e por estar disponível para esta pesquisa.

\subsubsection{Fundamentação Teórica da Fotoionização}

O detetor de fotoionização consiste basicamente de uma lâmpada ultravioleta e uma câmara de íons. O detetor mede a concentração de gases presentes em uma amostra, utilizando a fotoionização. A fotoionização ocorre quando uma molécula absorve um fóton com energia suficiente para causar a liberação de um elétron de seu orbital mais externo e criar assim um íon positivo:

$$
\mathrm{RH}+\mathrm{hv} \rightarrow \mathrm{RH}^{+}+\mathrm{e}^{-}
$$

Em que:

RH = molécula da espécie a ser ionizada;

hv = fóton com um nível de energia igual ou maior do que o potencial de ionização de RH;

$\mathrm{RH}^{+}=$íon positivo da espécie que foi ionizada;

$\mathrm{e}^{-}=$elétron livre . 
O potencial de fotoionização de uma molécula é a energia em eletron-volts requerida para liberar um elétron dessa molécula.

A técnica consiste em fazer com que amostras de gases adentrem a câmara de íons. Uma lâmpada ultravioleta, adjacente à câmara, gera fótons com certo nível energético, que causam a ionização das moléculas que tem potencial de ionização menor ou igual à energia dos fótons com que são bombardeados. Um eletrodo positivo repele os íons positivos fazendo com que se movimentem na direção de um coletor. Esses íons geram um sinal no coletor que é proporcional à sua concentração. Esse é amplificado proporcionando uma saída eletronicamente mensurável. A quantidade de ionização verificada e seu sinal no amplificador são proporcionais à quantidade de gás existente na câmara e à sensibilidade de ionização do gás.

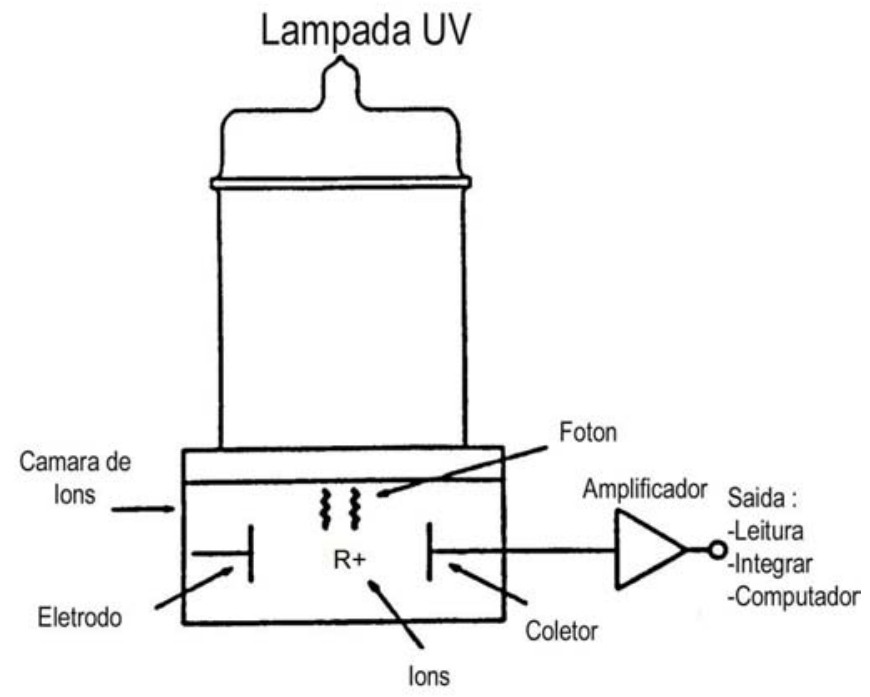

Figura 4. 3- Exemplo esquemático princípio do processo de fotoionização.

\subsubsection{Princípios de Funcionamento do Detetor de Fotoionização}

O kit que compõe o detetor de fotoionização é composto basicamente por: uma sonda, um módulo de controle (datalogger) e um cilindro com gás de calibração (no caso do equipamento utilizado, isobutileno).

A princípio, antes de inicializar o aparelho, deve-se tomar as devidas precauções com a voltagem, pois o aparelho apresenta duas formas de operação com relação à voltagem, uma que utiliza a energia elétrica comum (110volts) ou diretamente pela bateria armazenada no 
módulo de controle, sendo que a última é limitada a um período de operação máximo de 8 horas. Ao inicializar o aparelho é apresentada no módulo de controle a tela principal. Essa tela mostra: o modo de detecção, o canal de armazenamento, o horário e uma concentração qualquer no ar. A partir deste momento o equipamento deve ser preparado para o tipo de análise desejada. A princípio o equipamento deve ser calibrado. A calibração deve ser feita em termos de uma substância que possua um potencial de ionização igual ou inferior a 11,7 ev (que é o potencial de ionização da lâmpada utilizada). A substância utilizada para a calibração do equipamento nesta pesquisa foi o isobutileno que possui um potencial de ionização 8,82ev. A seqüência de calibração é a seguinte: pressionar a tecla de calibração; escolhe-se a opção calibrar. A princípio o equipamento irá ser "zerado" para a concentração do ar ambiente; em seguida será necessário entrar com o valor da concentração da substância usada para calibração (que neste caso foi de 100ppm); subseqüentemente deve-se conectar o bico da sonda do aparelho ao cilindro de calibração e ao final será necessário escolher um canal para armazenamento dessa calibração. Desta forma, o equipamento estará calibrado. A seguir deve-se escolher o módulo de operação. O equipamento possui quatro módulos de operação:

a) Amostragem: é utilizado para amostragens pontuais;

b) Substâncias perigosas: é utilizado para monitoramento específico de substâncias perigosas (sendo que este módulo de operação foi utilizado nesta pesquisa);

c) Higiene industrial: recomendado para monitoramento continuo de locais específicos;

d) Detecção de vazamento: utilizado para monitoramento de válvulas, bombas e flanges com vazamentos.

Seguindo os procedimentos acima descritos o aparelho estará pronto para ser utilizado (existem outras especificidades que podem ser encontradas no manual do equipamento).

Uma informação relevante a ser acrescentada é que o sistema de sucção possui um vazão de $1 \mathrm{~cm}^{3} / \mathrm{s}$, podendo succionar até a profundidade de $15 \mathrm{~m}$.

No anexo II é apresentado uma Tabela, na qual constam as substâncias que estão presentes na gasolina brasileira e são detectáveis pelo detetor de fotoionização, com seus referidos potenciais de ionização. 


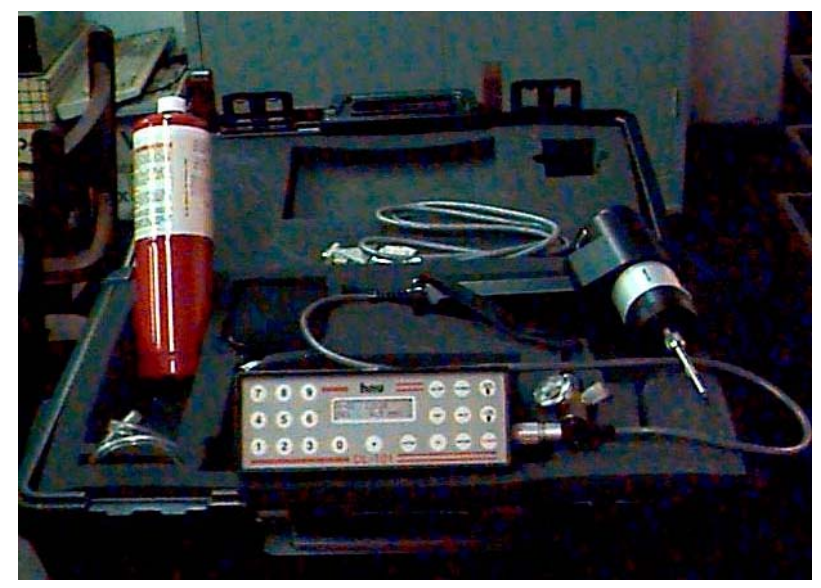

Figura 4. 4- A ilustração mostra kit que compõem o detetor de fotoionização. À esquerda está localizado o balão de calibração, na região central está localizado o datalogger e à direita, conectada ao datalogger, a sonda utilizada para realizar as leituras.

\subsection{Descrição dos Ensaios Experimentais}

Inicialmente foram feitos ensaios preliminares para definir a dimensão dos experimentos com relação aos parâmetros que seriam analisados como: a taxa de volatilização, a influência dos efeitos de borda do recipiente a serem utilizados e a influência da coluna de ar livre nos ensaios em provetas e em colunas de acrílico.

A princípio procedeu-se a calibração da balança (Marca QUIMIS, modelo ESL 1.000, com capacidade e precisão de 1.000 X 0,01 gramas respectivamente). Posteriormente foi feita uma nova calibração a título de comparação (ver anexo I). Também procedeu-se à calibração do fotoionizador como descrito no item 4.3.2.

Os ensaios experimentais podem ser divididos em duas etapas principais, uma de difusão direta do contaminante (gasolina) para a atmosfera com o intuito de determinar as taxas máximas de volatilização e variação da concentração em diversos tipos de recipientes (sempre com o bico da sonda do equipamento na interface entre a extremidade superior do recipiente e o ambiente externo); a outra etapa é a de difusão que ocorre na presença de solo. Nesta segunda etapa primeiramente usando-se balança analítica e detetor de fotoionização avaliou-se a taxa de volatilização e variação da concentração; porém com o aumento de 
escala não foi possível a utilização de balança analítica nos ensaios com coluna de acrílico e recipientes cilíndricos de 20 litros.

\subsubsection{Ensaios de Difusão do Contaminante Livre para a Atmosfera}

Como dito anteriormente esta etapa compreende os experimentos que avaliaram a difusão direta da gasolina comum para a atmosfera em recipientes de diversas formas com a finalidade de medir a taxa de volatilização através da perda de massa em balança analítica e uma parcela dos compostos orgânicos voláteis através de fotoionizador.

Esta etapa pode ser ainda subdividida em outras três assim descritas: preparação dos experimentos, ensaios preliminares e ensaios definitivos.

\subsubsection{Preparação dos Experimentos}

Os procedimentos seguidos para preparação destes experimentos são muito simples e podem ser assim descritos: retira-se uma quantidade de gasolina ligeiramente superior ao volume necessário e armazena-se em um becker, em seguida pipeta-se a quantidade necessária de gasolina e adiciona-se ao recipiente a ser utilizado no experimento.

\subsubsection{Ensaios Preliminares}

Os ensaios preliminares compreendem oito experimentos assim descritos: no primeiro tomou-se uma placa de Petri de volume igual a $100 \mathrm{ml}$, altura de $0,9 \mathrm{~cm}, 8,41 \mathrm{~cm}$ de diâmetro, em seguida adicionou-se $50 \mathrm{ml}$ de gasolina e mediu-se a variação da perda de massa durante oito horas de experimento; no segundo experimento tomou-se uma proveta graduada de volume igual a $100 \mathrm{ml}$, altura total da base à extremidade superior igual a 24,7 $\mathrm{cm}$, e diâmetro igual a $2,59 \mathrm{~cm}$, sendo adicionado um volume de $50 \mathrm{ml}$ de gasolina e mediuse a perda de massa durante 25 horas de experimento; nos seis experimentos seguintes tomou-se uma mesma proveta graduada de volume igual a $250 \mathrm{ml}$, altura total da base à extremidade superior igual a $33 \mathrm{~cm}$, e diâmetro igual a $3,90 \mathrm{~cm}$, e adicionou-se $300 \mathrm{ml}$ (borda livre da proveta), $250 \mathrm{ml}, 230 \mathrm{ml}, 210 \mathrm{ml}, 190 \mathrm{ml}$ e $170 \mathrm{ml}$ de gasolina respectivamente, em seguida mediu-se a variação da perda de massa durante oito horas para cada uma das respectivas quantidades adicionadas. 


\subsubsection{Ensaios Definitivos}

Os ensaios definitivos de difusão do contaminante livre para a atmosfera foram realizados medindo-se a variação de massa de gasolina contida no recipiente através de balança analítica e concentração de alguns compostos orgânicos voláteis através de fotoionizador. Neste item foram realizados seis ensaios que podem ser assim descritos: no primeiro ensaio tomou-se uma placa de Petri de volume igual a $100 \mathrm{ml}$, altura de $0,9 \mathrm{~cm}$, $8,41 \mathrm{~cm}$ de diâmetro, adicionando-se $50 \mathrm{ml}$ de gasolina, mediu-se a variação da perda de massa e concentração de alguns compostos orgânicos voláteis durante 27 horas de experimento, consecutivo ao primeiro experimento realizou-se o segundo que consistiu na utilização de uma proveta de volume graduado igual a $50 \mathrm{ml}$, de altura total da base a extremidade superior igual a $20,8 \mathrm{~cm}$ e $2,1 \mathrm{~cm}$ de diâmetro. Adicionou-se $60 \mathrm{ml}$ de gasolina, mediu-se a variação da perda de massa e concentração de alguns compostos orgânicos voláteis durante 96 horas de experimento; os quatro experimentos seguintes foram realizados em paralelo em provetas (similares) graduadas de volume igual a $500 \mathrm{ml}$, de altura total da base a extremidade superior igual a $38,5 \mathrm{~cm}$, e diâmetro igual a $4,6 \mathrm{~cm}$, adicionou-se $500 \mathrm{ml}$, $350 \mathrm{ml}, 225 \mathrm{ml}$ e $100 \mathrm{ml}$ de gasolina respectivamente, em seguida mediu-se a variação da perda de massa e concentração de alguns compostos orgânicos voláteis durante 98 dias, sendo que posteriormente foram realizadas leituras adicionais nos dias 193, 201, 208 e 216 a título de comparação como também para calibração dos modelos desenvolvidos. O ensaio pode ser melhor visualizado nas Figuras 4.5 e 4.6 . 


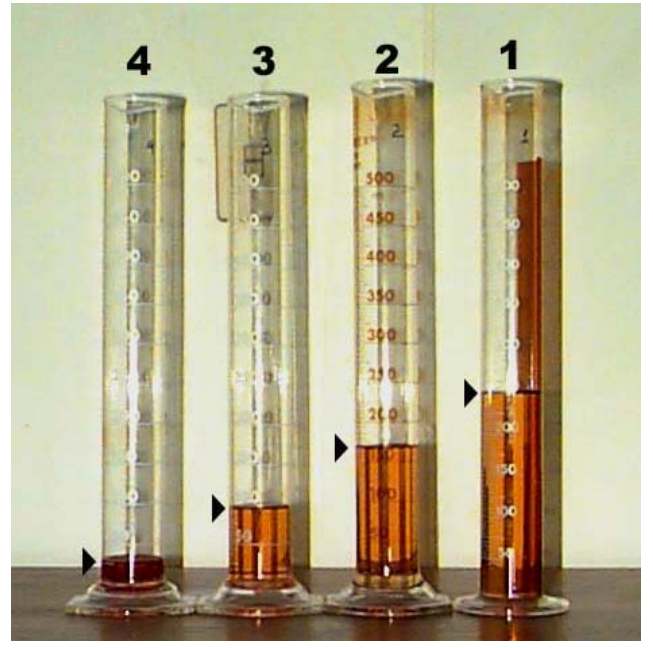

a)

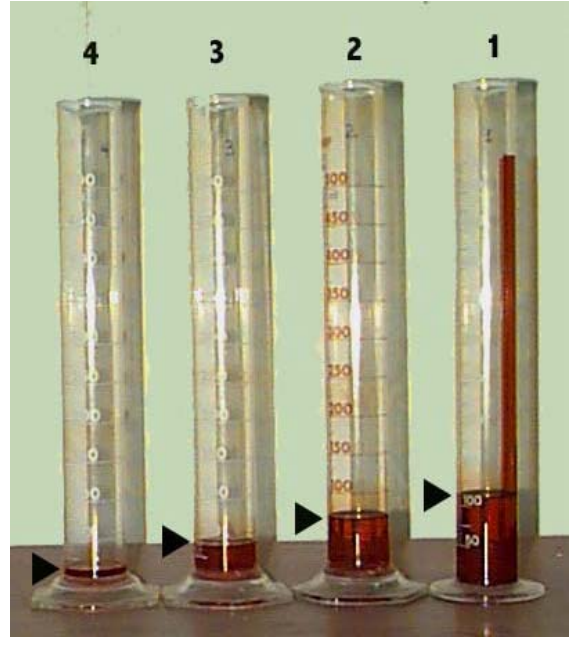

b)

Figura 4. 5- A ilustração mostra uma comparação entre as diversas fases de ensaio. a) mostra o desenvolvimento do ensaio com aproximadamente 95 dias; b) mostra o desenvolvimento do ensaio com aproximadamente 220 dias.

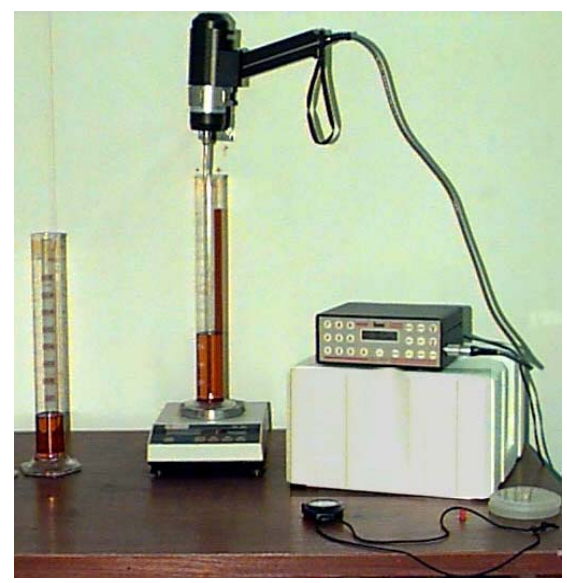

Figura 4. 6- Esta ilustração mostra como procederam-se as leituras em ensaios utilizando provetas (sempre com o bico da sonda do equipamento na interface entre a extremidade superior do recipiente e o ambiente externo). 


\subsubsection{Ensaios de Difusão de Contaminante em Solos Não Saturados}

Este item compreende os experimentos que visaram avaliar a difusão da gasolina através de solo não saturado, variando-se o modo de adição da gasolina, as quantidades de solo adicionadas, as formas dos recipientes e as dimensões dos experimentos. Nos experimentos iniciais mediu-se a taxa de volatilização através da perda de massa em balança analítica e a concentração dos compostos orgânicos voláteis através de detetor de fotoionização. Nos experimentos finais, os quais tiveram uma significativa mudança de escala, tornou-se impossível medir a taxa de volatilização com balança analítica.

Este item pode ser subdividido em outros dois subitens, que foram assim descritos: experimentos de difusão de gasolina em solo não saturado em provetas e experimentos de difusão de gasolina em solo não saturado em escala maior.

\subsubsection{Ensaios de Difusão de Gasolina em Solo Não Saturado em Provetas}

Nesta etapa foram realizados ensaios em pequena escala que utilizaram provetas com volume graduado de $250 \mathrm{ml}$ às quais, a princípio, foram adicionadas quantidades de solo equivalentes a $50 \mathrm{ml}$ em volume de solo, sendo o mesmo compactado por agitação manual. Em seguida adicionou-se $26 \mathrm{ml}$ de gasolina (volume suficiente para saturação de $50 \mathrm{ml}$ de solo) através de gotejamento com pipeta graduada. Utilizou-se neste ensaio cinco provetas. $\mathrm{Na}$ primeira proveta não se adicionou camada de recobrimento, na segunda adicionou-se o equivalente a $10 \mathrm{ml}$ em volume de solo de recobrimento, na terceira proveta adicionou-se o equivalente a $20 \mathrm{ml}$ em volume de solo de recobrimento, na quarta proveta adicionou-se o equivalente a $30 \mathrm{ml}$ em volume de solo de recobrimento e na quinta e última proveta adicionou-se o equivalente a $40 \mathrm{ml}$ em volume de solo de recobrimento. Neste ensaio as provetas possuíam ligeiras diferenças nas suas características geométricas com: alturas totais das provetas: $35 \mathrm{~cm}, 35 \mathrm{~cm}, 34,8 \mathrm{~cm}, 33 \mathrm{~cm}, 29,5 \mathrm{~cm}$ respectivamente nas provetas $1,2,3$, 4, e 5; diâmetro que variou de: $34,8 \mathrm{~mm}, 38,7 \mathrm{~mm}, 34,8 \mathrm{~mm}, 35,24 \mathrm{~mm}$ e $38,15 \mathrm{~mm}$ respectivamente (medidos com paquímetro). A principal diferenciação entre as mesmas foi que as provetas 1, 2 e 3 apresentaram na sua extremidade superior um suporte para tampa que gera um estreitamento de seção, influindo assim no fluxo de massa. Mediu-se durante 15 dias a perda de massa através de balança analítica e uma parcela da concentração dos compostos orgânicos voláteis através de fotoionizador, (ver Figura 4.7). 


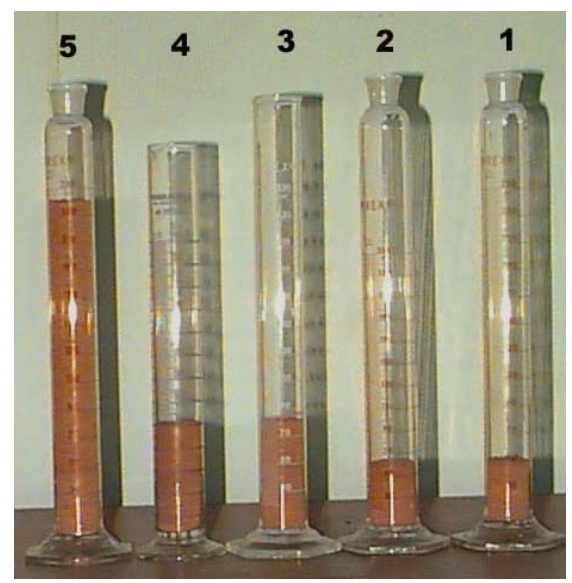

Figura 4. 7- A ilustração mostra como procedeu-se o ensaio de difusão em solo utilizando cinco provetas (há uma pequena diferença na ordem das provetas, sendo que a proveta 5 dessa foto deveria estar na posição 3, isso ocorreu devido a curta duração do experimento, onde não foi possível a retirada de fotografias).

Dando seqüência aos ensaios em pequena escala, devido às dificuldades encontradas no ensaio com cinco provetas, selecionou-se as provetas 1 e 3 do ensaio anterior (ou as provetas 1 e 5 da figura 4.7), pois apresentavam características semelhantes e iniciou-se outro ensaio com apenas duas provetas. Inicialmente procedeu-se da mesma forma que o ensaio anterior: a princípio adicionou-se uma camada de solo eqüivalente a $50 \mathrm{ml}$ em volume em cada proveta e em seguida adicionou-se $26 \mathrm{ml}$ de gasolina (eqüivalente à saturação). Posteriormente adicionou-se à segunda proveta (que corresponde à terceira do ensaio anterior) uma camada de recobrimento de $200 \mathrm{ml}$ em volume de solo. Mediu-se então a variação de massa e concentração de alguns compostos orgânicos voláteis durante 60 dias para as duas provetas. Finalmente foram realizadas leituras adicionais nos dias 154, 162, 169 e 177 a título de comparação e ainda para calibração dos modelos desenvolvidos. O ensaio pode ser visualizado na Figura 4.8. 


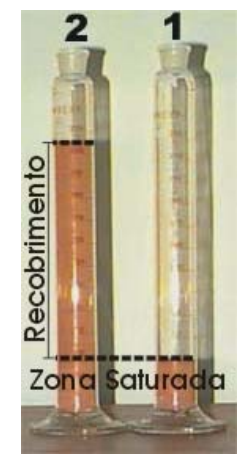

Figura 4. 8- Ilustra como procedeu-se o ensaio de difusão em solo utilizando duas provetas.

\subsubsection{Ensaios de Difusão de Gasolina em Solo Não Saturado em Escala Maior}

Prosseguindo-se nos ensaios de difusão de gasolina em solo não saturado, partiu-se para o segundo grupo de ensaios, os quais também foram ensaios em colunas, porém em dimensões maiores, utilizando-se duas colunas de acrílico de $1,5 \mathrm{~m}$ de altura e diâmetro 4" $(101,6 \mathrm{~mm})$. Na extremidade inferior de cada coluna conectou-se um cap também de acrílico. Sobre o cap colocou-se uma fina placa de acrílico perfurada e sobre ela uma malha " 200 " com a finalidade de reter o solo e permitir uma distribuição homogênea da gasolina no solo.

Para introdução da gasolina utilizou-se uma bureta graduada posicionada acima do nível do solo a ser saturado (porque a introdução de gasolina ocorre de baixo para cima). O fluxo de gasolina foi controlado por um registro. A primeira coluna possuía uma quantidade de solo equivalente a $20 \mathrm{~cm}$ em altura de coluna. A quantidade de $700 \mathrm{ml}$ de gasolina introduzida valeu à saturação completa da mesma. A segunda coluna possuía uma quantidade de solo equivalente $145 \mathrm{~cm}$ de coluna e com a adição dos mesmos $700 \mathrm{ml}$, visualmente formou-se uma mancha de gasolina na coluna até a altura $26 \mathrm{~cm}$ de altura de coluna no momento da injeção. Vale ressaltar que com este sistema de injeção de gasolina por gravidade necessitouse apenas de uma hora para que as duas colunas estivessem totalmente preparadas para o ensaio. $\mathrm{O}$ ensaio teve a finalidade de medir a concentração de alguns compostos orgânicos voláteis através de fotoionizador durante 76 dias para as duas colunas de acrílico. Posteriormente foram realizadas leituras adicionais nos dias 129, 137, 144, 152 e 167, (ver Figura 4.9). 

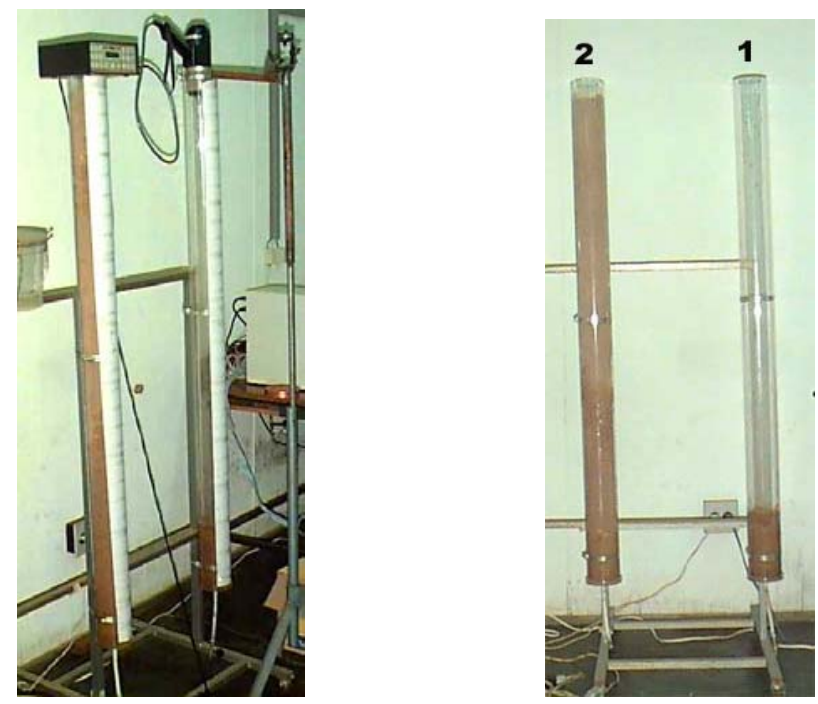

Figura 4. 9- Ilustração do ensaio utilizando colunas de acrílico. a) representa o experimento em andamento; b) representa uma visão geral do experimento.

Continuando os ensaios de difusão de gasolina em solo não saturado, realizou-se um último ensaio que consistiu na utilização de cinco recipientes cilíndricos, sendo que os mesmos possuíam as dimensões de $27,5 \mathrm{~cm}$ de diâmetro e $33 \mathrm{~cm}$ de altura (volume útil de aproximadamente 20 litros). Removeu-se a extremidade superior de cada recipiente e os mesmos foram então revestidos em seu interior com uma fina camada de borracha de silicone e solo para evitar a formação de caminhos preferenciais no fluxo. Após a secagem introduziu-se solo até a extremidade superior; em seguida o solo foi acomodado através de vibração manual, e então procedeu-se uma lenta adição de gasolina pela superfície superior de cada recipiente com o cuidado de não descaracterizar o meio poroso e evitar a formação de zonas de acumulação de ar no solo. As quantidades adicionadas foram as seguintes: ao primeiro recipiente introduziu-se cinco litros, ao segundo recipiente quatro litros, ao terceiro recipiente três litros, ao quarto recipiente dois litros e ao quinto recipiente um litro. $\mathrm{O}$ ensaio teve a finalidade de medir a concentração de alguns compostos orgânicos voláteis através de fotoionizador durante 51 dias em cada um dos cinco recipientes cilíndricos, sendo que foram realizadas leituras adicionais nos dias 104, 112, 119, 127 e 142, (ver Figura 4.10). 


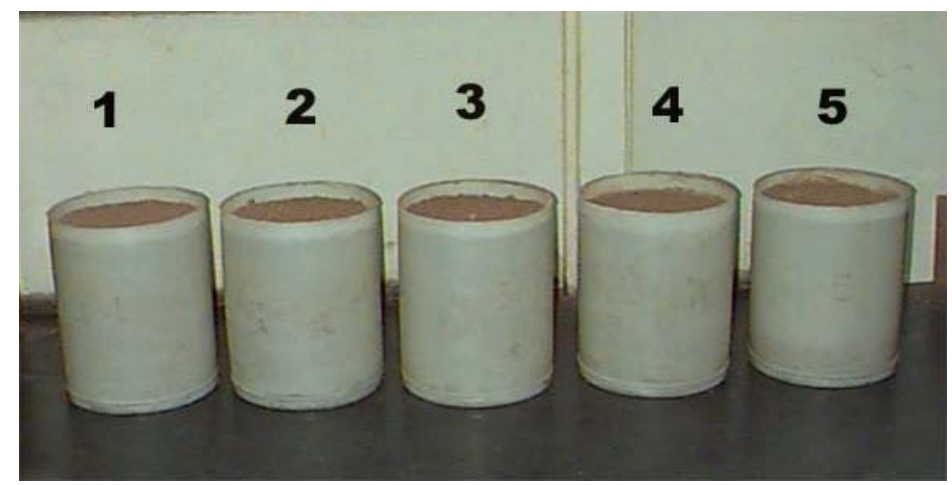

Figura 4. 10- A ilustra mostra como procedeu-se o ensaio com cinco recipientes cilíndricos (vale ressaltar que a princípio os recipientes foram totalmente preenchidos com solo e o solo acomodado por agitação manual, porém com a introdução de gasolina e após decorrem 120 dias de ensaio o solo compactou-se aproximadamente $3 \mathrm{~cm}$ ).

\subsection{Software APIDSS (Instituto Americano do Petróleo Sistema de Apoio à Decisão -} American Petroleum Institute Decision Support System)

O programa APIDSS foi desenvolvido pelo Instituto Americano do Petróleo (API) para auxiliar no sistema de tomada de decisões (DSS). O software estima exposições humanas e riscos provenientes de locais contaminados. É usado para identificar a necessidade de intervenção e avaliar o efeito de parâmetros e variáveis na estimativa do risco. Os arquivos de banco de dados para providenciar as propriedades físicas, químicas e toxicológicas dos contaminantes podem ser editados para alterar ou adicionar produtos químicos.

\subsubsection{DSS Versão 2.0}

O APIDSS versão 2.0 consiste de quatro módulos. O módulo de desenvolvimento do cenário de risco permite desenvolver um modelo conceitual para estimativa do risco. $\mathrm{O}$ módulo de concentração do ponto receptor permite a entrada das concentrações do ponto receptor ou estima concentrações pela modelagem de transporte e destino. Os modelos de 
transporte e destino incluídos no DSS são: modelos da zona não saturada SESOIL, VADSAT e JURY; modelos da zona saturada AT123D e VADSAT; modelos de emissão no ar (Farmer), JURY, VADSAT e Thibodeaux ligados a uma "caixa" ou modelo de dispersão Gaussiana. O módulo de cálculo do risco e quantidade química ingerida usa as concentrações do ponto receptor estimadas pelo modelo ou fornecidas de fora do modelo para avaliar quantidades químicas ingeridas por um receptor humano em diversas rotas diferentes de exposição. Além disso, este módulo usa as doses estimadas e toxidade específica do químico (fator de declividade ou valor potencial para carcinogênicos e a dose de referência para não carcinogênicos) para estimar risco de carcinoma e índice de perigo não carcinogênico. Finalmente, o módulo de apresentação de risco permite visualizar os resultados da análise em formatos de tabelas e gráficos.

O módulo de quantidade química ingerida e cálculo do risco pode ser implementado tanto nos modos de simulação determinístico ou de Monte Carlo. O último é usado para quantificar a incerteza na exposição e resultados de risco devido a incerteza nos parâmetros de entrada.

A Tabela 4.2 lista os modelos incluídos no APIDSS e as linhas de trajetória associadas a elas. A Figura 4.11 apresenta como os modelos trabalham juntos.

Tabela 4.2 - Modelos de Transporte e Destino nos tipos de Modelos do DSS. AMERICAN PETROLEUM INSTITUTE (1999).

\begin{tabular}{|c|c|c|c|}
\hline $\begin{array}{l}\text { Tipo do } \\
\text { Modelo }\end{array}$ & Nome do Modelo & Processos Simulados & $\begin{array}{c}\text { Concentrações do } \\
\text { Ponto Receptor } \\
\text { Calculadas }\end{array}$ \\
\hline Zona Vadosa & VADSAT & $\begin{array}{ll}\text { - } & \text { Lixiviamento à água subterrânea } \\
\text { - } & \text { Transporte de água subterrânea } \\
\text { - } & \text { Emissões de Voláteis }\end{array}$ & Água Subterrânea \\
\hline Zona Vadosa & SESOIL & $\begin{array}{l}\text { - } \quad \text { Lixiviamento à água subterrânea } \\
\text { - } \quad \text { Mistura na água subterrânea } \\
\text { - } \quad \text { Emissões de voláteis }\end{array}$ & $\begin{array}{c}\text { Água Subterrânea } \\
\text { (diretamente abaixo } \\
\text { da fonte) }\end{array}$ \\
\hline Zona Vadosa & JURY & $\begin{array}{l}\text { - Lixiviamento à água subterrânea } \\
\text { - Emissões de voláteis }\end{array}$ & Nenhum \\
\hline $\begin{array}{l}\text { Emissões Voláteis } \\
\text { somente }\end{array}$ & Farmers & - Emissões de voláteis & Nenhum \\
\hline $\begin{array}{l}\text { Emissões Voláteis } \\
\text { somente }\end{array}$ & Thibodeaux-Hwang & - Emissões de voláteis & Nenhum \\
\hline
\end{tabular}




\begin{tabular}{|c|c|c|c|}
\hline $\begin{array}{l}\text { Tipo do } \\
\text { Modelo }\end{array}$ & Nome do Modelo & Processos Simulados & $\begin{array}{c}\text { Concentrações do } \\
\text { Ponto Receptor } \\
\text { Calculadas }\end{array}$ \\
\hline $\begin{array}{l}\text { Emissões de } \\
\text { partículas (poeira) }\end{array}$ & Cowherd & - $\quad$ Emissões de partículas & Nenhum \\
\hline Zona Saturada & VADSAT & - Transporte de água subterrânea & Água Subterrânea \\
\hline Zona Saturada & AT123D & - Transporte de água subterrânea & Água Subterrânea \\
\hline $\mathrm{Ar}$ & Box (caixa) & - Mistura em uma "caixa" & $\mathrm{Ar}$ \\
\hline $\mathrm{Ar}$ & Gaussian & - Transporte vento abaixo & $\mathrm{Ar}$ \\
\hline
\end{tabular}

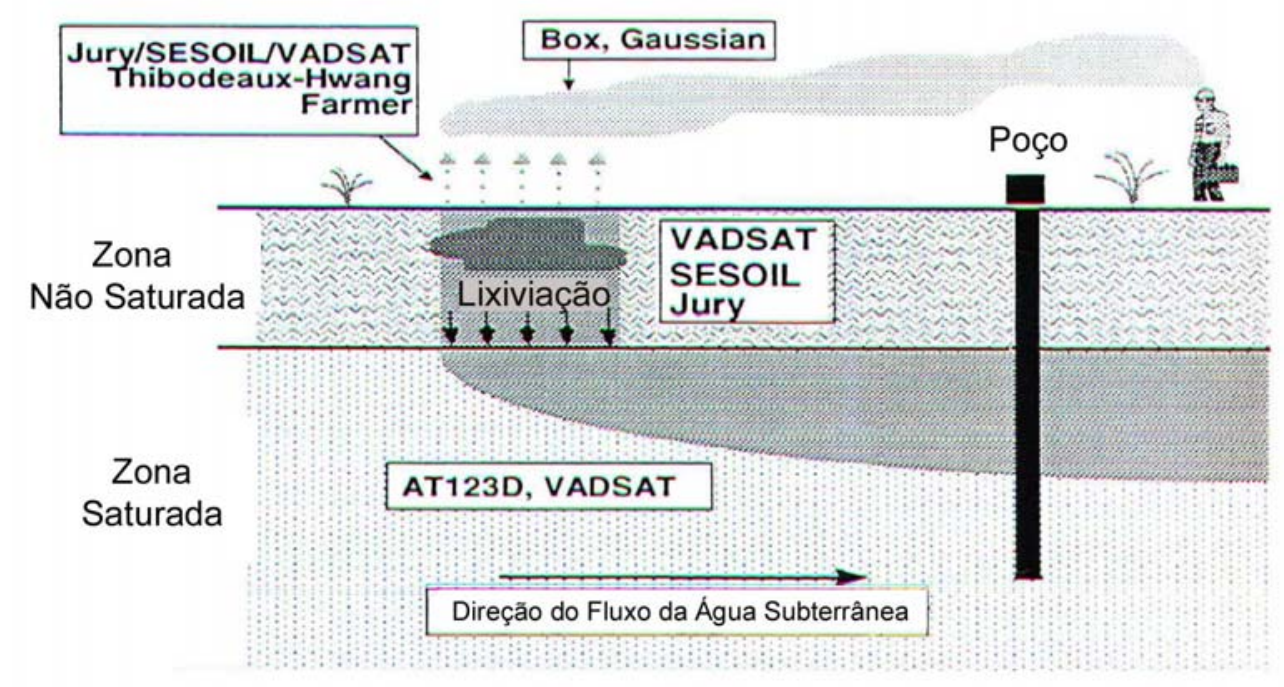

Figura 4. 11- Esquema dos modelos incluídos no DSS (AMERICAN PETROLEUM INSTITUTE, 1999).

Como com a versão 1.0, a versão 2.0 do DSS incorpora um número de modelos de transporte e destino para cálculo fácil de concentrações em pontos receptores. Exposição, riscos carcinogênicos, e efeitos não carcinogênicos (índices de risco) são calculados usando procedimentos coerentes com aqueles descritos no guia da EPA.

Novas características incorporadas dentro da versão 2.0 do DSS são projetadas para tornar o software fácil de usar, e aumentar as opções de modelagem disponíveis para o usuário. Essas novas características incluem: 
- Novo modelo de transporte e destino do contaminante da zona vadosa/zona saturada;

- Atualização do modelo da zona vadosa SESOIL (permite o modelamento de camadas de solos adicionais);

- Atualização do modelo de zona saturada AT123D (permite ao usuário o ajustamento de passos de tempo);

- Melhora o sistema de coordenadas do AT123D da zona da fonte;

- Novo módulo permite importação de dados de séries de concentração de módulos de outros processamentos externos.

A expansão da base de dados proporciona dados de propriedades físico/químicas e toxicológicas para 86 hidrocarbonetos de petróleo, aditivos de produtos de petróleo, hidrocarbonetos cloratados, e metais.

A nova interface permite uma fácil modificação pelo usuário da base de dados de propriedades físico/químicas e toxicológicas.

A nova versão do AT123D desenvolvida pelo HSI Geo Trans (para a EPA) foi incorporada; essa versão corrigiu um problema com a opção de fonte pulso no código original do AT123D.

VADSAT é um modelo de Zona Vadosa (VADose zone) e zona saturada (SATured zone) e pode somente ser rodado em seu modo ligado. Esse modelo oferece diversas vantagens sobre SESOIL e JURY. Foi desenvolvido especificamente para tratar de misturas tais como hidrocarbonetos de petróleo totais (TPH - Total Petroleum Hidrocarbons). Essa é uma importante consideração se os contaminantes de interesse são parte de uma mistura porque eles irão solubilizar e transportar diferentemente caso fossem os únicos contaminantes presentes no solo.

\subsubsection{Propriedades de transporte e destino}

A Tabela 4.3 lista os valores de propriedades das substâncias pertencentes a ambos transporte e destino, como também a toxicidade (API, 1999). 
Tabela 4.3 - Base de dados das propriedades químicas (API, 1999).

\begin{tabular}{|c|c|c|c|c|}
\hline & Benzeno & Etilbenzeno & Tolueno & Xileno \\
\hline Peso Molecular [g/mol] & 78 & 106,2 & 92,1 & 106,2 \\
\hline Densidade $[\mathrm{g} / \mathrm{cc}]$ & 0,88 & 0,87 & 0,87 & 0,87 \\
\hline Pressão de Vapor [mmHg] & $9,5210^{+01}$ & $9,6010^{+00}$ & $2,8410^{+01}$ & $8,8410^{+00}$ \\
\hline Solubilidade & $1,7510^{+03}$ & $1,6910^{+02}$ & $5,2610^{+02}$ & $1,9810^{+02}$ \\
\hline $\begin{array}{l}\text { Constante da Lei de Henry } \\
{[(\mathrm{mg} / \mathrm{l}) /(\mathrm{mg} / \mathrm{l})]}\end{array}$ & $2,2810^{-01}$ & $3,2310^{-01}$ & $2,7210^{-01}$ & $2,9010^{-01}$ \\
\hline $\mathrm{K}_{\mathrm{OC}}[\mathrm{ml} / \mathrm{g}] \quad 5,8910^{+01} \quad 3,6310^{+02}$ & $1,8210^{+02}$ & $2,4010^{+02}$ & & \\
\hline Coeficiente de Difusão no ar $\left[\mathrm{cm}^{2} / \mathrm{s}\right]$ & $8,8010^{-02}$ & $7,5010^{-02}$ & $8,7010^{-02}$ & $7,2010^{-02}$ \\
\hline Coeficiente de Difusão na água $\left[\mathrm{cm}^{2} / \mathrm{s}\right]$ & $9,8010^{-06}$ & $7,8010^{-06}$ & $8,6010^{-06}$ & $8,5010^{-06}$ \\
\hline $\mathrm{K}_{\mathrm{d}}[-]$ & ND & ND & ND & ND \\
\hline
\end{tabular}

\subsubsection{Modelo JURY de Zona Não Saturada}

O modelo desenvolvido por JURY et al. (1990), é um modelo em nível de seleção, que estima o fluxo de volatilização no solo e o perfil da concentração variando com o tempo dentro da zona não saturada. Esse modelo é baseado na solução analítica para equação diferencial de balanço de massa e as condições iniciais e limites apresentadas abaixo:

$$
\left(\partial \mathrm{C}_{\mathrm{T}} / \partial \mathrm{t}\right)+\mu \mathrm{C}_{\mathrm{T}}=\mathrm{D}_{\mathrm{E}}\left(\partial^{2} \mathrm{C}_{\mathrm{T}} / \partial \mathrm{z}^{2}\right)-\mathrm{V}_{\mathrm{E}}\left(\partial \mathrm{C}_{\mathrm{T}} / \partial \mathrm{z}\right)
$$

Onde:

$\mathrm{C}_{\mathrm{T}}=$ Concentração total no solo, definida pela eq. 4.5 (mg de contaminante $/ \mathrm{cm}^{3}$ de solo);

$\mathrm{t}=$ Tempo (dia);

$\mu=$ Constante de proporção de decaimento de primeira ordem (1/dia);

$\mathrm{D}_{\mathrm{E}}=$ Coeficiente de difusão estimado pela eq. $4.8\left(\mathrm{~cm}^{2} / \mathrm{d}\right)$;

$\mathrm{z}=$ Profundidade medida da superfície do solo $(\mathrm{cm}) ;$

$\mathrm{V}_{\mathrm{E}}=$ Velocidade efetiva do contaminante estimado pela eq. $4.9(\mathrm{~cm} / \mathrm{d})$.

A condição inicial é:

$$
\mathrm{C}_{\mathrm{T}}(0<\mathrm{z}<\mathrm{L}, \mathrm{t}=0)=\mathrm{C}_{0}
$$




$$
\mathrm{C}_{\mathrm{T}}(\mathrm{z} \geq \mathrm{L}, \mathrm{t}=0)=0
$$

Onde:

$\mathrm{C}_{0}=$ Concentração total inicial de contaminante no solo $\left(\mathrm{mg} / \mathrm{cm}^{3}\right)$;

$\mathrm{L}=$ Profundidade inicial da concentração de contaminante $(\mathrm{cm})$.

As eqs. 4.2-a e 4.2-b informam que inicialmente a contaminação é uniformemente incorporada a profundidade $\mathrm{L}$.

$$
-\mathrm{D}_{\mathrm{E}}\left(\partial \mathrm{C}_{\mathrm{T}} / \partial \mathrm{z}\right)+\mathrm{V}_{\mathrm{E}} \cdot \mathrm{C}_{\mathrm{T}}=-\mathrm{H}_{\mathrm{E}} \cdot \mathrm{C}_{\mathrm{T}} \quad \text { em } \mathrm{z}=0
$$

Onde:

$\mathrm{H}_{\mathrm{E}}=$ Coeficiente de transferência de massa variável estimado pela eq. $4.10(\mathrm{~cm} / \mathrm{dia})$.

A eq. 4.3 simula a volatilização de vapores químicos para a atmosfera através de uma camada de uma camada de ar estagnado sobre a qual a concentração química no ar é assumida como zero.

Sendo a condição limite:

$$
\mathrm{C}_{\mathrm{T}}(\mathrm{z}=\infty \text {, todo } \mathrm{t})=0
$$

$\mathrm{Na}$ eq. 4.1, a concentração total no solo assume-se como distribuída ao longo das fases sólida, aquosa e vapor e é estimada usando:

$$
\mathrm{C}_{\mathrm{T}}=\rho_{\mathrm{b}} \cdot \mathrm{C}_{\mathrm{S}}+\theta_{\mathrm{w}} \cdot \mathrm{C}_{\mathrm{w}}+\theta_{\mathrm{a}} \cdot \mathrm{C}_{\mathrm{v}}
$$

Onde:

$\rho_{\mathrm{b}}=$ Densidade do volume de solo ( $\mathrm{g}$ de solo $\mathrm{seco} / \mathrm{cm}^{3}$ de solo úmido);

$\mathrm{C}_{\mathrm{S}}=$ Concentração da fase adsorvida ( $\mathrm{g}$ de contaminante/g de solo seco);

$\theta_{\mathrm{w}}=$ Conteúdo volumétrico de água $\left(\mathrm{cm}^{3}\right.$ de água $/ \mathrm{cm}^{3}$ de solo úmido);

$\mathrm{C}_{\mathrm{w}}=$ Concentração da fase dissolvida ( $\mathrm{g}$ de contaminante $/ \mathrm{cm}^{3}$ de solução);

$\theta_{\mathrm{a}}=$ Conteúdo volumétrico de $\operatorname{ar}\left(\mathrm{cm}^{3}\right.$ ar no solo $/ \mathrm{cm}^{3}$ de solo úmido);

$\mathrm{C}_{\mathrm{v}}=$ Concentração da fase de vapor ( $\mathrm{g}$ de contaminante $/ \mathrm{cm}^{3}$ gás no solo).

As três concentrações nas fases iniciais $\mathrm{C}_{\mathrm{s}}$ (solo), $\mathrm{C}_{1}$ (liquida) e $\mathrm{C}_{\mathrm{g}}$ (gasosa) são relacionadas pelos coeficientes de partição seguintes: 


$$
\begin{aligned}
& \mathrm{C}_{\mathrm{S}}=\mathrm{K}_{\mathrm{d}} \cdot \mathrm{C}_{\mathrm{w}} \\
& \mathrm{C}_{\mathrm{v}}=\mathrm{H} \cdot \mathrm{C}_{\mathrm{w}}
\end{aligned}
$$

Onde:

$\mathrm{K}_{\mathrm{d}}=$ Coeficiente de partição solo-água específico para cada substância $[(\mathrm{mg} / \mathrm{g}$ de solo seco) $/\left(\mathrm{g} / \mathrm{cm}^{3}\right.$ de solução $\left.)\right]\left(K_{d}=K_{o c} \cdot f_{o c}\right)$;

$\mathrm{K}_{\mathrm{oc}}=$ Coeficiente de partição do carbono orgânico $\left(\mathrm{cm}^{3} / \mathrm{g}\right)$;

$\mathrm{H}=$ Constante da Lei de Henry [(mg/L de vapor) / (mg/L de solução)].

O coeficiente de difusão efetivo presente na eq. 4.1 é estimado por:

$$
D_{\mathrm{E}}=\left[\left(\theta_{\mathrm{a}}{ }^{3,33} \mathrm{D}_{\mathrm{g}}{ }^{\mathrm{a}} \mathrm{H}+\theta_{\mathrm{w}}{ }^{3,33} \mathrm{D}_{\mathrm{l}}{ }^{\mathrm{W}}\right) / \theta^{2}\right] /\left(\rho_{\mathrm{b}} \mathrm{f}_{\mathrm{oc}} \mathrm{K}_{\mathrm{oc}}+\theta_{\mathrm{w}}+\theta_{\mathrm{a}} \mathrm{H}\right)
$$

Onde:

$\mathrm{D}_{\mathrm{g}}{ }^{\mathrm{a}}=$ Coeficiente de difusão gasosa específico para cada substância no $\operatorname{ar}\left(\mathrm{cm}^{2} / \mathrm{dia}\right)$;

$\mathrm{D}_{1}{ }^{\mathrm{W}}=$ Coeficiente de difusão líquida específico para cada substância na água $\left(\mathrm{cm}^{2} / \mathrm{dia}\right)$;

$f_{o c}=$ Fração de carbono orgânico no solo (mg de carbono orgânico/mg de solo).

Todas as outras variáveis foram definidas previamente. A velocidade efetiva do contaminante no solo referente a eq. 4.1 é estimada por:

$$
\mathrm{V}_{\mathrm{E}}=\mathrm{J}_{\mathrm{w}} /\left(\rho_{\mathrm{b}} \mathrm{f}_{\mathrm{oc}} \mathrm{K}_{\mathrm{oc}}+\theta_{\mathrm{w}}+\theta_{\mathrm{a}} \mathrm{H}\right)
$$

Onde:

$\mathrm{J}_{\mathrm{w}}=$ Fluxo volumétrico solo-água $(\mathrm{cm} / \mathrm{dia})$.

Finalmente, a variável $\mathrm{H}_{\mathrm{E}}$ é definida como:

$$
\begin{gathered}
\mathrm{H}_{\mathrm{E}}=(\mathrm{h} \cdot \mathrm{H}) /\left(\rho_{\mathrm{b}} \cdot \mathrm{K}_{\mathrm{D}}+\theta_{\mathrm{w}}+\theta_{\mathrm{a}} \cdot \mathrm{H}\right) \\
\mathrm{h}=\mathrm{D}_{\mathrm{g}}{ }^{\mathrm{a}} / \mathrm{d}
\end{gathered}
$$

onde:

$\mathrm{h}=$ Coeficiente de transferência da camada limite $(\mathrm{cm} /$ dia $)$;

$\mathrm{D}=$ Espessura de ar estagnado na camada limite $(\mathrm{cm})$. 
JURY et al. (1990), resolveram esse conjunto de equações e propuseram a seguinte equação para a concentração:

$C_{T}(z, t ; L)=1 / 2 C_{0} \exp (-\mu t) \quad\left\{\operatorname{erfc}\left[\left(z-L-V_{E} t\right) /\left(4 D_{E} t\right)^{1 / 2}\right]-\operatorname{erfc}\left[\left(z-V_{E} t\right) /\left(4 D_{E} t\right)^{1 / 2}\right]\right.$ $+\left(1+V_{E} / H_{E}\right) \exp \left(V_{E} z / D_{E}\right)\left[\operatorname{erfc}\left[\left(z+L+V_{E} t\right) /\left(4 D_{E} t\right)^{1 / 2}\right]-\operatorname{erfc}\left[\left(z+V_{E} t\right)\right]+(2+\right.$ $\left.V_{E} / H_{E}\right) \exp \left\{\left[H_{E}\left(H_{E}+V_{E}\right) t+\left(H_{E}+V_{E}\right) z\right] / D_{E}\right\}\left\{\operatorname{erfc}\left[z+\left(2 H_{E}+V_{E}\right) t /\left(4 D_{E} t\right)^{1 / 2}\right]-\right.$ $\left.\exp \left(H_{E} L / D_{E}\right) \operatorname{erfc}\left[z+L+\left(2 H_{E}+V_{E}\right) t /\left(4 D_{E} t\right)^{1 / 2}\right]\right\}$

JURY et al. (1990) também apresentaram o fluxo de volatilização cumulativo $\mathrm{V}_{\mathrm{C}}(\mathrm{t})$, massa volatilizada por unidade de área, da superfície de solo entre o início da volatilização e um tempo qualquer " $t$ " como:

$\mathrm{V}_{\mathrm{C}}(\mathrm{t})=-\mathrm{C}_{0} / 2\left\{\mathrm{~V}_{\mathrm{E}} / \mu[1-\exp (-\mu \mathrm{t})]\left(\mathrm{S}_{1}-\mathrm{S}_{2}\right)-\left[\left(\mathrm{V}_{\mathrm{E}}-2 \mathrm{H}_{\mathrm{E}}\right) /(\mu-\xi)\right]\left[1-\exp (-\mu \mathrm{t})\left[\left(\mathrm{S}_{3}-\right.\right.\right.\right.$ $\left.\left.\mathrm{S}_{4}\right)\right]+\exp \left[-\mathrm{P} / 2+\beta\left(\mathrm{L} \mathrm{D}_{\mathrm{E}}^{1 / 2}\right)\right]\left[\left(\mathrm{V}_{\mathrm{E}}+2 \mathrm{H}_{\mathrm{E}}\right) / 2(\mu-\xi)-\mathrm{V}_{\mathrm{E}} / 2 \mu-\left(\mathrm{V}_{\mathrm{E}}+2 \mathrm{H}_{\mathrm{E}}\right)^{2} / 4(\mu-\xi) \beta\right.$ $\left.D_{\mathrm{E}}^{1 / 2}+\mathrm{V}_{\mathrm{E}}^{2} / 4 \mu \beta \mathrm{D}_{\mathrm{E}}^{1 / 2}\right] \mathrm{S}_{5}+\exp \left[-\mathrm{P} / 2+\beta\left(\mathrm{L} \mathrm{D}_{\mathrm{E}}^{1 / 2}\right)\right]\left[\left(\mathrm{V}_{\mathrm{E}}+2 \mathrm{H}_{\mathrm{E}}\right) / 2(\mu-\xi)-\mathrm{V}_{\mathrm{E}} / 2 \mu-\left(\mathrm{V}_{\mathrm{E}}\right.\right.$ $\left.\left.+2 \mathrm{H}_{\mathrm{E}}\right)^{2} / 4(\mu-\xi) \beta \mathrm{D}_{\mathrm{E}}^{1 / 2}+\mathrm{V}_{\mathrm{E}}^{2} / 4 \mu \beta \mathrm{D}_{\mathrm{E}}^{1 / 2}\right] \mathrm{S}_{6}+\left[1 / 2 \beta \mathrm{D}_{\mathrm{E}}^{1 / 2}\right]\left[\left(\mathrm{V}_{\mathrm{E}}+2 \mathrm{H}_{\mathrm{E}}\right)^{2} /(\mu-\xi)-\mathrm{V}_{\mathrm{E}}^{2} /\right.$ $\mu] \mathrm{S}_{7}$

Onde:

$\mathrm{P}=\mathrm{V}_{\mathrm{E}} \mathrm{L} / \mathrm{D}_{\mathrm{E}}$;

$\xi=\left(H_{E}+V_{E}\right) H_{E} / V_{E}$;

$\beta=\left(V_{E}^{2} / 4 D_{E}+\mu\right)^{1 / 2}$;

$\mathrm{S}_{1}=\operatorname{erfc}\left[\mathrm{V}_{\mathrm{E}} \mathrm{t} /\left(4 \mathrm{D}_{\mathrm{E}} \mathrm{t}\right)^{1 / 2}\right]$;

$\mathrm{S}_{2}=\operatorname{erfc}\left[\left(\mathrm{L}+\mathrm{V}_{\mathrm{E}} \mathrm{t}\right) /\left(4 \mathrm{D}_{\mathrm{E}} \mathrm{t}\right)^{1 / 2}\right]$;

$\mathrm{S}_{3}=\exp (\xi \mathrm{t}) \operatorname{erfc}\left[\left(\mathrm{V}_{\mathrm{E}}+2 \mathrm{H}_{\mathrm{E}}\right) \mathrm{t} /\left(4 \mathrm{D}_{\mathrm{E}} \mathrm{t}\right)^{1 / 2}\right]$;

$\mathrm{S}_{4}=\exp \left(\xi \mathrm{t}+\mathrm{H}_{\mathrm{E}} \mathrm{L} / \mathrm{D}_{\mathrm{E}}\right) \operatorname{erfc}\left[\mathrm{L}+\left(\mathrm{V}_{\mathrm{E}}+2 \mathrm{H}_{\mathrm{E}}\right) \mathrm{t} /\left(4 \mathrm{D}_{\mathrm{E}} \mathrm{t}\right)^{1 / 2}\right]$;

$\mathrm{S}_{5}=\operatorname{erfc}\left[\mathrm{L} /\left(4 \mathrm{D}_{\mathrm{E}} \mathrm{t}\right)^{1 / 2}-\beta(\mathrm{t})^{1 / 2}\right]$;

$\mathrm{S}_{6}=\operatorname{erfc}\left[\mathrm{L} /\left(4 \mathrm{D}_{\mathrm{E}} \mathrm{t}\right)^{1 / 2}+\beta(\mathrm{t})^{1 / 2}\right]$;

$\mathrm{S}_{7}=\operatorname{erfc}\left[\beta(\mathrm{t})^{1 / 2}\right]$.

As eqs. 4.12 e 4.13 apresentam o perfil de concentração variando com o tempo e o fluxo de volatilização acumulada para o caso quando o contaminante é inicialmente uniformemente incorporado sobre uma profundidade L. 
As concentrações estimadas na superfície de água são usadas para computar o fluxo de contaminante na superfície de água usando:

$$
\mathrm{M}_{\mathrm{WT}}=\mathrm{V} \mathrm{C}_{\mathrm{W}} \mathrm{A}+\mathrm{D}(\Delta \mathrm{C} / \Delta \mathrm{z}) \mathrm{A}
$$

Onde:

$\mathrm{M}_{\mathrm{WT}}=$ massa anual preenchendo a superfície de água ( $\left.\mathrm{mg} / \mathrm{ano}\right)$;

$\mathrm{V}=$ proporção de infiltração (m/ano);

$\mathrm{A}=$ área da fonte $\left(\mathrm{cm}^{2}\right)$;

$\mathrm{C}_{\mathrm{w}}=$ concentração da fase dissolvida na superfície de água $\left(\mathrm{mg} / \mathrm{cm}^{3}\right)$;

$\mathrm{D}=$ coeficiente de dispersão hidrodinâmica ( $\left.\mathrm{cm}^{2} / \mathrm{ano}\right)$;

$(\Delta \mathrm{C} / \Delta \mathrm{z})=$ gradiente de concentração na superfície de água $\left(\mathrm{mg} / \mathrm{cm}^{3} / \mathrm{cm}\right)$.

O modelo JURY assume que a substância química está em equilíbrio entre as fases: adsorvida, dissolvida e vapor. O residual não é tratado nas equações de JURY. O modelo contido no DSS checa a condição seguinte para verificar se os níveis residuais estão presentes. Caso exceda a solubilidade inserida para a substância química, o modelo enviará uma mensagem.

Resumindo é necessário o fornecimento de parâmetros químicos como: concentração total no solo, coeficiente de difusão no ar, solubilidade, etc. Em seguida introduz-se parâmetro da coluna de solo como: porosidade efetiva, densidade volumétrica do solo, espessura da fonte, etc. Finalmente estipula-se um tempo de simulação em anos. O programa fornece os valores de fluxo de massa para cada mês do intervalo de tempo escolhido.

\subsection{Análise de Erro: Critério de Chauvenet}

Para todos os resultados obtidos verificou-se a possibilidade de rejeição pelo critério de Chauvenet que afirma o seguinte: uma observação é rejeitada se o desvio em relação à média da amostra for maior que aquela correspondente a uma probabilidade de ocorrer igual a $1 / 2$ n, onde $n$ é o tamanho da amostra.

Para facilitar a aplicação existem tabelas que fornecem o máximo desvio admissível em função do tamanho da amostra. Por exemplo para uma amostra com até 25 observações $\mathrm{d}_{\text {máx. }} / \sigma$ (desvio em relação a média) não deve ser superior a 2,33.

Este critério é muito criticado pela facilidade de rejeição de pontos, porém todos os resultados obtidos nesta pesquisa se mostram válidos pelo referido método. 


\section{RESULTADOS E DISCUSSÃO}

\subsection{Introdução}

A presente seção analisa e discute os resultados obtidos de acordo com os procedimentos descritos na seção anterior. São abordados aqui os tópicos referentes a características da gasolina, caracterização do solo, ensaios de difusão do contaminante livre para a atmosfera e ensaios de difusão em solos não saturados.

Nas figuras que representam graficamente valores experimentais, os pontos foram unidos por linha, contudo estas linhas não representam a tendência do fenômeno e foram utilizadas para facilitar a visualização.

\subsection{Características da Gasolina}

Esta pesquisa não teve como finalidade caracterizar a composição da gasolina comum utilizada no Brasil, e sim utiliza-la como é encontrada nos postos de abastecimento. A única determinação efetuada foi a verificação da quantidade de etanol presente na mesma. Os resultados obtidos não apresentaram nenhuma ilegitimidade com relação à quantidade de etanol máxima permissível segundo BRASIL, LEIS, etc. (1999), sendo que foram realizados quatro testes em momentos diferentes para medir o referido parâmetro, seguindo-se as recomendações descritas no item 4.2.1, e os valores obtidos foram: dia 15/06/1999 composição de etanol de 21,60 \%, dia 24/08/1999 composição de etanol de 21,80\%, dia 16/11/1999 composição de etanol de 21,70 \% e dia 04/12/1999 composição de etanol de $22,00 \%$. Baseado nos valores obtidos conclui-se que a quantidade de etanol média adicionada à gasolina em estudo foi ligeiramente inferior a $22,00 \%$ e com isso inferior a quantidade máxima permissível que é de $24,00 \%$. 


\subsection{Caracterização do Solo}

Na Tabela 5.1 são apresentados os valores de umidade natural, massa específica dos sólidos, análise granulométrica e fração de carbono orgânico do solo residual da região denominada Santa Felícia, localizada na cidade de São Carlos, para amostras deformadas. O valor de massa específica dos sólidos e composição representam a média dos valores calculados a partir da realização de três ensaios.

Tabela 5.1 - Valores de umidade $(w)$, porosidade $(\eta)$, massa específica dos sólidos $\left(\rho_{s}\right)$, composição e fração de carbono orgânico $\left(f_{o c}\right)$ obtidos em ensaios realizados em amostras deformadas.

\begin{tabular}{cc}
\hline Parâmetro & Valor Obtido \\
\hline $\mathrm{w}(\%)$ & 14,0 \\
$\eta(\%)$ & 51,0 \\
$\rho_{\mathrm{s}}\left(\mathrm{g} / \mathrm{cm}^{3}\right)$ & 2,692 \\
Areia (\%) & 60,0 \\
Silte (\%) & 10,0 \\
Argila (\%) & 30,0 \\
$\mathrm{~F}_{\mathrm{oc}}(\%)$ & 6,79 \\
\hline
\end{tabular}

Como pode ser observado o solo foi caracterizado quanto a composição como uma areia argilosa. Quanto ao teor de carbono orgânico $f_{o c}$ (matéria orgânica presente) o valor pode ser considerado alto comparado com os valores obtidos por FERREIRA (2000) que foi de $0,6 \%$ e por SHONNARD \& BELL (1993) que foi de $0,5 \%$.

\subsection{Ensaios de Difusão do Contaminante Livre para a Atmosfera}

\subsubsection{Ensaios Preliminares}

Os resultados dos ensaios preliminares podem ser visualizados na Tabela 5.2 e nas Figura 5.1 e 5.2, os quais mostram os valores de massa de gasolina (gramas) e o tempo 
(segundos) transcorrido para cada ensaio. Vale ressaltar que estes ensaios foram realizados a princípio com o intuito de conhecer como se processava a difusão da gasolina livre para a atmosfera. Com estes ensaios preliminares concluiu-se que a área de contato gasolina-ar e coluna de ar livre em cada proveta são diretamente proporcional e inversamente proporcional respectivamente ao processo de difusão da gasolina e seria necessário um intervalo maior de tempo de ensaio para se compreender melhor o processo de difusão, bem como verificar a funcionalidade de um detetor de fotoionização. 
Tabela 5.2 - Valores de massa medidos em função do tempo para os diversos ensaios preliminares.

\begin{tabular}{|c|c|c|c|c|c|c|c|c|c|c|c|c|c|c|c|}
\hline \multicolumn{2}{|c|}{$\begin{array}{c}\text { Ensaio } 01 \\
\text { (Placa de Petri) }\end{array}$} & \multicolumn{2}{|c|}{$\begin{array}{c}\text { Ensaio } 02 \\
\text { (Proveta } 100 \mathrm{ml} \mathrm{e} \\
\text { adição de } 50 \mathrm{ml} \text { ) }\end{array}$} & \multicolumn{2}{|c|}{$\begin{array}{c}\text { Ensaio } 03 \\
\text { (Proveta } 250 \mathrm{ml} \mathrm{e} \\
\text { adição de } 300 \mathrm{ml} \text { ) }\end{array}$} & \multicolumn{2}{|c|}{$\begin{array}{c}\text { Ensaio } 04 \\
\text { (Proveta } 250 \mathrm{ml} \mathrm{e} \\
\text { adição de } 250 \mathrm{ml} \text { ) }\end{array}$} & \multicolumn{2}{|c|}{$\begin{array}{c}\text { Ensaio 05 } \\
\text { (Proveta } 250 \mathrm{ml} \mathrm{e} \\
\text { adição de } 230 \mathrm{ml} \text { ) }\end{array}$} & \multicolumn{2}{|c|}{$\begin{array}{c}\text { Ensaio } 06 \\
\text { (Proveta } 250 \mathrm{ml} \mathrm{e} \\
\text { adição de } 210 \mathrm{ml} \text { ) }\end{array}$} & \multicolumn{2}{|c|}{$\begin{array}{c}\text { Ensaio } 07 \\
\text { (Proveta } 250 \mathrm{ml} \mathrm{e} \\
\text { adição de } 190 \mathrm{ml} \text { ) }\end{array}$} & \multicolumn{2}{|c|}{$\begin{array}{c}\text { Ensaio } 08 \\
\text { (Proveta } 250 \mathrm{ml} \mathrm{e} \\
\text { adição de } 210 \mathrm{ml} \text { ) }\end{array}$} \\
\hline $\begin{array}{c}\text { Tempo } \\
\text { (segundos) }\end{array}$ & $\begin{array}{c}\text { Massa } \\
\text { (gramas) }\end{array}$ & $\begin{array}{c}\text { Tempo } \\
\text { (segundos) }\end{array}$ & $\begin{array}{c}\text { Massa } \\
\text { (gramas) }\end{array}$ & $\begin{array}{c}\text { Tempo } \\
\text { (segundos) }\end{array}$ & $\begin{array}{c}\text { Massa } \\
\text { (gramas) }\end{array}$ & $\begin{array}{c}\text { Tempo } \\
\text { (segundos) }\end{array}$ & $\begin{array}{c}\text { Massa } \\
\text { (gramas) }\end{array}$ & $\begin{array}{c}\text { Tempo } \\
\text { (segundos) }\end{array}$ & $\begin{array}{c}\text { Massa } \\
\text { (gramas) }\end{array}$ & $\begin{array}{c}\text { Tempo } \\
\text { (segundos) }\end{array}$ & $\begin{array}{c}\text { Massa } \\
\text { (gramas) }\end{array}$ & $\begin{array}{c}\text { Tempo } \\
\text { (segundos) }\end{array}$ & $\begin{array}{c}\text { Massa } \\
\text { (gramas) }\end{array}$ & $\begin{array}{c}\text { Tempo } \\
\text { (segundos) }\end{array}$ & $\begin{array}{c}\text { Massa } \\
\text { (gramas) }\end{array}$ \\
\hline 0 & 37,10 & 0 & 38,21 & 0 & 225,34 & 0 & 189,52 & 0 & 174,41 & 0 & 157,77 & 0 & 141,56 & 0 & 126,28 \\
\hline 14 & 37,00 & 1565 & 38,14 & 162 & 225,28 & 61 & 189,51 & 333 & 174,35 & 1169 & 157,62 & 1169 & 141,42 & 1474 & 126,14 \\
\hline 80 & 36,70 & 4083 & 38,04 & 267 & 225,25 & 1220 & 189,34 & 1507 & 174,20 & 3154 & 157,40 & 3588 & 141,22 & 2992 & 126,02 \\
\hline 132 & 36,50 & 8168 & 37,87 & 1936 & 224,75 & 2390 & 189,18 & 3460 & 173,96 & 4331 & 157,27 & 4460 & 141,07 & 5685 & 125,81 \\
\hline 155 & 36,40 & 11248 & 37,76 & 3823 & 224,23 & 3433 & 189,04 & 5245 & 173,73 & 5590 & 157,13 & 5817 & 140,92 & 7981 & 125,62 \\
\hline 206 & 36,20 & 18417 & 37,52 & 6048 & 223,60 & 5114 & 188,81 & 7339 & 173,46 & 8223 & 156,83 & 7666 & 140,72 & 9356 & 125,51 \\
\hline 269 & 35,90 & 69921 & 36,09 & 8388 & 223,00 & 11998 & 187,86 & 9773 & 173,14 & 11012 & 156,52 & 14664 & 139,94 & 10990 & 125,38 \\
\hline 296 & 35,80 & 76301 & 35,92 & 9941 & 222,61 & 13263 & 187,68 & 10790 & 173,01 & 12084 & 156,40 & 16173 & 139,77 & 12351 & 125,27 \\
\hline 353 & 35,60 & 78152 & 35,87 & 12465 & 221,98 & 15099 & 187,42 & 14109 & 172,57 & 14010 & 156,18 & 19008 & 139,44 & 14214 & 125,11 \\
\hline 383 & 35,50 & 81963 & 35,76 & 13500 & 221,70 & 18386 & 186,94 & 17660 & 172,10 & 15507 & 156,01 & 21100 & 139,21 & 15249 & 125,03 \\
\hline 563 & 35,40 & 84677 & 35,68 & 14945 & 221,32 & 19634 & 186,72 & 18782 & 171,93 & 16701 & 155,87 & 22877 & 139,02 & 16818 & 124,90 \\
\hline 783 & 34,90 & - & - & 16090 & 220,99 & 28629 & 185,39 & 21339 & 171,54 & 17916 & 155,72 & 24479 & 138,84 & - & - \\
\hline 1349 & 32,60 & - & - & 17390 & 220,55 & 29599 & 185,27 & 22246 & 171,42 & 19184 & 155,55 & 25651 & 138,72 & - & - \\
\hline 1589 & 32,00 & - & - & 18582 & 220,17 & 30401 & 185,17 & - & - & 20830 & 155,30 & 27004 & 138,57 & - & - \\
\hline 1725 & 31,70 & - & - & 19359 & 219,92 & - & - & - & - & 21190 & 155,25 & 28046 & 138,45 & - & - \\
\hline 3103 & 29,20 & - & - & 20498 & 219,57 & - & - & - & - & 28249 & 154,47 & 29034 & 138,34 & - & - \\
\hline 5877 & 25,20 & - & - & 22600 & 218,88 & - & - & - & - & 29147 & 154,38 & 29899 & 138,26 & - & - \\
\hline 9787 & 20,40 & - & - & 29966 & 217,14 & - & - & - & - & 29945 & 154,30 & - & - & - & - \\
\hline 9908 & 20,30 & - & - & 30257 & 217,08 & - & - & - & - & - & - & - & - & - & - \\
\hline 24765 & 10,85 & - & - & 31389 & 216,83 & - & - & - & - & - & - & - & - & - & - \\
\hline
\end{tabular}




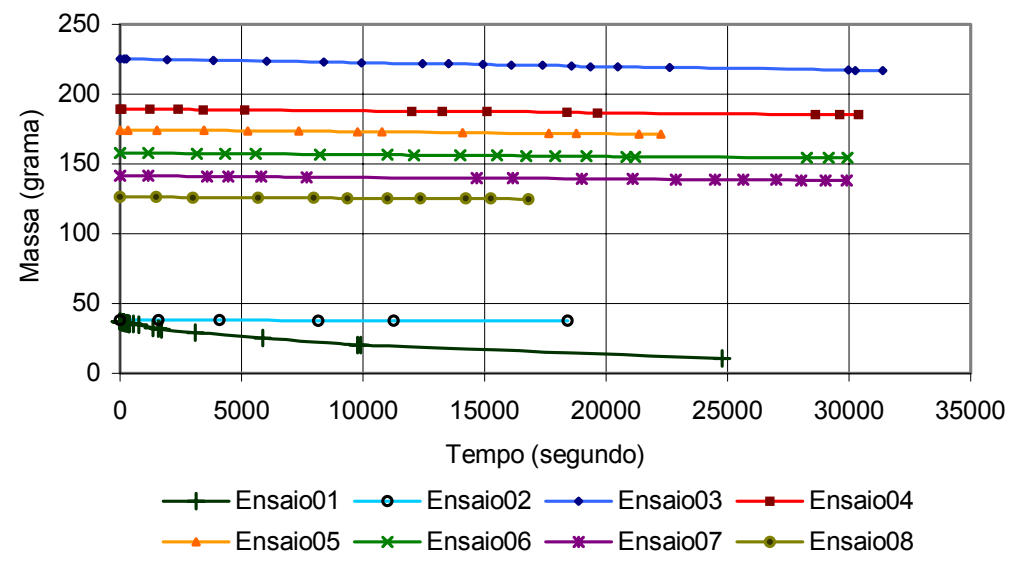

Figura 5. 5- A figura representa graficamente os valores de massa em função do tempo.

Vale ressaltar que a Figura 5.1 não representa todos os pontos da Tabela 5.2, devido aos intervalos de tempo não serem os mesmos, com isso adotou-se um intervalo de 35000 segundos com o limite máximo e utilizou-se somente os pontos que estavam dentro deste intervalo. Os ensaios apresentaram uma perda massa media por hora de 3,$82 ; 0,98 ; 0,52$; 0,$48 ; 0,42 ; 0,40$ e 0,30 (gramas por hora) respectivamente.

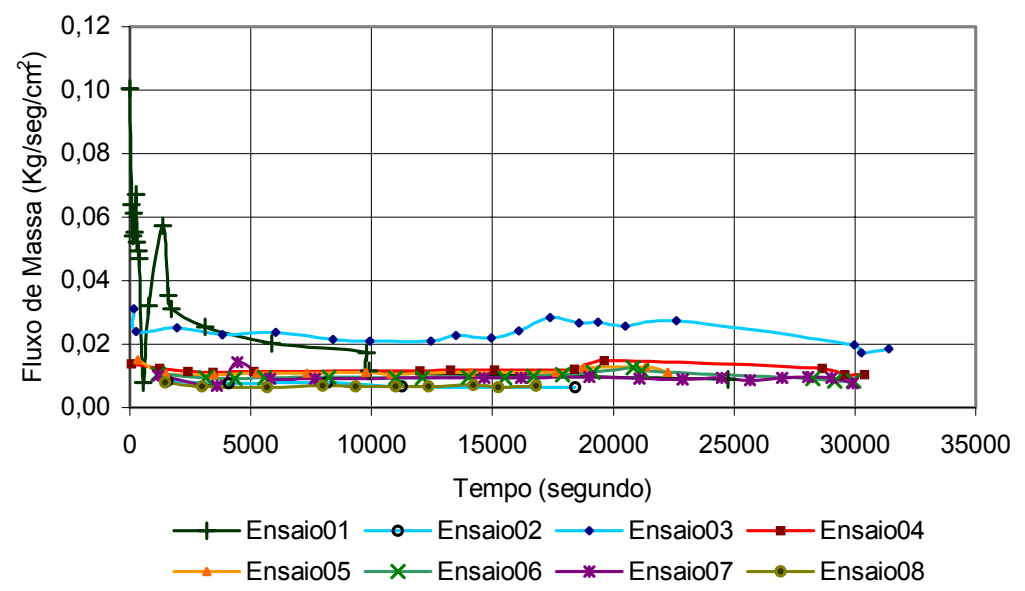

Figura 5. 6- Representação gráfica dos resultados de fluxo de massa em função do tempo.

Na Figura 5.2 verificou-se a influência da coluna de ar livre entre a superfície da gasolina e a extremidade superior dos recipientes. Percebe-se que quanto menor é a dimensão da referida coluna maior é o fluxo. 


\subsubsection{Ensaios Definitivos}

Nesta etapa foram realizados diversos ensaios com a finalidade de avaliar o processo de difusão da gasolina livre, bem com verificar a funcionalidade do detetor de fotoionização em avaliar o processo de difusão de gasolina livre. Os dois primeiros ensaios realizados nesta fase serviram para confirmar os resultados obtidos anteriormente, porém os mesmos utilizaram leituras feitas com detetor de fotoionização, tentando correlacioná-las às medidas de perda de massa realizadas com balança analítica. A Tabela 5.3 apresenta valores de massa (gramas) e de concentração (ppm ou mg/l) medidas em função do tempo (segundos), sendo que as Figuras 5.3 e 5.4 ilustram graficamente os pontos contidos na tabela anteriormente citada. Utilizou-se uma placa de Petri com volume aproximado de $130 \mathrm{ml}$ e adicionou-se $50 \mathrm{ml}$ de gasolina e uma proveta graduada de $50 \mathrm{ml}$ sendo adicionado um volume de $60 \mathrm{ml}$ de gasolina. Verifica-se que o experimento utilizando placa de Petri e proveta de $50 \mathrm{ml}$ apresentou uma perda de massa média por hora de 1,22 e 0,13 (gramas por hora) respectivamente. A Figura 5.5 representa a variação do fluxo com o tempo, confirmando o que foi verificado nos ensaios preliminares.

Tabela 5.3 - Valores de massa e concentração medidos ao longo do tempo.

\begin{tabular}{cccccc}
\hline \multicolumn{5}{c}{ Placa de Petri } & \multicolumn{3}{c}{ Proveta 50ml } \\
\hline $\begin{array}{c}\text { Tempo } \\
\text { (Segundos) }\end{array}$ & $\begin{array}{c}\text { Massa } \\
\text { (Gramas) }\end{array}$ & $\begin{array}{c}\text { Concentração } \\
(\mathrm{ppm})\end{array}$ & $\begin{array}{c}\text { Tempo } \\
\text { (Segundos) }\end{array}$ & $\begin{array}{c}\text { Massa } \\
\text { (Gramas) }\end{array}$ & $\begin{array}{c}\text { Concentração } \\
\text { (ppm) }\end{array}$ \\
\hline 0 & 37,93 & 332,4 & 0 & 47,73 & 198,7 \\
1197 & 34,37 & 350,4 & 1506 & 47,48 & 151,4 \\
12694 & 15,74 & 326,3 & 2737 & 47,29 & 180,4 \\
13818 & 14,20 & 310,8 & 4070 & 47,10 & 191,7 \\
15522 & 12,09 & 365,4 & 6081 & 46,82 & 204,3 \\
17216 & 11,28 & 285,0 & 17001 & 45,57 & 190,5 \\
19124 & 10,63 & 324,9 & 19672 & 45,31 & 218,4 \\
20936 & 10,25 & 335,9 & 21715 & 45,12 & 265,8 \\
23382 & 9,83 & 247,6 & 24895 & 44,85 & 218,9 \\
25076 & 9,49 & 237,9 & 27173 & 44,67 & 229,5 \\
26298 & 9,28 & 159,2 & 30993 & 44,40 & 209,7 \\
79783 & 5,08 & 131,8 & 86849 & 42,04 & 178,1 \\
81244 & 5,00 & 170,7 & 88915 & 41,96 & 201,6 \\
83721 & 4,87 & 155,3 & 91118 & 41,87 & 188,5 \\
86301 & 4,73 & 169,3 & 93047 & 41,79 & 171,4 \\
93999 & 4,36 & 110,8 & 94976 & 41,71 & 163,5 \\
95218 & 4,31 & 88,5 & 105658 & 41,27 & 141,2 \\
97552 & 4,22 & 78,2 & 108032 & 41,17 & 156,3 \\
99449 & 4,15 & 82,6 & 109743 & 41,10 & 119,6 \\
- & - & - & 347865 & 35,51 & 50,4 \\
\hline
\end{tabular}




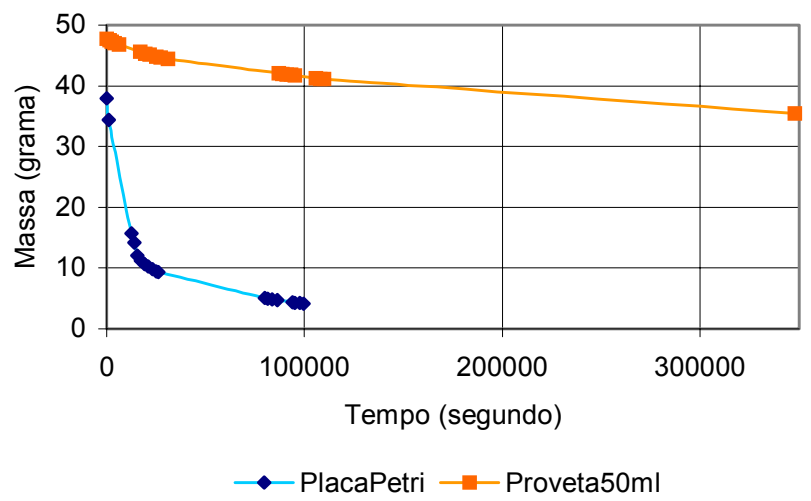

Figura 5. 7- A figura representa graficamente os valores de massa em função do tempo.

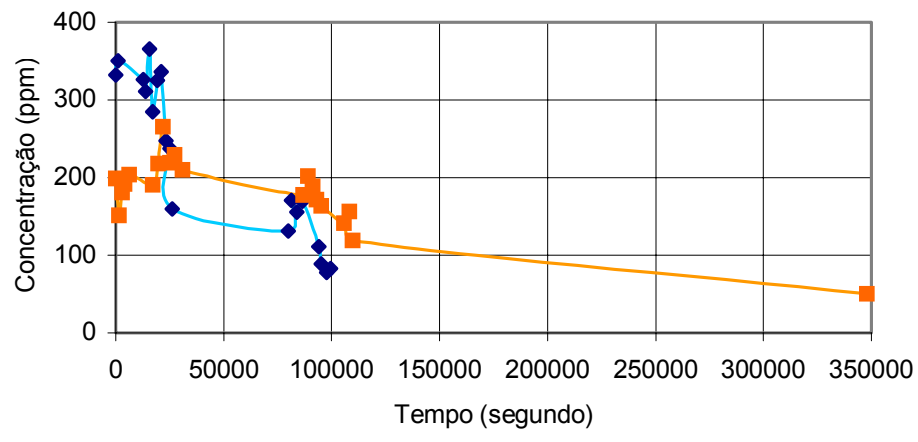

$\leadsto$ Concent.PlacaPetri $\_$Concent.Proveta50ml

Figura 5. 8- A figura representa graficamente os valores de concentração (obtidos com detetor de fotoionização) em função do tempo.

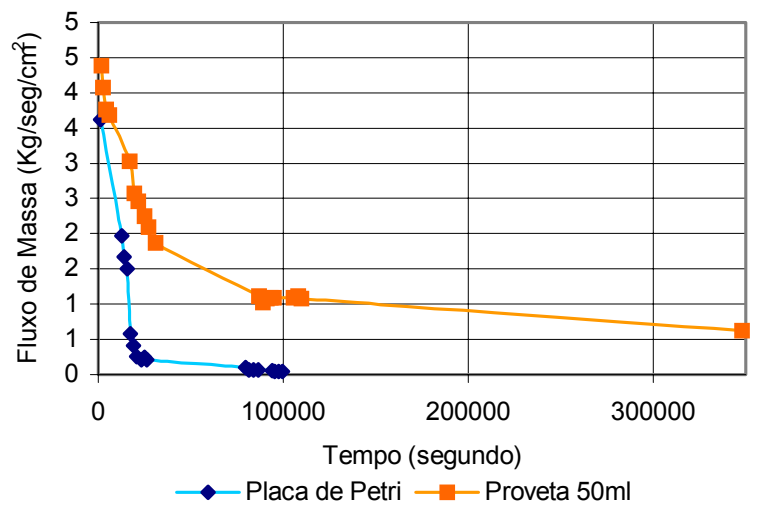

Figura 5. 5- Representação gráfica do fluxo de massa em função do tempo. 


\subsubsection{Ensaios Definitivos em Quatro Provetas de 500ml}

Os ensaios utilizaram quatro provetas de $500 \mathrm{ml}$ e os resultados podem ser visualizados na Tabela 5.4, a qual apresenta valores de massa (gramas) e concentração (ppm ou mg/l) medidos em função do tempo (dias), sendo ainda que as Figuras 5.6 e 5.8(a) representam graficamente os valores contidos na tabela citada.

Tabela 5.4 - Valores de massa e concentração medidos ao longo do tempo.

\begin{tabular}{|c|c|c|c|c|c|c|c|c|c|c|c|c|}
\hline \multicolumn{3}{|c|}{ Proveta 01 (500 ml gasolina) } & \multicolumn{3}{|c|}{ Proveta 02 (350 ml gasolina) } & \multicolumn{3}{|c|}{ Proveta 03 (225 ml gasolina) } & \multicolumn{3}{|c|}{ Proveta 04 (100 ml gasolina) } & \multirow[b]{2}{*}{$\begin{array}{c}\text { Tempe- } \\
\text { ratura } \\
\left({ }^{0} \mathrm{C}\right)\end{array}$} \\
\hline $\begin{array}{l}\text { Tempo } \\
\text { (dias) }\end{array}$ & $\begin{array}{c}\text { Massa } \\
\text { (gramas) }\end{array}$ & $\begin{array}{c}\text { Concen } \\
\text {-tração } \\
\text { (ppm) }\end{array}$ & $\begin{array}{l}\text { Tempo } \\
\text { (dias) }\end{array}$ & $\begin{array}{c}\text { Massa } \\
\text { (gramas) }\end{array}$ & $\begin{array}{c}\text { Concen } \\
\text {-tração } \\
\text { (ppm) }\end{array}$ & $\begin{array}{l}\text { Tempo } \\
\text { (dias) }\end{array}$ & $\begin{array}{c}\text { Massa } \\
\text { (gramas) }\end{array}$ & $\begin{array}{c}\text { Concen } \\
\text {-tração } \\
\text { (ppm) }\end{array}$ & $\begin{array}{c}\text { Tempo } \\
\text { (dias) }\end{array}$ & $\begin{array}{c}\text { Massa } \\
\text { (gramas) }\end{array}$ & $\begin{array}{c}\text { Concen } \\
\text {-tração } \\
\text { (ppm) }\end{array}$ & \\
\hline 0 & 372,41 & 152,7 & 0 & 263,43 & 242,7 & 0 & 166,99 & 157,1 & 0 & 74,72 & 152,2 & 25,0 \\
\hline $7,96 \mathrm{E}-03$ & 372,22 & 141,8 & $8,92 \mathrm{E}-03$ & 263,31 & 237,1 & $1,03 \mathrm{E}-02$ & 166,88 & 225,7 & $1,09 \mathrm{E}-02$ & 74,64 & 276,3 & 25,0 \\
\hline $1,68 \mathrm{E}-02$ & 372,02 & 179,1 & $1,83 \mathrm{E}-02$ & 263,19 & 123,3 & $1,96 \mathrm{E}-02$ & 166,79 & 215,4 & $2,17 \mathrm{E}-02$ & 74,57 & 161,3 & 25,0 \\
\hline $2,84 \mathrm{E}-02$ & 371,74 & 191,1 & $2,92 \mathrm{E}-02$ & 263,05 & 187,5 & $3,07 \mathrm{E}-02$ & 166,68 & 104,5 & $3,25 \mathrm{E}-02$ & 74,50 & 117,0 & 25,0 \\
\hline $3,99 \mathrm{E}-02$ & 371,46 & 168,2 & $4,08 \mathrm{E}-02$ & 262,90 & 198,9 & $4,17 \mathrm{E}-02$ & 166,57 & 229,8 & $4,28 \mathrm{E}-02$ & 74,40 & 129,3 & 25,0 \\
\hline $5,72 \mathrm{E}-02$ & 371,07 & 170,8 & $5,81 \mathrm{E}-02$ & 262,69 & 221,0 & $5,91 \mathrm{E}-02$ & 166,42 & 156,1 & $6,05 \mathrm{E}-02$ & 74,32 & 103,8 & 25,0 \\
\hline $1,33 \mathrm{E}-01$ & 369,23 & 169,3 & $1,34 \mathrm{E}-01$ & 261,74 & 212,0 & $1,35 \mathrm{E}-01$ & 165,75 & 213,2 & $1,36 \mathrm{E}-01$ & 73,83 & 182,2 & 26,0 \\
\hline $1,54 \mathrm{E}-01$ & 368,70 & 166,7 & $1,55 \mathrm{E}-01$ & 261,47 & 215,6 & $1,53 \mathrm{E}-01$ & 165,55 & 141,0 & $1,58 \mathrm{E}-01$ & 73,69 & 88,7 & 26,0 \\
\hline $1,76 \mathrm{E}-01$ & 368,15 & 176,9 & $1,77 \mathrm{E}-01$ & 261,17 & 183,3 & 1,79E-01 & 165,34 & 196,6 & $1,80 \mathrm{E}-01$ & 73,54 & 238,0 & 26,0 \\
\hline $2,01 \mathrm{E}-01$ & 367,52 & 66,9 & $2,02 \mathrm{E}-01$ & 260,83 & 124,9 & $2,04 \mathrm{E}-01$ & 165,10 & 150,0 & $2,04 \mathrm{E}-01$ & 73,37 & 134,2 & 26,0 \\
\hline $2,32 \mathrm{E}-01$ & 366,78 & 82,1 & $2,33 \mathrm{E}-01$ & 260,43 & 161,4 & $2,34 \mathrm{E}-01$ & 164,82 & 206,1 & $2,35 \mathrm{E}-01$ & 73,17 & 235,9 & 26,0 \\
\hline $3,26 \mathrm{E}-01$ & 364,74 & 184,9 & $3,27 \mathrm{E}-01$ & 259,28 & 234,4 & $3,29 \mathrm{E}-01$ & 163,99 & 220,7 & $3,31 \mathrm{E}-01$ & 72,58 & 266,8 & 25,5 \\
\hline $3,45 \mathrm{E}-01$ & 364,35 & 95,7 & $3,46 \mathrm{E}-01$ & 259,06 & 159,1 & $3,47 \mathrm{E}-01$ & 163,84 & 221,9 & $3,50 \mathrm{E}-01$ & 72,47 & 253,2 & 25,5 \\
\hline $9,41 \mathrm{E}-01$ & 355,14 & 192,0 & $9,42 \mathrm{E}-01$ & 253,62 & 209,6 & $9,44 \mathrm{E}-01$ & 159,92 & 142,2 & $9,45 \mathrm{E}-01$ & 69,78 & 149,5 & 27,0 \\
\hline $9,81 \mathrm{E}-01$ & 354,49 & 173,8 & $9,82 \mathrm{E}-01$ & 253,23 & 191,3 & $9,83 \mathrm{E}-01$ & 159,65 & 230,5 & $9,85 \mathrm{E}-01$ & 69,59 & 185,7 & 27,0 \\
\hline 1,025 & 353,73 & 215,1 & 1,026 & 252,78 & 160,8 & 1,027 & 159,34 & 137,6 & 1,027 & 69,40 & 131,4 & 27,5 \\
\hline 1,154 & 351,33 & 115,0 & 1,154 & 251,33 & 225,3 & 1,156 & 158,32 & 251,1 & 1,157 & 68,72 & 206,9 & 28,0 \\
\hline 1,191 & 350,60 & 210,1 & 1,192 & 250,87 & 244,4 & 1,189 & 157,99 & 258,4 & 1,195 & 68,51 & 241,4 & 28,0 \\
\hline 1,235 & 349,78 & 227,7 & 1,236 & 250,36 & 243,2 & 1,237 & 157,63 & 249,7 & 1,238 & 68,28 & 151,5 & 28,0 \\
\hline 1,256 & 349,35 & 230,6 & 1,257 & 250,10 & 219,4 & 1,258 & 157,45 & 151,7 & 1,259 & 68,16 & 125,8 & 27,5 \\
\hline 1,972 & 340,10 & 203,5 & 1,973 & 244,09 & 237,8 & 1,975 & 153,16 & 211,6 & 1,978 & 65,41 & 159,3 & 24,0 \\
\hline 1,995 & 339,80 & 147,2 & 1,997 & 243,89 & 269,0 & 2,002 & 153,01 & 186,8 & 2,004 & 65,32 & 232,6 & 24,0 \\
\hline 2,043 & 339,24 & 227,0 & 2,044 & 243,53 & 174,6 & 2,045 & 152,77 & 238,2 & 2,047 & 65,17 & 226,3 & 24,0 \\
\hline 2,107 & 338,50 & 241,1 & 2,109 & 243,03 & 230,0 & 2,111 & 152,41 & 138,3 & 2,115 & 64,94 & 184,8 & 24,5 \\
\hline 2,151 & 337,98 & 239,9 & 2,152 & 242,70 & 242,3 & 2,155 & 152,19 & 257,5 & 2,156 & 64,81 & 190,4 & 25,0 \\
\hline 2,201 & 337,45 & 226,0 & 2,202 & 242,34 & 256,6 & 2,204 & 151,93 & 156,5 & 2,207 & 64,65 & 193,1 & 25,0 \\
\hline 2,236 & 337,06 & 147,7 & 2,238 & 242,08 & 230,8 & 2,238 & 151,75 & 251,4 & 2,239 & 64,54 & 240,6 & 24,5 \\
\hline 2,328 & 336,14 & 184,0 & 2,328 & 241,46 & 216,0 & 2,329 & 151,31 & 264,1 & 2,331 & 64,27 & 156,2 & 24,5 \\
\hline 2,952 & 331,02 & 237,2 & 2,954 & 237,89 & 264,9 & 2,955 & 148,74 & 267,5 & 2,958 & 62,67 & 265,2 & 26,0 \\
\hline 2,993 & 330,69 & 224,2 & 2,995 & 237,66 & 222,0 & 2,999 & 148,57 & 249,2 & 3,003 & 62,56 & 181,4 & 26,0 \\
\hline 3,034 & 330,35 & 202,8 & 3,035 & 237,43 & 256,8 & 3,036 & 148,41 & 252,0 & 3,040 & 62,46 & 251,8 & 26,0 \\
\hline 3,157 & 329,23 & 213,8 & 3,159 & 236,65 & 239,9 & 3,160 & 147,86 & 246,3 & 3,162 & 62,13 & 140,6 & 26,5 \\
\hline 3,200 & 328,82 & 223,5 & 3,200 & 236,37 & 234,0 & 3,203 & 147,65 & 273,6 & 3,206 & 61,99 & 201,4 & 27,0 \\
\hline 3,239 & 328,44 & 269,5 & 3,240 & 236,10 & 258,2 & 3,244 & 147,45 & 269,2 & 3,248 & 61,86 & 241,9 & 27,0 \\
\hline 3,286 & 328,00 & 222,6 & 3,286 & 235,79 & 268,2 & 3,287 & 147,24 & 214,9 & 3,288 & 61,74 & 257,7 & 26,5 \\
\hline 3,950 & 323,06 & 250,0 & 3,952 & 232,29 & 219,8 & 3,953 & 144,73 & 176,1 & 3,954 & 60,21 & 112,0 & 26,5 \\
\hline 3,983 & 322,81 & 259,7 & 3,983 & 232,12 & 204,5 & 3,986 & 144,60 & 276,6 & 3,989 & 60,12 & 246,7 & 26,0 \\
\hline 4,052 & 322,23 & 223,8 & 4,054 & 231,71 & 258,7 & 4,056 & 144,31 & 124,6 & 4,058 & 59,95 & 109,9 & 26,0 \\
\hline 4,117 & 321,65 & 192,3 & 4,118 & 231,30 & 247,8 & 4,119 & 144,03 & 231,8 & 4,120 & 59,78 & 243,2 & 26,5 \\
\hline 4,169 & 321,19 & 244,0 & 4,171 & 230,96 & 264,0 & 4,172 & 143,78 & 269,8 & 4,175 & 59,62 & 178,2 & 26,5 \\
\hline 4,210 & 320,83 & 255,2 & 4,213 & 230,70 & 231,3 & 4,215 & 143,60 & 268,4 & 4,218 & 59,51 & 186,3 & 27,0 \\
\hline 4,254 & 320,44 & 254,0 & 4,255 & 230,43 & 276,0 & 4,258 & 143,40 & 221,4 & 4,261 & 59,39 & 264,7 & 26,5 \\
\hline 4,971 & 315,51 & 264,0 & 4,972 & 226,88 & 290,8 & 4,973 & 140,86 & 194,6 & 4,974 & 57,86 & 96,2 & 26,0 \\
\hline 5,049 & 314,94 & 271,9 & 5,050 & 226,48 & 211,1 & 5,052 & 140,57 & 261,6 & 5,053 & 57,69 & 264,4 & 26,0 \\
\hline 6,987 & 302,78 & 226,5 & 6,989 & 217,53 & 228,5 & 6,990 & 134,15 & 214,6 & 6,992 & 53,88 & 123,9 & 24,0 \\
\hline
\end{tabular}




\begin{tabular}{|c|c|c|c|c|c|c|c|c|c|c|c|c|}
\hline \multicolumn{3}{|c|}{ Proveta 01 (500 ml gasolina) } & \multicolumn{3}{|c|}{ Proveta 02 (350 ml gasolina) } & \multicolumn{3}{|c|}{ Proveta 03 (225 ml gasolina) } & \multicolumn{3}{|c|}{ Proveta 04 (100 ml gasolina) } & \multirow[b]{2}{*}{$\begin{array}{c}\text { Tempe- } \\
\text { ratura } \\
\left({ }^{\circ} \mathrm{C}\right)\end{array}$} \\
\hline $\begin{array}{l}\text { Tempo } \\
\text { (dias) }\end{array}$ & $\begin{array}{c}\text { Massa } \\
\text { (gramas) }\end{array}$ & $\begin{array}{c}\text { Concen } \\
\text {-tração } \\
(\mathrm{ppm})\end{array}$ & $\begin{array}{l}\text { Tempo } \\
\text { (dias) }\end{array}$ & $\begin{array}{c}\text { Massa } \\
\text { (gramas) }\end{array}$ & $\begin{array}{c}\text { Concen } \\
\text {-tração } \\
(\mathrm{ppm})\end{array}$ & $\begin{array}{c}\text { Tempo } \\
\text { (dias) }\end{array}$ & $\begin{array}{c}\text { Massa } \\
\text { (gramas) }\end{array}$ & $\begin{array}{c}\text { Concen } \\
\text {-tração } \\
(\mathrm{ppm})\end{array}$ & $\begin{array}{l}\text { Tempo } \\
\text { (dias) }\end{array}$ & $\begin{array}{c}\text { Massa } \\
\text { (gramas) }\end{array}$ & $\begin{array}{c}\text { Concen } \\
\text {-tração } \\
(\mathrm{ppm})\end{array}$ & \\
\hline 7,223 & 301,28 & 302,1 & 7,224 & 216,41 & 298,4 & 7,227 & 133,34 & 248,0 & 7,231 & 53,39 & 182,9 & 28,0 \\
\hline 7,954 & 297,33 & 261,3 & 7,956 & 213,44 & 264,1 & 7,958 & 131,20 & 248,6 & 7,959 & 52,14 & 274,4 & 24,0 \\
\hline 8,229 & 295,58 & 294,2 & 8,232 & 212,14 & 292,7 & 8,233 & 130,28 & 277,0 & 8,238 & 51,59 & 182,5 & 28,0 \\
\hline 9,044 & 291,42 & 172,1 & 9,047 & 208,99 & 276,5 & 9,048 & 128,00 & 309,6 & 9,051 & 50,25 & 168,4 & 25,0 \\
\hline 9,224 & 290,44 & 268,0 & 9,225 & 208,25 & 324,6 & 9,227 & 127,47 & 227,2 & 9,229 & 49,93 & 152,8 & 28,0 \\
\hline 9,952 & 287,11 & 279,0 & 9,954 & 205,78 & 265,6 & 9,961 & 125,72 & 202,8 & 9,962 & 48,92 & 148,8 & 22,0 \\
\hline 10,243 & 285,87 & 314,6 & 10,245 & 204,83 & 270,5 & 10,248 & 125,05 & 207,0 & 10,249 & 48,52 & 174,6 & 23,5 \\
\hline 11,191 & 282,36 & 312,1 & 11,193 & 202,19 & 342,9 & 11,197 & 123,18 & 166,4 & 11,202 & 47,43 & 162,4 & 22,0 \\
\hline 12,016 & 279,71 & 332,0 & 12,018 & 200,16 & 228,0 & 12,024 & 121,72 & 315,4 & 12,025 & 46,57 & 291,9 & 19,0 \\
\hline 14,036 & 272,73 & 328,8 & 14,039 & 194,72 & 319,9 & 14,043 & 117,79 & 257,4 & 14,048 & 44,20 & 226,8 & 25,5 \\
\hline 14,236 & 271,79 & 336,3 & 14,239 & 193,98 & 343,5 & 14,242 & 117,27 & 301,5 & 14,246 & 43,88 & 216,0 & 30,0 \\
\hline 14,993 & 269,04 & 306,5 & 14,997 & 191,84 & 266,2 & 14,998 & 115,72 & 179,1 & 15,000 & 42,93 & 248,0 & 26,0 \\
\hline 15,221 & 268,01 & 310,7 & 15,223 & 191,04 & 322,8 & 15,225 & 115,15 & 239,7 & 15,225 & 42,58 & 223,7 & 28,5 \\
\hline 15,992 & 265,20 & 227,4 & 15,995 & 188,82 & 211,7 & 15,998 & 113,52 & 212,3 & 16,001 & 41,55 & 171,5 & 26,0 \\
\hline 16,228 & 263,97 & 290,7 & 16,236 & 187,87 & 300,6 & 16,239 & 112,84 & 290,5 & 16,243 & 41,12 & 209,1 & 30,0 \\
\hline 16,943 & 261,26 & 287,7 & 16,946 & 185,75 & 291,3 & 16,948 & 111,29 & 249,4 & 16,953 & 40,15 & 213,6 & 25,0 \\
\hline 17,142 & 260,51 & 268,0 & 17,145 & 185,16 & 264,6 & 17,148 & 110,85 & 230,9 & 17,150 & 39,87 & 174,5 & 28,0 \\
\hline 17,958 & 257,58 & 265,7 & 17,959 & 182,85 & 245,2 & 17,963 & 109,16 & 133,6 & 17,966 & 38,80 & 66,5 & 27,0 \\
\hline 18,257 & 256,15 & 275,8 & 18,259 & 181,72 & 281,4 & 18,263 & 108,34 & 272,5 & 18,267 & 38,26 & 185,5 & 31,0 \\
\hline 18,971 & 253,34 & 251,2 & 18,972 & 179,51 & 255,6 & 18,976 & 106,71 & 157,1 & 18,978 & 37,23 & 144,1 & 29,0 \\
\hline 20,912 & 246,81 & 186,1 & 20,918 & 174,43 & 232,3 & 20,920 & 103,03 & 143,9 & 20,930 & 34,89 & 61,2 & 21,0 \\
\hline 21,168 & 246,19 & 229,7 & 21,172 & 173,94 & 273,7 & 21,178 & 102,37 & 125,0 & 21,184 & 34,66 & 101,4 & 22,5 \\
\hline 21,943 & 244,52 & 312,4 & 21,946 & 172,62 & 313,8 & 21,951 & 101,71 & 188,2 & 21,954 & 34,06 & 265,6 & 20,0 \\
\hline 22,240 & 243,83 & 314,5 & 22,244 & 172,06 & 298,2 & 22,248 & 101,30 & 223,9 & 22,249 & 33,80 & 142,5 & 24,0 \\
\hline 22,914 & 242,37 & 257,2 & 22,917 & 170,88 & 259,8 & 22,919 & 100,43 & 210,2 & 22,921 & 33,24 & 204,8 & 21,0 \\
\hline 23,139 & 241,70 & 262,0 & 23,140 & 170,35 & 271,2 & 23,141 & 100,04 & 157,9 & 23,143 & 32,99 & 156,6 & 25,0 \\
\hline 23,893 & 239,88 & 185,1 & 23,895 & 168,89 & 164,2 & 23,898 & 98,95 & 156,4 & 23,900 & 32,29 & 180,9 & 23,0 \\
\hline 24,190 & 238,97 & 238,6 & 24,192 & 168,16 & 229,8 & 24,195 & 98,41 & 187,3 & 24,203 & 31,91 & 207,3 & 28,0 \\
\hline 25,186 & 236,29 & 222,0 & 25,191 & 166,01 & 215,7 & 25,196 & 96,81 & 216,1 & 25,209 & 30,89 & 194,4 & 26,5 \\
\hline 26,185 & 233,77 & 284,0 & 26,185 & 164,00 & 253,6 & 26,187 & 95,32 & 259,1 & 26,188 & 29,94 & 261,1 & 27,0 \\
\hline 28,291 & 228,88 & 264,1 & 28,292 & 160,07 & 262,7 & 28,293 & 92,41 & 225,9 & 28,301 & 28,05 & 217,9 & 26,0 \\
\hline 29,178 & 227,04 & 207,1 & 29,180 & 158,55 & 232,1 & 29,181 & 91,27 & 207,2 & 29,185 & 27,32 & 192,4 & 25,5 \\
\hline 30,200 & 224,70 & 216,6 & 30,201 & 156,65 & 229,3 & 30,203 & 89,83 & 200,4 & 30,207 & 26,41 & 192,0 & 28,0 \\
\hline 31,187 & 222,15 & 216,6 & 31,193 & 154,55 & 203,6 & 31,196 & 88,24 & 202,7 & 31,199 & 25,52 & 204,8 & 31,5 \\
\hline 32,332 & 219,01 & 188,8 & 32,334 & 151,98 & 190,3 & 32,337 & 86,30 & 182,7 & 32,339 & 24,73 & 193,7 & 29,0 \\
\hline 33,218 & 216,57 & 213,4 & 33,219 & 149,99 & 207,9 & 33,220 & 84,78 & 180,3 & 33,223 & 24,36 & 222,1 & 30,0 \\
\hline 34,242 & 214,09 & 177,9 & 34,245 & 147,94 & 179,6 & 34,250 & 83,21 & 159,6 & 34,253 & 24,03 & 164,3 & 26,5 \\
\hline 35,175 & 212,30 & 174,8 & 35,177 & 146,46 & 169,3 & 35,179 & 82,09 & 155,6 & 35,192 & 23,78 & 154,3 & 27,0 \\
\hline 36,178 & 210,35 & 162,0 & 36,178 & 144,84 & 157,5 & 36,182 & 80,85 & 145,8 & 36,188 & 23,52 & 150,6 & 27,0 \\
\hline 37,166 & 208,47 & 161,5 & 37,169 & 143,26 & 157,4 & 37,170 & 79,66 & 149,4 & 37,178 & 23,27 & 152,9 & 25,5 \\
\hline 38,214 & 206,48 & 165,2 & 38,218 & 141,59 & 154,7 & 38,221 & 78,39 & 163,9 & 38,222 & 23,01 & 154,4 & 27,0 \\
\hline 39,069 & 204,89 & 167,2 & 39,074 & 140,25 & 147,2 & 39,075 & 77,38 & 151,6 & 39,079 & 22,80 & 136,2 & 26,0 \\
\hline 40,266 & 202,61 & 177,5 & 40,271 & 138,35 & 158,9 & 40,274 & 75,92 & 153,6 & 40,280 & 22,52 & 150,4 & 28,0 \\
\hline 41,340 & 200,72 & 166,1 & 41,344 & 136,78 & 166,4 & 41,347 & 74,71 & 163,6 & 41,348 & 22,30 & 170,8 & 25,5 \\
\hline 42,180 & 199,38 & 156,8 & 42,184 & 135,68 & 151,0 & 42,185 & 73,87 & 147,0 & 42,187 & 22,16 & 138,4 & 26,0 \\
\hline 43,242 & 197,67 & 142,8 & 43,248 & 134,25 & 141,4 & 43,251 & 72,76 & 128,5 & 43,257 & 21,95 & 118,6 & 24,5 \\
\hline 44,170 & 196,19 & 140,1 & 44,174 & 133,03 & 138,1 & 44,178 & 71,82 & 124,7 & 44,187 & 21,76 & 108,4 & 25,5 \\
\hline 45,205 & 194,36 & 142,2 & 45,208 & 131,51 & 137,1 & 45,212 & 70,65 & 131,2 & 45,216 & 21,55 & 141,5 & 27,0 \\
\hline 46,091 & 192,80 & 139,0 & 46,093 & 130,25 & 130,0 & 46,095 & 69,66 & 134,8 & 46,096 & 21,37 & 115,2 & 27,0 \\
\hline 47,074 & 191,10 & 125,8 & 47,075 & 128,83 & 117,0 & 47,076 & 68,55 & 120,3 & 47,078 & 21,18 & 111,1 & 27,0 \\
\hline 48,128 & 189,28 & 139,4 & 48,131 & 127,33 & 148,8 & 48,134 & 67,37 & 144,4 & 48,137 & 20,96 & 114,5 & 26,0 \\
\hline 49,043 & 187,85 & 141,9 & 49,045 & 126,15 & 145,2 & 49,049 & 66,44 & 119,0 & 49,050 & 20,81 & 121,9 & 25,0 \\
\hline 50,120 & 186,04 & 142,7 & 50,124 & 124,66 & 138,4 & 50,128 & 65,26 & 136,6 & 50,130 & 20,61 & 113,4 & 27,0 \\
\hline 51,300 & 183,85 & 134,6 & 51,303 & 122,84 & 131,2 & 51,306 & 63,83 & 134,8 & 51,307 & 20,37 & 119,0 & 29,0 \\
\hline 52,152 & 182,30 & 127,3 & 52,156 & 121,55 & 127,4 & 52,157 & 62,82 & 127,2 & 52,160 & 20,21 & 113,3 & 27,0 \\
\hline 53,140 & 180,50 & 120,2 & 53,146 & 120,07 & 112,4 & 53,148 & 61,67 & 105,0 & 53,150 & 20,03 & 103,6 & 26,5 \\
\hline 54,313 & 178,72 & 138,9 & 54,318 & 118,58 & 135,8 & 54,319 & 60,51 & 132,8 & 54,321 & 19,82 & 104,4 & 25,0 \\
\hline 55,193 & 177,43 & 126,3 & 55,196 & 117,50 & 125,3 & 55,198 & 59,67 & 127,8 & 55,200 & 19,68 & 102,9 & 27,0 \\
\hline 56,170 & 175,77 & 116,1 & 56,175 & 116,10 & 112,2 & 56,176 & 58,62 & 113,6 & 56,177 & 19,51 & 101,9 & 28,5 \\
\hline
\end{tabular}




\begin{tabular}{|c|c|c|c|c|c|c|c|c|c|c|c|c|}
\hline \multicolumn{3}{|c|}{ Proveta 01 (500 ml gasolina) } & \multicolumn{3}{|c|}{ Proveta 02 (350 ml gasolina) } & \multicolumn{3}{|c|}{ Proveta 03 (225 ml gasolina) } & \multicolumn{3}{|c|}{ Proveta 04 (100 ml gasolina) } & \multirow[b]{2}{*}{$\begin{array}{c}\text { Tempe- } \\
\text { ratura } \\
\left({ }^{0} \mathrm{C}\right)\end{array}$} \\
\hline $\begin{array}{l}\text { Tempo } \\
\text { (dias) }\end{array}$ & $\begin{array}{c}\text { Massa } \\
\text { (gramas) }\end{array}$ & $\begin{array}{l}\text { Concen } \\
\text {-tração } \\
\text { (ppm) }\end{array}$ & $\begin{array}{l}\text { Tempo } \\
\text { (dias) }\end{array}$ & $\begin{array}{c}\text { Massa } \\
\text { (gramas) }\end{array}$ & $\begin{array}{c}\text { Concen } \\
\text {-tração } \\
(\mathrm{ppm})\end{array}$ & $\begin{array}{l}\text { Tempo } \\
\text { (dias) }\end{array}$ & $\begin{array}{c}\text { Massa } \\
\text { (gramas) }\end{array}$ & $\begin{array}{c}\text { Concen } \\
\text {-tração } \\
(\mathrm{ppm})\end{array}$ & $\begin{array}{l}\text { Tempo } \\
\text { (dias) }\end{array}$ & $\begin{array}{c}\text { Massa } \\
\text { (gramas) }\end{array}$ & $\begin{array}{c}\text { Concen } \\
\text {-tração } \\
(\mathrm{ppm})\end{array}$ & \\
\hline 57,258 & 173,96 & 110,7 & 57,264 & 114,58 & 105,6 & 57,268 & 57,52 & 101,3 & 57,271 & 19,32 & 100,6 & 27,0 \\
\hline 58,189 & 172,71 & 142,3 & 58,193 & 113,54 & 130,9 & 58,194 & 56,80 & 122,3 & 58,195 & 19,18 & 113,5 & 22,0 \\
\hline 59,211 & 171,52 & 128,9 & 59,213 & 112,55 & 124,9 & 59,215 & 56,15 & 110,3 & 59,216 & 19,05 & 103,7 & 25,0 \\
\hline 60,249 & 170,15 & 111,7 & 60,252 & 111,41 & 106,5 & 60,255 & 55,49 & 105,9 & 60,258 & 18,92 & 101,4 & 24,0 \\
\hline 61,008 & 169,25 & 114,4 & 61,012 & 110,66 & 106,0 & 61,018 & 55,12 & 103,6 & 61,019 & 18,81 & 103,1 & 24,0 \\
\hline 62,101 & 167,95 & 113,5 & 62,104 & 109,57 & 113,3 & 62,106 & 54,68 & 107,8 & 62,109 & 18,68 & 102,6 & 24,0 \\
\hline 63,141 & 166,65 & 121,4 & 63,142 & 108,48 & 117,8 & 63,145 & 54,33 & 109,6 & 63,150 & 18,54 & 104,1 & 25,0 \\
\hline 64,240 & 165,27 & 129,3 & 64,242 & 107,32 & 120,7 & 64,245 & 54,00 & 110,9 & 64,248 & 18,40 & 102,9 & 25,0 \\
\hline 65,374 & 163,81 & 132,9 & 65,376 & 106,09 & 129,2 & 65,378 & 53,67 & 112,6 & 65,380 & 18,26 & 102,4 & 25,5 \\
\hline 66,466 & 162,32 & 125,4 & 66,468 & 104,84 & 122,7 & 66,470 & 53,35 & 110,9 & 66,472 & 18,11 & 103,8 & 25,0 \\
\hline 67,241 & 161,26 & 122,2 & 67,244 & 103,93 & 119,5 & 67,247 & 53,13 & 113,2 & 67,254 & 18,01 & 104,0 & 27,5 \\
\hline 68,305 & 159,67 & 115,7 & 68,310 & 102,60 & 112,1 & 68,312 & 52,79 & 103,9 & 68,318 & 17,86 & 101,7 & 26,5 \\
\hline 69,271 & 158,43 & 106,0 & 69,277 & 101,56 & 104,4 & 69,279 & 52,52 & 102,6 & 69,286 & 17,74 & 99,3 & 25,0 \\
\hline 70,179 & 157,27 & 116,2 & 70,183 & 100,59 & 105,8 & 70,186 & 52,27 & 103,8 & 70,188 & 17,63 & 102,2 & 27,0 \\
\hline 71,172 & 155,95 & 112,6 & 71,178 & 99,48 & 109,0 & 71,181 & 51,99 & 104,1 & 71,183 & 17,51 & 100,9 & 28,0 \\
\hline 72,144 & 154,53 & 113,6 & 72,147 & 98,31 & 111,3 & 72,149 & 51,71 & 107,1 & 72,152 & 17,38 & 100,2 & 28,0 \\
\hline 73,191 & 152,84 & 108,7 & 73,196 & 96,89 & 106,3 & 73,200 & 51,36 & 104,2 & 73,202 & 17,22 & 99,5 & 29,0 \\
\hline 74,182 & 151,33 & 103,9 & 74,192 & 95,62 & 100,5 & 74,195 & 51,06 & 95,8 & 74,199 & 17,09 & 92,5 & 28,0 \\
\hline 75,236 & 149,78 & 110,5 & 75,240 & 94,35 & 107,8 & 75,242 & 50,75 & 97,1 & 75,244 & 16,95 & 92,9 & 29,0 \\
\hline 76,144 & 148,47 & 108,9 & 76,148 & 93,25 & 108,9 & 76,151 & 50,50 & 102,3 & 76,153 & 16,83 & 99,2 & 28,5 \\
\hline 77,194 & 146,95 & 109,1 & 77,196 & 92,02 & 106,5 & 77,198 & 50,21 & 105,9 & 77,200 & 16,71 & 99,0 & 28,5 \\
\hline 78,168 & 145,46 & 109,3 & 78,172 & 90,80 & 104,5 & 78,176 & 49,93 & 104,2 & 78,178 & 16,58 & 97,6 & 29,0 \\
\hline 79,059 & 144,27 & 114,7 & 79,064 & 89,86 & 109,0 & 79,066 & 49,69 & 105,3 & 79,070 & 16,47 & 97,3 & 27,0 \\
\hline 80,174 & 142,53 & 119,7 & 80,178 & 88,58 & 111,9 & 80,185 & 49,35 & 105,1 & 80,187 & 16,32 & 93,4 & 30,0 \\
\hline 81,177 & 140,90 & 117,5 & 81,179 & 87,47 & 110,0 & 81,181 & 49,04 & 105,5 & 81,182 & 16,20 & 90,9 & 29,0 \\
\hline 82,260 & 139,48 & 118,3 & 82,261 & 86,54 & 112,8 & 82,263 & 48,77 & 107,1 & 82,265 & 16,08 & 89,6 & 26,0 \\
\hline 83,187 & 138,35 & 117,5 & 83,189 & 85,84 & 113,0 & 83,192 & 48,54 & 104,8 & 83,195 & 15,97 & 93,8 & 28,0 \\
\hline 84,335 & 136,81 & 114,6 & 84,338 & 85,08 & 106,2 & 84,342 & 48,23 & 101,9 & 84,342 & 15,84 & 91,5 & 27,0 \\
\hline 85,259 & 135,72 & 115,9 & 85,261 & 84,63 & 112,7 & 85,263 & 48,01 & 105,9 & 85,265 & 15,73 & 94,5 & 28,0 \\
\hline 86,146 & 134,67 & 116,4 & 86,148 & 84,25 & 112,0 & 86,149 & 47,80 & 107,2 & 86,151 & 15,65 & 89,6 & 27,5 \\
\hline 87,217 & 133,12 & 118,8 & 87,219 & 83,75 & 114,4 & 87,220 & 47,49 & 106,9 & 87,221 & 15,51 & 90,0 & 27,5 \\
\hline 89,378 & 130,97 & 116,9 & 89,379 & 83,10 & 114,7 & 89,380 & 47,06 & 105,8 & 89,381 & 15,33 & 91,5 & 24,0 \\
\hline 90,163 & 130,18 & 110,4 & 90,165 & 82,86 & 109,7 & 90,166 & 46,90 & 105,6 & 90,167 & 15,26 & 85,6 & 24,5 \\
\hline 91,177 & 129,19 & 110,0 & 91,179 & 82,54 & 108,4 & 91,181 & 46,70 & 96,0 & 91,182 & 15,18 & 78,5 & 24,0 \\
\hline 92,324 & 128,11 & 108,4 & 92,325 & 82,22 & 107,0 & 92,327 & 46,47 & 97,8 & 92,328 & 15,09 & 82,8 & 25,0 \\
\hline 93,233 & 127,17 & 117,1 & 93,234 & 81,94 & 119,4 & 93,236 & 46,28 & 110,2 & 93,237 & 15,00 & 82,5 & 27,5 \\
\hline 94,196 & 126,07 & 116,8 & 94,200 & 81,62 & 113,2 & 94,201 & 46,07 & 106,9 & 94,203 & 14,91 & 93,1 & 28,5 \\
\hline 95,203 & 124,76 & 117,1 & 95,205 & 81,24 & 112,0 & 95,207 & 45,81 & 104,0 & 95,208 & 14,80 & 92,6 & 29,0 \\
\hline 96,199 & 123,36 & 118,7 & 96,202 & 80,83 & 113,8 & 96,203 & 45,53 & 109,2 & 96,205 & 14,69 & 98,2 & 29,0 \\
\hline 97,159 & 122,07 & 120,0 & 97,160 & 80,41 & 111,0 & 97,162 & 45,26 & 105,6 & 97,163 & 14,57 & 91,7 & 30,0 \\
\hline 98,001 & 121,08 & 120,2 & 98,003 & 80,09 & 113,7 & 98,005 & 45,05 & 107,9 & 98,007 & 14,49 & 93,8 & 29,0 \\
\hline 192,937 & 94,10 & 70,7 & 192,940 & 60,17 & 36,2 & 192,942 & 32,08 & 27,1 & 192,946 & 9,16 & 12,1 & 27,0 \\
\hline 200,910 & 92,66 & 66,1 & 200,915 & 59,06 & 39,3 & 200,920 & 31,39 & 25,2 & 200,925 & 8,89 & 14,0 & 24,5 \\
\hline 207,937 & 91,52 & 63,6 & 207,944 & 58,19 & 33,3 & 207,950 & 30,84 & 22,8 & 207,957 & 8,65 & 12,2 & 24,0 \\
\hline 215,998 & 89,97 & 65,2 & 216,007 & 57,02 & 40,3 & 216,014 & 30,10 & 26,3 & 216,022 & 8,33 & 17,3 & 25,0 \\
\hline
\end{tabular}




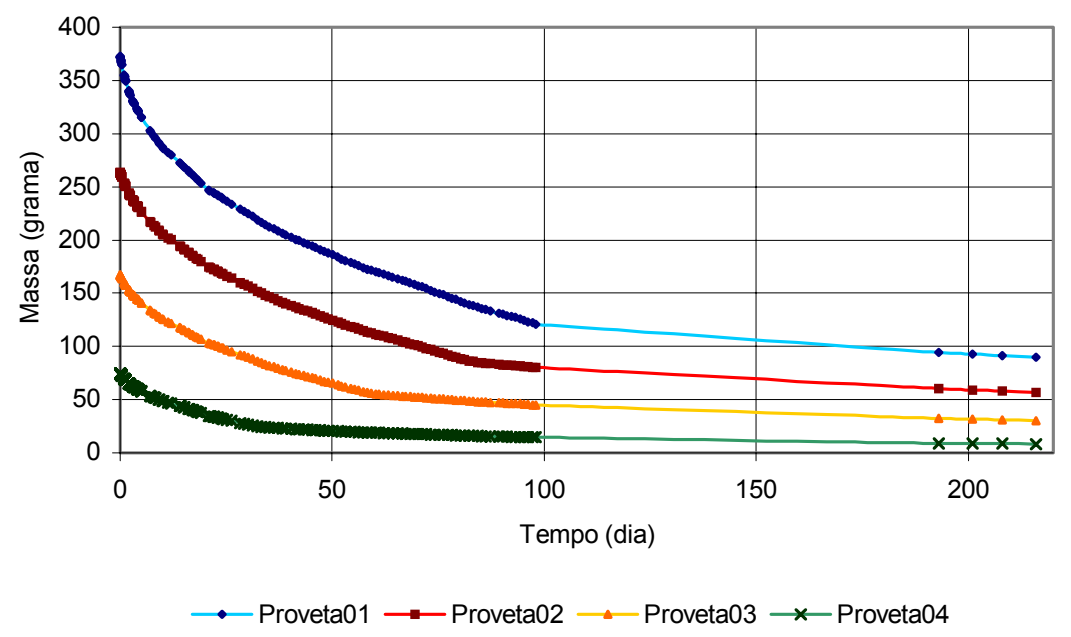

Figura 5. 6- A figura representa graficamente os valores de massa em função do tempo.

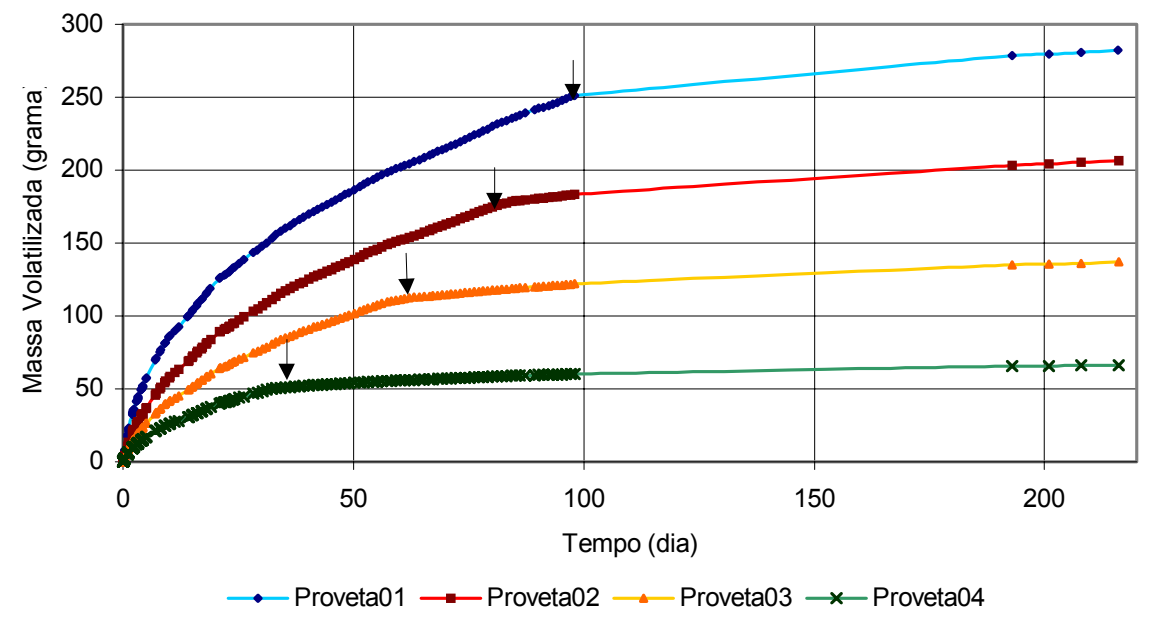

Figura 5. 7- A figura representa graficamente os valores de massa volatilizada em função do tempo. 


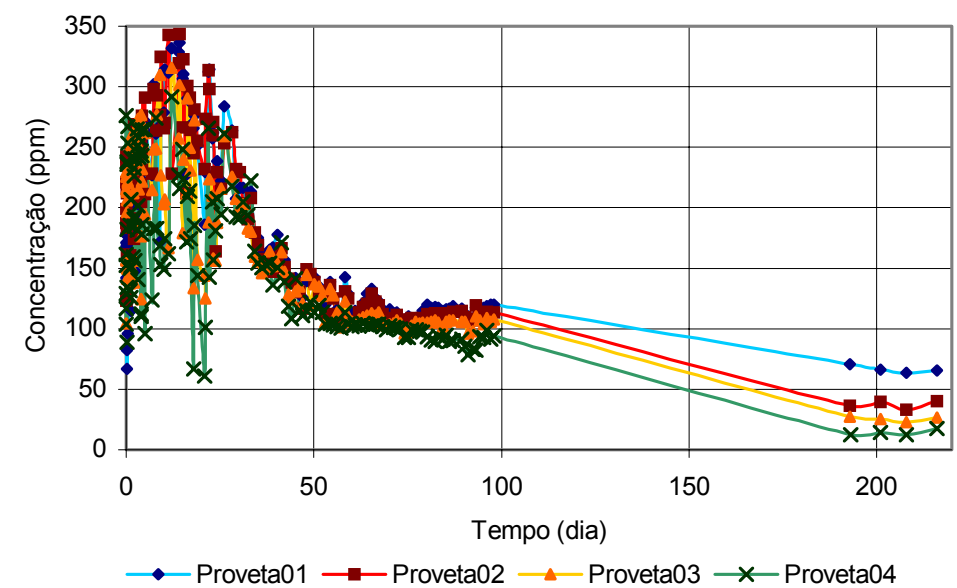

Figura 5. 8(a)- A figura representa graficamente os valores de concentração em função do tempo.

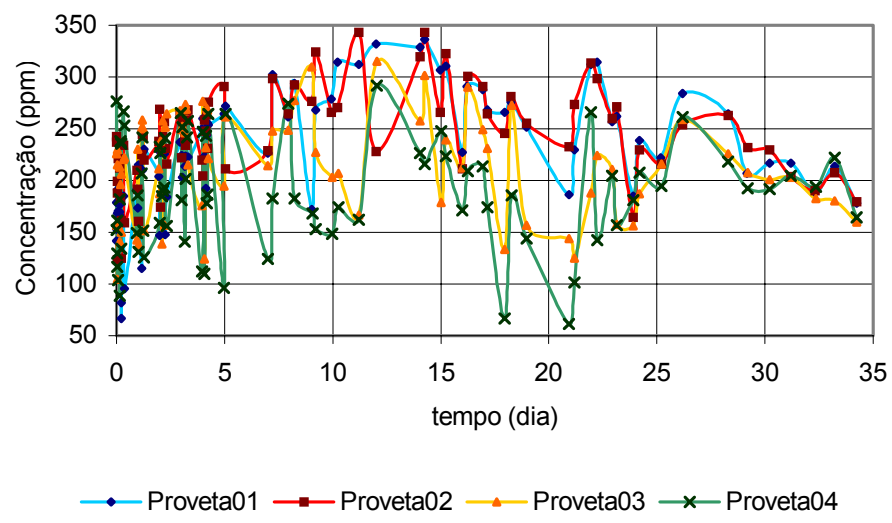

Figura5. 8(b)- A figura representa graficamente os valores de concentração em função do tempo até 34 dias.

A Figura 5.6 mostra a variação com o tempo da massa contida em cada proveta. A Figura 5.7 mostra a massa volatilizada acumulada em função do tempo. Observação: seja $\mathrm{m}_{0}$ a massa no tempo zero e $m_{k}$ a massa no tempo " $k$ ". Então $\left(m_{0}-m_{k}\right)$ é a massa volatilizada acumulada até o tempo "k". A Figura 5.7 mostra ainda que quando aproximadamente 68\% da massa inicial se volatiliza, a variação da massa com o tempo muda de tendência, ou seja, o valor da derivada $\partial \mathrm{m} / \partial \mathrm{t}$ diminui (como o assinalado com os marcadores). Esta mudança na curva de tendência após 68\% será facilmente visualizada na Figura 5.11. A Figura 5.8(a) mostra a variação da concentração medida com detetor de fotoionização em função do tempo, para o período todo do experimento. As Figuras 5.8(b) e (c) mostram a mesma grandeza em períodos distintos: 5.8(b) para os primeiros 34 dias e 5.8(c) para o restante. 


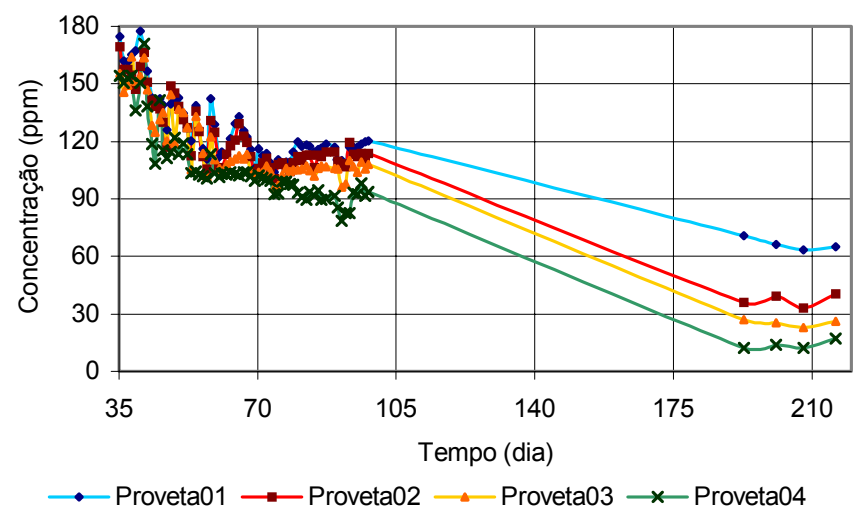

Figura5. 8(c)- A figura representa graficamente os valores de concentração em função do tempo para tempo superior a 34 dias.

Os resultados mostrados nas tabelas e figuras anteriores são os valores obtidos, sem qualquer tipo de tratamento.

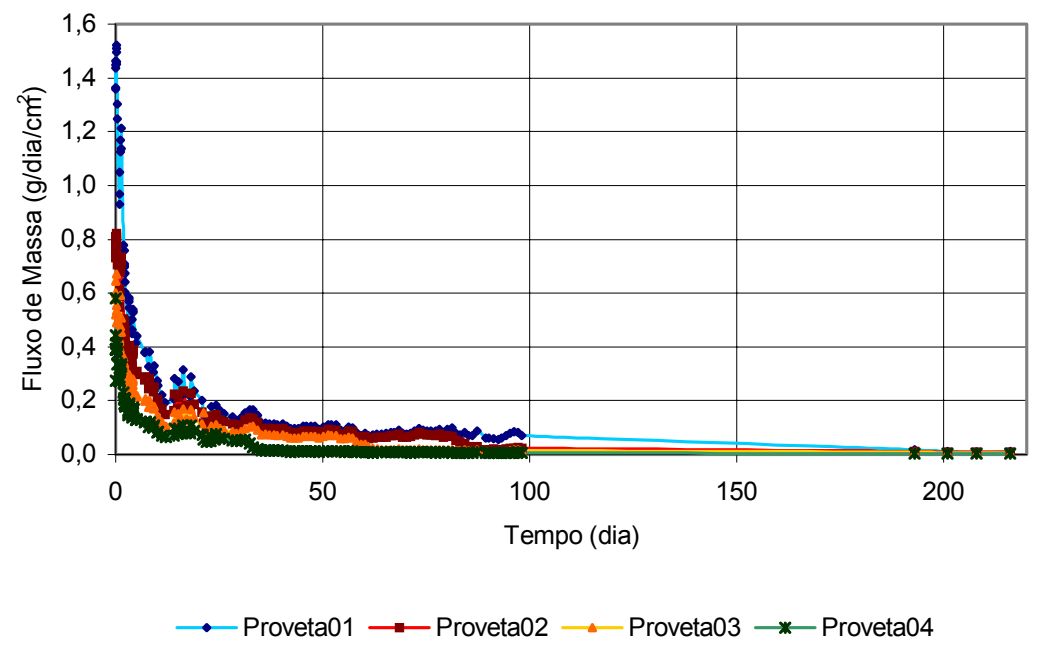

Figura 5. 9- Representação gráfica dos resultados de fluxo de massa em função do tempo.

Na Figura 5.9 transformou-se os resultados de massa em fluxo (variação de massa $\Delta \mathrm{m}$ dividido pelo intervalo de tempo correspondente $\Delta \mathrm{t}$ e pela área da seção transversal da proveta). Correlacionando-se os valores de fluxo com os referidos tempos, nota-se que ao iniciar-se o experimento o fluxo é sensivelmente afetado pela altura da coluna de ar livre entre a superfície da gasolina e a extremidade superior da proveta; com o decorrer do tempo essa influência diminui consideravelmente praticamente deixando de existir. Isto pode ser justificado pela composição da gasolina que possui algumas substâncias com alta pressão de vapor e com isso rapidamente volatilizam; com o transcorrer do tempo estas substâncias 
serão encontradas em pequenas concentrações ou deixaram de existir. O fluxo, em qualquer tempo, é maior para as provetas com maior volume de combustível "mais cheias".

A Figura 5.10 mostra o fluxo adimensionalizado em relação ao fluxo inicial para cada experimento. Pode-se observar que os valores do fluxo diminuem para a metade do valor inicial entre 2 e 2,5 dias. Nota-se também que para todos os experimentos ocorreram valores de fluxo maiores que o valor inicial, embora isto tenha acontecido apenas até as seis primeiras horas. Quando todo o volume livre estava preenchido com vapores da gasolina.

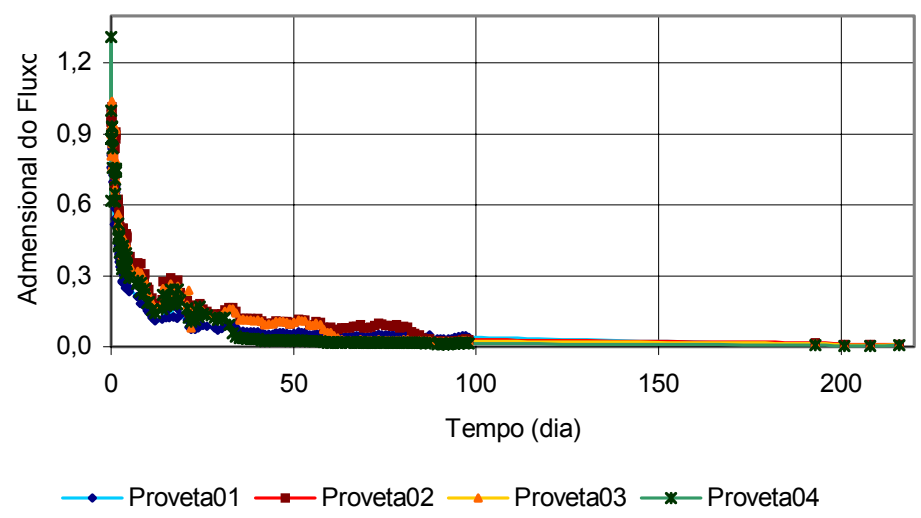

Figura 5. 10- Representação gráfica do fluxo adimensionalizado em função do tempo.

Em seguida adimensionalizou-se os eixos de massa volatilizada e de tempo, para obter-se um gráfico que represente a tendência do fenômeno. Para isso criou-se um adimensional de massa $\mu=\frac{m_{0}-m_{k}}{m_{0}}$ onde $\mathrm{m}_{0}$ é a massa no tempo zero e $\mathrm{m}_{\mathrm{k}}$ a massa no tempo "k" e um adimensional de tempo $\tau=\frac{t}{t_{r}}$ onde " $\mathrm{t}$ " é um tempo qualquer e $\mathrm{t}_{\mathrm{r}}$ é a "meia vida" de cada ensaio, sendo o tempo necessária para que a metade da massa inicial seja volatilizada. Assim confirmou-se que para os experimentos com provetas similares a tendência do fenômeno de volatilização era a mesma e com isso criou-se a Figura 5.11 que representa graficamente os valores de massa adimensionalizados em função dos valores do tempo adimensionalizado. 


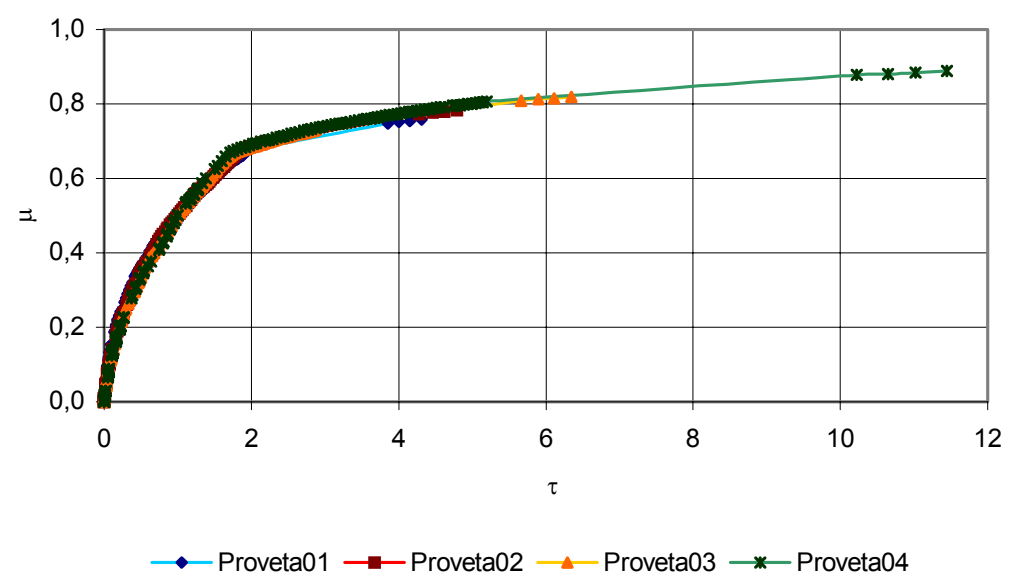

Figura 5. 11- Representação gráfica dos resultados de massa adimensionalizados em função dos resultados de tempo adimensionalizados.

Como a adimensionalização resultou em uma única tendência para o fenômeno, partiu-se para a tentativa de desenvolver-se um modelo físico-matemático.

Assim para iniciar o estudo do processo de difusão partiu-se da $1^{\text {a }}$ lei de Fick que diz:

$$
F_{x}=-D \frac{d C}{d x}
$$

Onde:

$\mathrm{F}_{\mathrm{x}}=$ Fluxo de massa na direção $\mathrm{x}$;

$\mathrm{D}=$ Coeficiente de difusão molecular;

$\frac{d C}{d x}=$ Gradiente de concentração, que significa variação da concentração ao longo de uma direção $\mathrm{x}$.

Outro conceito importante é o de descarga de massa, que se refere a uma determinada quantidade de massa em um determinado intervalo de tempo:

$$
\dot{M}=\frac{\Delta M}{\Delta t}=F_{x} \cdot A
$$

$\dot{M}=$ Descarga de massa;

$\Delta \mathrm{M}=$ Variação de Massa;

$\Delta \mathrm{t}=$ Intervalo de tempo. 


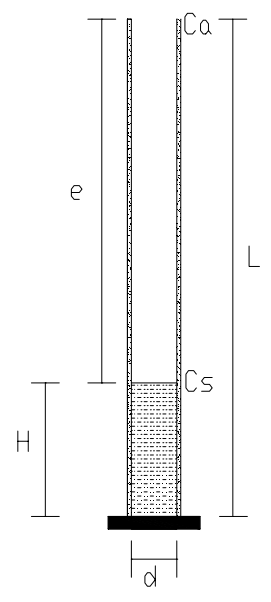

Figura 5. 12- Representação esquemática das dimensões adotadas para equacionar o ensaio com quatro provetas (sendo que esta hipótese considera o equacionamento quase-permanente).

Atribui-se como primeira hipótese que "D" seja um valor constante. Como pode ser visualizado na Figura 5.12 a grandeza "x" está variando de "0 a e" e a concentração está variando de "Cs a Ca", então calcula-se $\dot{M}$ :

$$
-\frac{\dot{M}}{D \cdot A} d X=d C
$$

Para a eq. 5.3 as condições de contorno são:

$$
\begin{gathered}
0 \leq \mathrm{x} \leq \mathrm{e} ; \text { para } \mathrm{x}=0 \rightarrow \mathrm{C}=\mathrm{C}_{\mathrm{s}} ; \text { para } \mathrm{x}=\mathrm{e} \rightarrow \mathrm{C}=\mathrm{C}_{\mathrm{a}} \\
-\frac{\dot{M}}{D \cdot A} \int_{0}^{e} d X=\int_{C s}^{C a} d C \\
-\left.\frac{\dot{M}}{D \cdot A} X\right|_{0} ^{e}=\left.C\right|_{C s} ^{C a} \\
\dot{M}=-\frac{D \cdot A \cdot(C a-C s)}{e}
\end{gathered}
$$

Voltando ao conceito de descarga temos que:

$$
\begin{gathered}
M=\rho \cdot \text { Vol } \\
M=\left(\frac{\rho \cdot \pi \cdot d^{2}}{4}\right) H
\end{gathered}
$$




$$
\dot{M}=\frac{d M}{d t}=\frac{d\left(\frac{\rho \cdot \pi \cdot d^{2}}{4}\right) H}{d t}=\frac{\rho \cdot \pi \cdot d^{2}}{4} \cdot \frac{d H}{d t}
$$

Sendo:

$\mathrm{M}=$ Massa de gasolina;

$\rho=$ Massa específica;

$\mathrm{Vol}=$ Volume de gasolina .

Igualando-se a eq. 5.9 com a eq. 5.6 , temos:

$$
\frac{\rho \cdot \pi \cdot d^{2}}{4} \cdot \frac{d H}{d t}=-\frac{D \cdot A \cdot(C a-C s)}{e}
$$

As áreas devem ser canceladas, o sinal do lado esquerdo da eq. 5.9 deve ser corrigido devido a altura $\mathrm{H}$ estar diminuindo com o tempo e substituindo-se em e $=\mathrm{L}-\mathrm{H}$.

$$
\rho \cdot \frac{d H}{d t}=\frac{D \cdot(C a-C s)}{L-H}
$$

Rearranjando a eq. 5.11 a atribuindo-se os limites de integração:

$$
\rho \cdot L \int_{H i}^{H} d H-\rho \int_{H i}^{H} H \cdot D H=D \cdot(C a-C s) \int_{o}^{t} d t
$$

Substituindo-se em H por $\frac{M}{\rho \cdot \frac{\pi \cdot d^{2}}{4}}$, $\mathrm{H}_{\mathrm{i}}$ por $\frac{M_{i}}{\rho \cdot \frac{\pi \cdot d^{2}}{4}}$ e $\frac{D}{\rho}$ por K, temos:

$$
\frac{L \cdot M}{\rho \cdot \frac{\pi \cdot d^{2}}{4}}-\frac{1}{2} \cdot\left(\frac{M}{\rho \frac{\pi \cdot d^{2}}{4}}\right)^{2}=K \cdot t+\frac{L \cdot M_{i}}{\rho \cdot \frac{\pi \cdot d^{2}}{4}}-\frac{1}{2} \cdot\left(\frac{M_{i}}{\rho \frac{\pi \cdot d^{2}}{4}}\right)^{2}
$$

Apesar da eq. 5.13 ser uma equação de segunda ordem, adotou-se a forma de uma equação do $1^{\circ}$ grau do tipo $Y=K \cdot t+b$, e para que este modelo representasse bem o fenômeno os resultados deveriam tender há uma reta, porém pelo que se vê na Figura 5.13, os pontos azuis representam os valores de "Y-b" e os pontos vermelhos representam os valores de " $K \cdot t$ ", sendo que o valor de " $K$ " foi ajustado pelo método de mínimos 
quadrados. Percebesse-se então que o modelo não se ajusta bem aos resultados experimentais. Esta tentativa de ajuste só foi aplicada aos resultados da Proveta01, pois como se viu na Figura 5.11, um equacionamento que descreva este tipo de fenômeno deve ser representativo para todos os experimento similares.

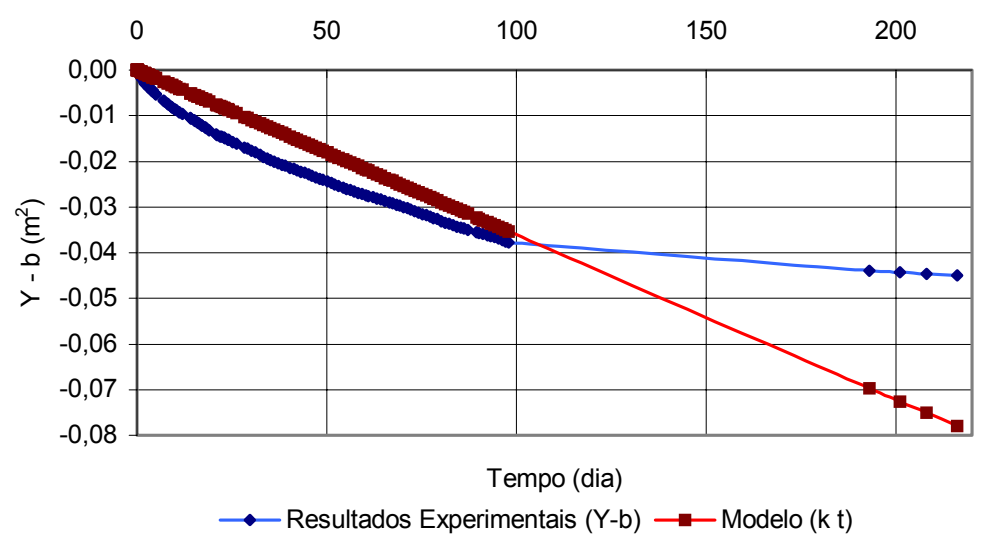

Figura 5. 13- Representação gráfica dos resultados experimentais para um ajuste linear.

Entretanto se considerarmos apenas os resultados obtidos até 100 dias o ajuste linear para a Proveta01, pode ser considerado satisfatório. Isso acontece porque em 100 dias aproximadamente $68 \%$ da massa inicial da Proveta01 foi volatilizada e pela observação dos demais experimentos a partir de $68 \%$ da massa volatilizada ocorre uma mudança na curvatura da linha de tendência do fenômeno que pode ser observado nas Figuras 5.7 e 5.11.

Outra tentativa de modelar o fenômeno de volatilização da gasolina foi mudar a hipótese inicial que afirma ser a concentração $C_{a}$ medida na superfície superior das provetas constante. Passou-se a considerar uma variação linear de $C_{a}$ com o tempo da forma $C_{a}=a_{0}+a_{1} \cdot t$. Substituindo-se na eq. 5.11 obtém-se:

$$
\frac{L \cdot M}{\rho \cdot \frac{\pi \cdot d^{2}}{4}}-\frac{1}{2} \cdot\left(\frac{M}{\rho \frac{\pi \cdot d^{2}}{4}}\right)^{2}=-D \cdot C_{s} \cdot t+D \cdot a_{0} \cdot t+\frac{D \cdot a_{1} \cdot t^{2}}{2}+\frac{L \cdot M_{i}}{\rho \cdot \frac{\pi \cdot d^{2}}{4}}-\frac{1}{2} \cdot\left(\frac{M_{i}}{\rho \frac{\pi \cdot d^{2}}{4}}\right)^{2}
$$

Fazendo-se algumas simplificações temos: 


$$
\frac{L \cdot M}{\rho \cdot \frac{\pi \cdot d^{2}}{4}}-\frac{1}{2} \cdot\left(\frac{M}{\rho \frac{\pi \cdot d^{2}}{4}}\right)^{2}=K_{1}^{\prime} \cdot t+K_{2}^{\prime} \cdot t^{2}+\frac{L \cdot M_{i}}{\rho \cdot \frac{\pi \cdot d^{2}}{4}}-\frac{1}{2} \cdot\left(\frac{M_{i}}{\rho \frac{\pi \cdot d^{2}}{4}}\right)^{2}
$$

A equação obtida tem a forma de $Y=K_{1}^{\prime} \cdot t^{2}+K_{2}^{\prime} \cdot t+b$. Ajustou-se os valores de $K_{1}^{\prime}$ e $K_{2}^{\prime}$ pelo método de mínimos quadrados, sendo que os resultados podem ser visualizados na Figura 5.14, a qual compara os valores de Y-b com os valores de $K_{1}^{\prime} \cdot t^{2}+K_{2}^{\prime} \cdot t$.

Percebe-se que modelo ajustou-se bem aos valores iniciais, porém apresentou uma tendência crescente para os valores finais que na realidade não ocorre. Esta comparação também só foi aplicada a Proveta01, pois com foi dito anteriormente, qualquer modelo desenvolvido deve aplicar-se bem a qualquer um dos experimentos similares. Vale ressaltar que outras aproximações foram feitas imbutindo-se mais termos no valor de $C_{a}$, porém os resultados apresentavam pequenas variações na curvatura dos últimos valores passando a decrescer drasticamente.

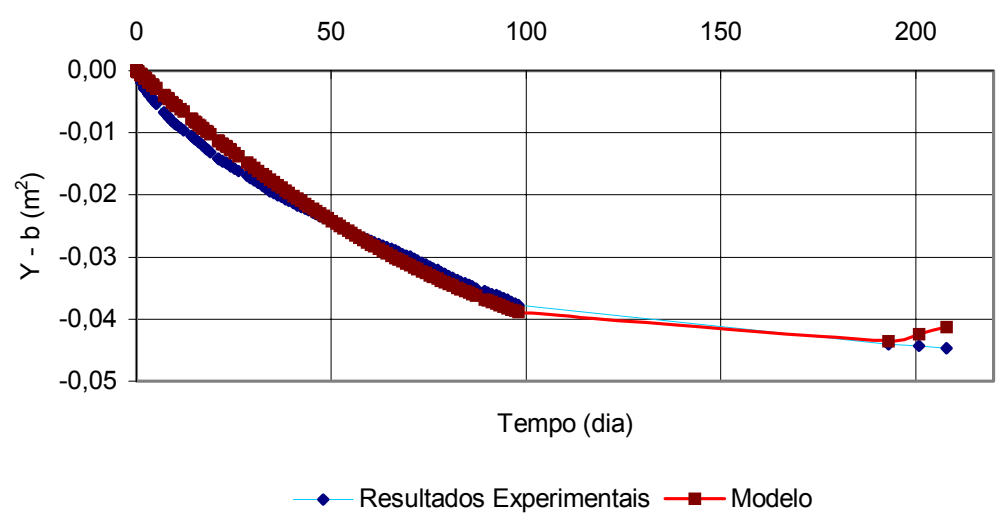

Figura 5. 14- Representação gráfica dos resultados experimentais comparados com um modelo com $C_{a}$ variável.

Como última tentativa para desenvolver-se um modelo a partir do equacionamento proposto e dos dados obtidos, utilizou-se as leituras realizadas com o detetor de fotoionização. Para isso era preciso encontrar uma equação para a variação da concentração medida em função do tempo. Adotou-se uma linha de tendência baseada em uma equação empírica da forma $C_{a}=\alpha \cdot t \cdot e^{-\beta \cdot t}+a-b \cdot t$, onde $C_{a}$ é a concentração medida na 
extremidade superior das provetas. A Figura 5.15 ilustra a representação gráfica dos resultados de concentração para a Proveta01 com o melhor ajuste da equação empírica proposta. Os coeficientes " $\alpha, \beta$, a e $b$ " foram ajustados pelo método dos mínimos quadrados.

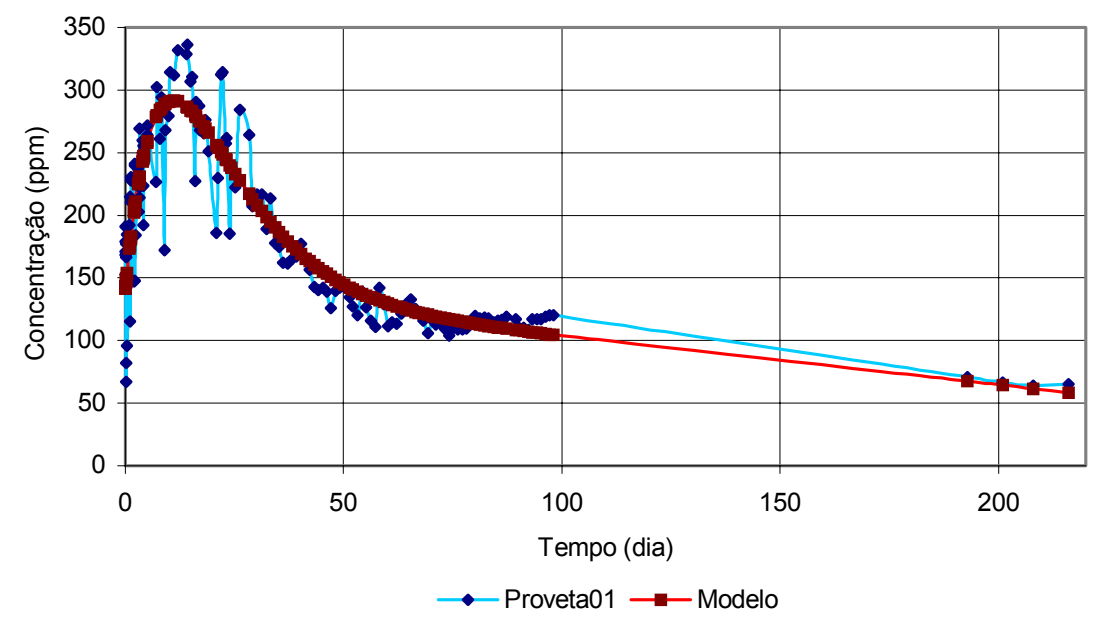

Figura 5. 15- Representação gráfica dos resultados de concentração (para a Proveta01 com 500ml de gasolina) obtidos com o detetor comparados com o modelo empírico.

Em face dos resultados, esse modelo para $\mathrm{C}_{\mathrm{a}}$ foi adotado.

Considerando-se então $C_{a}=\alpha \cdot t \cdot e^{-\beta \cdot t}+a-b \cdot t$ e $K=\frac{D}{\rho}$ obtém-se:

$$
(L-H) d H=-K\left(C_{s}-\alpha \cdot t \cdot e^{-\beta \cdot t}-a+b \cdot t\right) d t
$$

Integrando encontra-se:

$\frac{L \cdot M}{\rho \cdot \frac{\pi \cdot d^{2}}{4}}-\frac{1}{2} \cdot\left(\frac{M}{\rho \frac{\pi \cdot d^{2}}{4}}\right)^{2}-\frac{L \cdot M_{i}}{\rho \cdot \frac{\pi \cdot d^{2}}{4}}+\frac{1}{2} \cdot\left(\frac{M_{i}}{\rho \frac{\pi \cdot d^{2}}{4}}\right)^{2}=-K\left(C_{S} \cdot t+\frac{\alpha}{\beta^{2}} e^{-\beta \cdot t}+\frac{\alpha \cdot t}{\beta} e^{-\beta \cdot t}-\frac{\alpha}{\beta^{2}}-a \cdot t+\frac{b \cdot t^{2}}{2}\right)^{5.17}$

Baseando-se na eq. 5.17 encontrada, calculou-se o lado esquerdo da equação aplicando-se os valores de massa encontrados experimentalmente; em seguida calculou-se o lado direito da equação aplicando-se também os valores dos tempos correspondentes e as

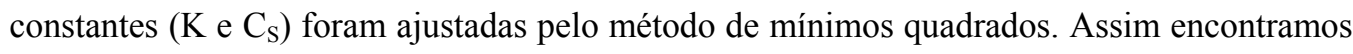
como resultado a representação gráfica que é apresentada na Figura 5.16, na qual "Y-Y, representa o lado esquerdo da equação enquanto o lado direito foi chamado de "modelo". 


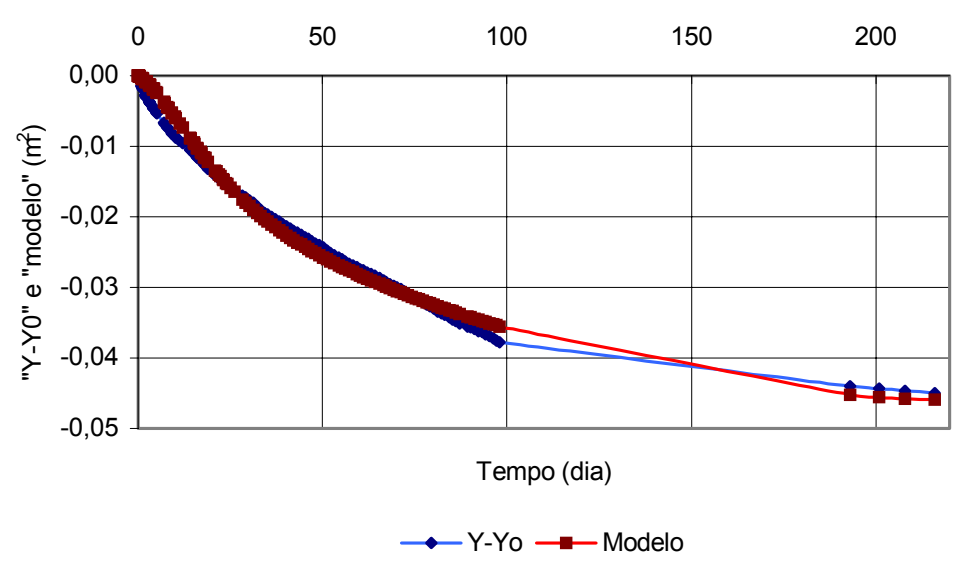

Figura 5. 16- Representação gráfica dos resultados obtidos comparando-se os dois lados da equação proposta.

Pelos resultados obtidos percebe-se que o equacionamento proposto ajustou-se bem aos resultados experimentais da Proveta01 e com isso partiu-se para a aplicação para as demais provetas com características semelhantes.

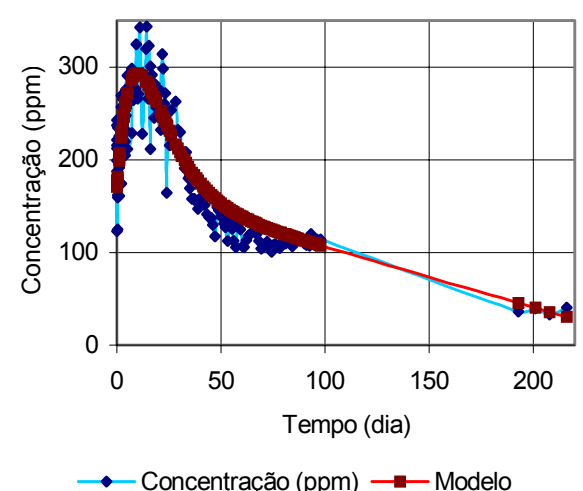

a

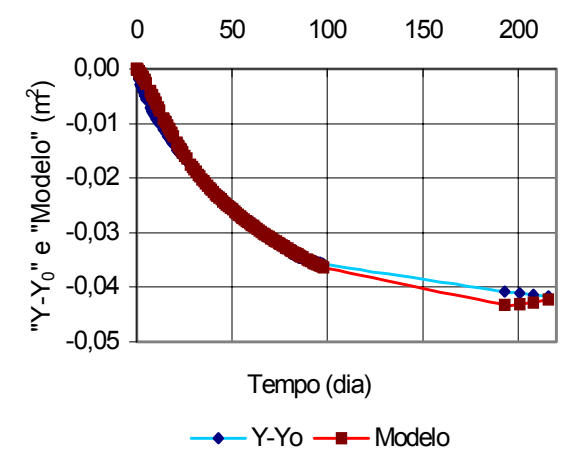

b

Figura 5. 17- Representação gráfica dos resultados para a Proveta02 (a e b). 

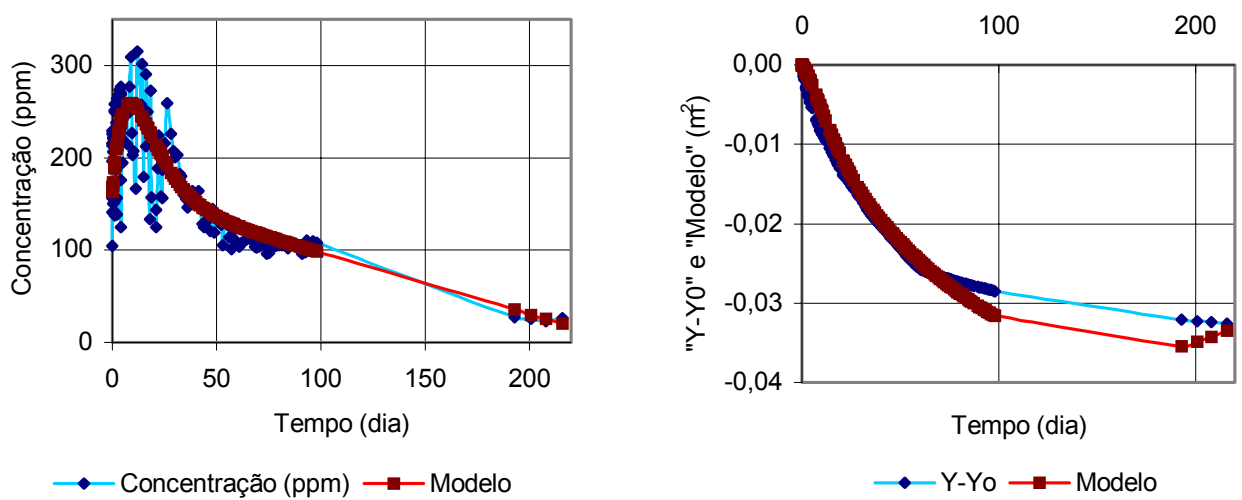

a

$\mathrm{b}$

Figura 5. 18 - Representação gráfica dos resultados para a Proveta03 (a e b).
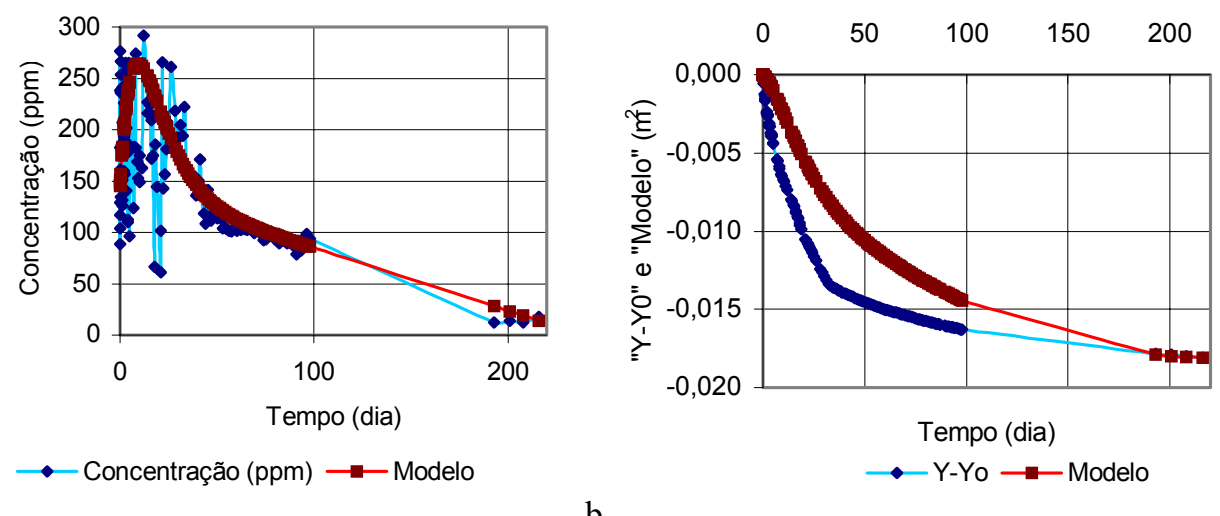

a

b

Figura 5. 19 - Representação gráfica dos resultados para a Proveta04 (a e b).

Os resultados apresentados nas Figuras 5.17 (a e b), 5.18 (a e b) e 5.19 (a e b), mostram bom ajuste para as provetas 01 e 02 . Para as provetas 03 e 04 os resultados não foram tão bons, ou seja, à medida que se reduz a quantidade de gasolina utilizada o modelo apresentou uma performance pior. Isso pode ser justificado pelas limitações do detetor de fotoionização utilizado. O aparelho mede apenas uma determinada gama de substâncias presentes na gasolina, aquelas substâncias que pertencem ao grupo das mais voláteis. Nos primeiros momentos os resultados fornecidos seriam representativos e com o decorrer do tempo, como as substâncias mais voláteis já estariam próximas de se esgotar, as leituras realizadas deixaram de ser representativas da massa volatilizada. Outros interferentes que não foram considerados no modelo se referem às condições ambientais como: temperatura, umidade, ventos, etc. Segundo SCHWARZENBACH et al. (1993), a transferência de 
produto para a fase de vapor é regida pela pressão de vapor do produto e quanto maior a pressão de vapor, mais volátil será a substância e maior será sua concentração na fase de vapor. Assim sendo, como a temperatura está diretamente ligada à pressão de vapor, estaria também influindo no fenômeno. Outra informação que pode ser observada nessas figuras é que desde o início dos experimentos até aproximadamente 30 dias os resultados obtidos apresentam características turbulentas e com isso se torna difícil traçar uma tendência realmente representativa para este período de experimento. Apesar de serem seguidos todos os passo descritos na metodologia, erros sistemáticos ou aleatórios podem ter ocorrido ao longo da fase experimental. Finalmente, o equacionamento proposto é quase-permanente, que também pode ocasionar desvios.

\subsection{Ensaios de Difusão em Solo Não Saturado}

Como dito anteriormente, abordou-se nesta seção de resultados a mesma ordenação anterior, assim primeiro são apresentados os resultados dos ensaios de difusão em solo não saturado em pequena escala e seus referidos comentários e em seguida, para encerrar, são apresentados os resultados dos ensaios de difusão em solo não saturado em escala maior.

\subsubsection{Ensaios de Difusão em Solo Não Saturado em Provetas}

Esta fase de ensaios foi realizada com a finalidade de compreender as respostas do detetor de fotoionização para casos de contaminação do solo por gasolina e também avaliar os princípio básicos do processo de difusão. Como já mencionado, foram realizadas leituras com o detetor de fotoionização concomitantemente com as leituras realizadas com balança analítica, iniciando este tópico com os resultados do experimento utilizando cinco provetas, os quais podem ser visualizados na Tabela 5.5. 
Tabela 5.5 - Valores de massa, concentração e temperatura medidos ao longo do tempo para o experimento com cinco provetas.

\begin{tabular}{|c|c|c|c|c|c|c|c|c|c|c|c|c|c|c|c|}
\hline \multicolumn{3}{|c|}{ Proveta 01 (50 $\mathrm{ml}$ de solo $)$} & \multicolumn{3}{|c|}{ Proveta $02(60 \mathrm{ml}$ de solo $)$} & \multicolumn{3}{|c|}{ Proveta $03(70 \mathrm{ml}$ de solo $)$} & \multicolumn{3}{|c|}{ Proveta $04(80 \mathrm{ml}$ de solo $)$} & \multicolumn{3}{|c|}{ Proveta $05(90 \mathrm{ml}$ de solo $)$} & \multirow{2}{*}{$\begin{array}{c}\text { Tem- } \\
\text { pera- } \\
\text { tura } \\
\left({ }^{0} \mathrm{C}\right)\end{array}$} \\
\hline $\begin{array}{l}\text { Tempo } \\
\text { (dias) }\end{array}$ & $\begin{array}{c}\text { Massa } \\
\text { (gramas) }\end{array}$ & $\begin{array}{c}\text { Concen- } \\
\text { tração } \\
\text { (ppm) }\end{array}$ & $\begin{array}{c}\text { Tempo } \\
\text { (dias) }\end{array}$ & $\begin{array}{c}\text { Massa } \\
\text { (gramas) }\end{array}$ & $\begin{array}{c}\text { Concen- } \\
\text { tração } \\
(\mathrm{ppm})\end{array}$ & $\begin{array}{c}\text { Tempo } \\
\text { (dias) }\end{array}$ & $\begin{array}{c}\text { Massa } \\
\text { (gramas) }\end{array}$ & $\begin{array}{c}\text { Concen- } \\
\text { tração } \\
(\mathrm{ppm})\end{array}$ & $\begin{array}{c}\text { Tempo } \\
\text { (dias) }\end{array}$ & $\begin{array}{c}\text { Massa } \\
\text { (gramas) }\end{array}$ & $\begin{array}{c}\text { Concen- } \\
\text { tração } \\
(\mathrm{ppm})\end{array}$ & $\begin{array}{c}\text { Tempo } \\
\text { (dias) }\end{array}$ & $\begin{array}{c}\text { Massa } \\
\text { (gramas) }\end{array}$ & $\begin{array}{c}\text { Concen- } \\
\text { tração } \\
\text { (ppm) }\end{array}$ & \\
\hline 0,000 & 19,42 & 224,9 & 000 & 9,19 & 109,7 & 0,000 & 21,59 & 135,5 & 0,000 & 19,97 & 253,7 & 0,000 & 19,95 & 251 & 28,0 \\
\hline 1,042 & 18,14 & 222,2 & 1,044 & 17,64 & 198,5 & 1,050 & 20,16 & 208,2 & 1,052 & 18,29 & 226,0 & 1,055 & 17,79 & 220,9 & 26,0 \\
\hline 1,994 & 17,16 & 268,6 & 1,998 & 16,56 & 247,9 & 2,000 & 19,18 & 283,1 & 2,002 & 17,12 & 295,5 & 2,004 & 16,34 & 263,6 & 27,0 \\
\hline 4,982 & 14,81 & 234,7 & 4,988 & 13,97 & 240,3 & 4,989 & 16,76 & 240,4 & 4,994 & 14,45 & 232,4 & 4,994 & 13,24 & 215,7 & 25,5 \\
\hline 6,007 & 14,07 & 223,0 & 6,008 & 13,20 & 225,6 & 6,010 & 16,02 & 233,0 & 6,016 & 13,67 & 225,5 & 6,017 & 12,35 & 209,3 & 28,0 \\
\hline 6,989 & 13,30 & 212,6 & 6,990 & 12,40 & 212,9 & 6,994 & 15,26 & 222,4 & 7,000 & 12,88 & 218,7 & 7,007 & 11,48 & 194,2 & 31,5 \\
\hline 8,144 & 12,42 & 201,4 & 8,146 & 11,50 & 202,5 & 8,146 & 14,40 & 207,9 & 8,148 & 11,99 & 192,4 & 8,152 & 10,56 & 170,7 & 29,0 \\
\hline 9,021 & 11,81 & 219,4 & 9,024 & 10,86 & 218,9 & 9,026 & 13,78 & 223,4 & 9,030 & & 215,6 & 9,032 & 9,96 & & 30,0 \\
\hline 10,038 & 11,21 & 187,3 & 10,043 & 10,24 & 187,5 & 10,044 & 13,18 & 190,5 & 10,055 & 10,75 & 168,5 & 10,057 & 9,42 & 161,9 & 26,5 \\
\hline 10,982 & 10,78 & 167,8 & 10,985 & 9,81 & 175,2 & 10,989 & 12,75 & 179,1 & 10,991 & 10,35 & 171,3 & 10,992 & 9,05 & 165,5 & 27,0 \\
\hline 11,972 & 10,35 & 170,8 & 11,975 & 9,36 & 165,5 & 11,985 & 12,31 & 173,0 & 11,986 & 9,97 & 160,8 & 11,993 & 8,71 & 155,0 & 27,0 \\
\hline 12,965 & 9,94 & 155,7 & 12,968 & 8,93 & 161,8 & 12,972 & 11,89 & 167,5 & 12,977 & 9,59 & 142,6 & 12,983 & 8,44 & 152,2 & 25,5 \\
\hline 14,872 & 9,19 & 153,8 & 14,878 & 8,18 & 155,2 & 14,878 & 11,11 & 157,1 & 14,883 & 8,96 & 152,92 & 14,884 & 8,04 & 127,6 & 26,0 \\
\hline
\end{tabular}


Seguindo-se, são apresentadas as figuras das representações gráficas dos resultados da Tabela 5.5.

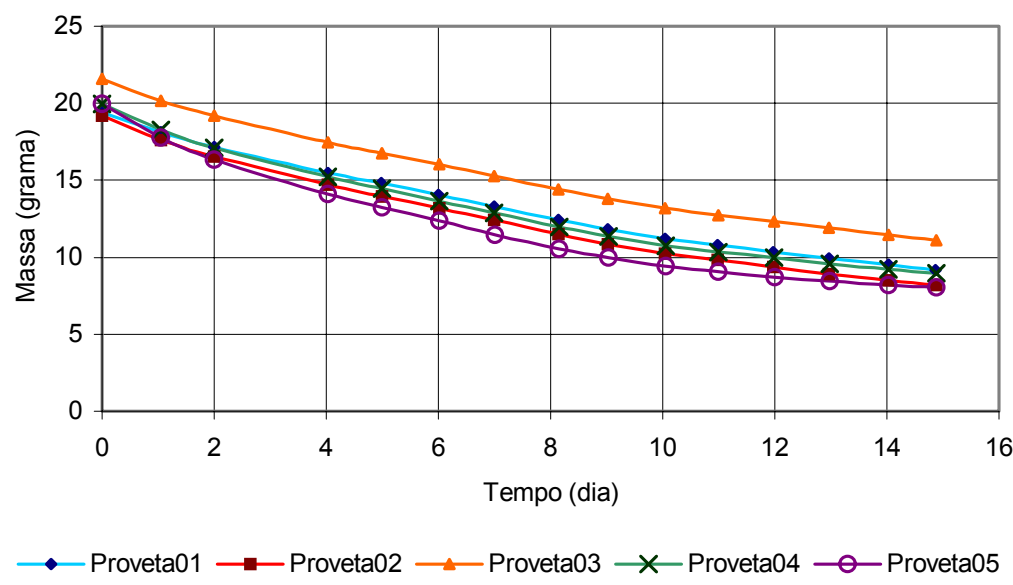

Figura 5. 20- Representação gráfica dos resultados de massa em função do tempo.

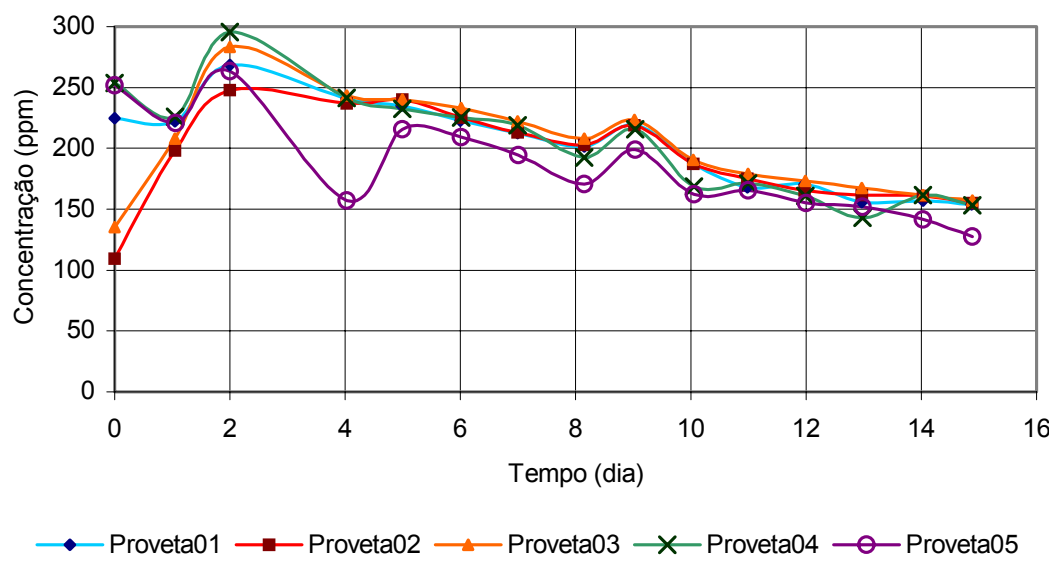

Figura 5. 21- Representação gráfica dos resultados de concentração em função do tempo. 


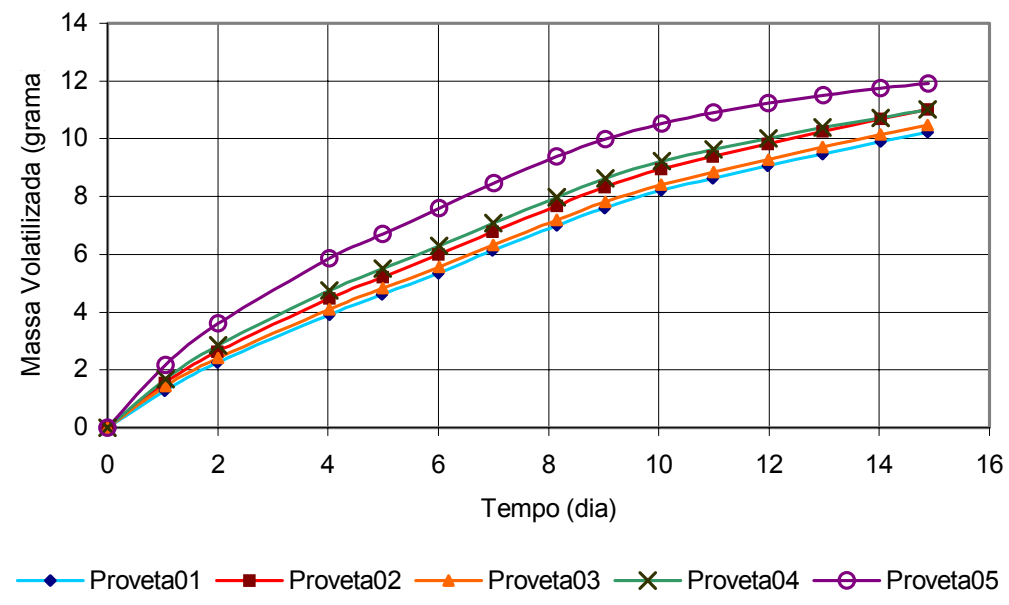

Figura 5. 22- Representação gráfica da massa volatilizada em função do tempo.

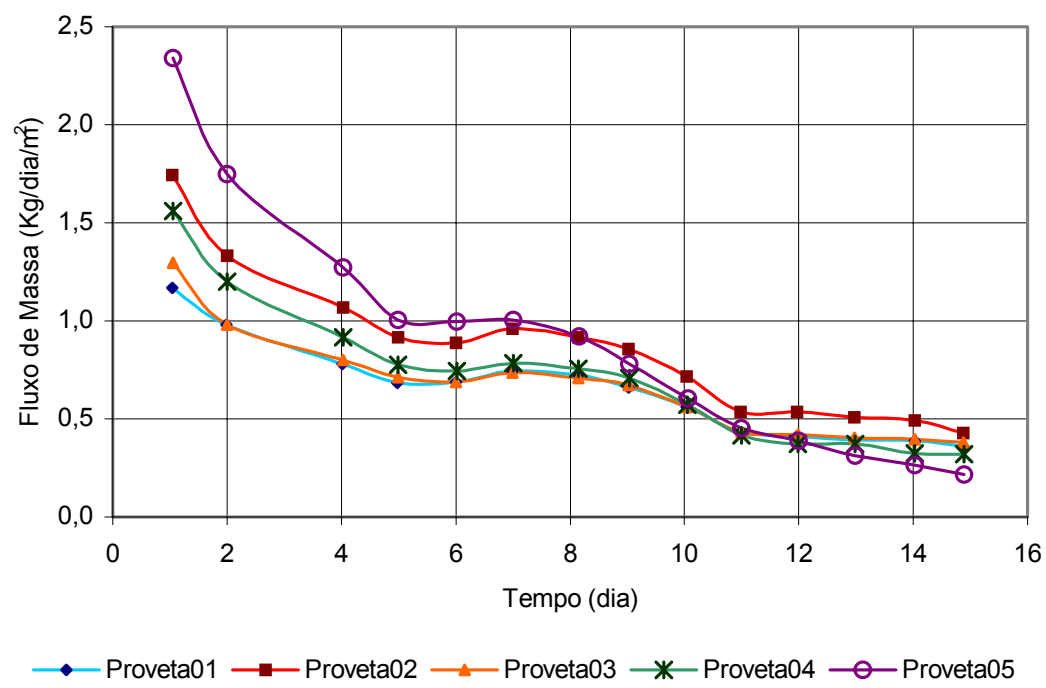

Figura 5. 23- Representação gráfica dos resultados de fluxo de massa em função do tempo.

Pelos resultados apresentados acima percebe-se a heterogeneidade entre as provetas utilizadas no experimento. Pela Figura 5.20 percebe-se que houve uma adição de gasolina ligeiramente superior na Proveta03, o que prejudica a comparação direta entre as diversas 
provetas. Na Figura 5.21 observa-se que as camadas de solo adicionadas às provetas 2, 3, $4 \mathrm{e}$ 5 não apresentaram-se como obstáculo no retardamento do processo de volatilização. $\mathrm{Na}$ Figura 5.22 constata-se que a proveta que apresentou a maior perda de massa foi a Proveta05 sendo que a mesma possuía a maior camada de recobrimento porém com maior gradiente de concentração, isto é, menor distância entre a superfície saturada por gasolina e a extremidade superior da proveta. Pela Figura 5.23 conclui-se que inicialmente, apesar da Proveta03 apresentar maior quantidade de massa, a Proveta05 apresentou um maior fluxo de massa, comprovando que a massa volatilizada é proporcional a área de contato gasolina-ar e ao gradiente de concentração.

Como dito no item 4.4.1, devido às dificuldades encontradas neste experimento, realizou-se um outro no qual buscou-se minimizar as discrepâncias, assim utilizou-se apenas duas provetas semelhantes. A Tabela 5.6 apresenta os resultados obtidos.

Tabela 5.6 - Valores de massa, concentração e temperatura medidos ao longo do tempo para o experimento com duas provetas com solo.

\begin{tabular}{ccccccc}
\hline \multicolumn{2}{c}{ Proveta $01(50 \mathrm{ml}$ de solo) } & \multicolumn{2}{c}{ Proveta $02(250 \mathrm{ml}$ de solo) } & Temperatura \\
\cline { 1 - 5 } Tempo & Massa & Concentra- & Tempo & Massa & Concentra- & ( ${ }^{0}$ C) \\
(dias) & (gramas) & ção $(\mathrm{ppm})$ & (dias) & (gramas) & ção (ppm) & \\
\hline 0,000 & 19,08 & 174,2 & 0,000 & 19,12 & 16,7 & 27,0 \\
0,128 & 18,87 & 174,2 & 0,130 & 19,11 & 16,7 & 26,5 \\
1,082 & 18,00 & 181,3 & 1,072 & 19,07 & 137,1 & 28,0 \\
2,152 & 17,15 & 175,9 & 2,153 & 18,84 & 183,8 & 25,5 \\
2,995 & 16,57 & 161,0 & 2,993 & 18,69 & 183,4 & 26,0 \\
4,058 & 15,85 & 139,8 & 4,052 & 18,47 & 158,9 & 24,5 \\
4,983 & 15,28 & 141,8 & 4,981 & 18,26 & 156,2 & 25,5 \\
6,023 & 14,58 & 143,8 & 6,018 & 17,98 & 138,9 & 27,0 \\
6,909 & 14,00 & 136,7 & 6,905 & 17,72 & 134,8 & 27,0 \\
7,890 & 13,38 & 129,3 & 7,889 & 17,41 & 131,7 & 27,0 \\
8,945 & 12,78 & 150,4 & 8,943 & 17,09 & 133,0 & 26,0 \\
9,860 & 12,30 & 130,5 & 9,856 & 16,83 & 121,3 & 25,0 \\
10,937 & 11,76 & 139,9 & 10,935 & 16,53 & 131,0 & 27,0 \\
12,115 & 11,12 & 135,3 & 12,113 & 16,16 & 125,6 & 29,0 \\
12,968 & 10,69 & 129,4 & 12,964 & 15,91 & 118,1 & 27,0 \\
13,999 & 10,26 & 109,5 & 13,996 & 15,69 & 104,3 & 26,5 \\
15,131 & 9,82 & 122,4 & 15,128 & 15,45 & 111,6 & 25,0 \\
16,010 & 9,50 & 121,8 & 16,008 & 15,25 & 110,3 & 27,0 \\
16,985 & 9,12 & 110,8 & 16,983 & 15,01 & 113,6 & 28,5 \\
17,948 & 8,73 & 105,8 & 17,946 & 14,79 & 106,6 & 27,0 \\
19,006 & 8,46 & 107,2 & 19,004 & 14,62 & 100,7 & 22,0 \\
20,025 & 8,22 & 117,7 & 20,024 & 14,48 & 106,0 & 25,0 \\
21,064 & 7,95 & 104,0 & 21,060 & 14,32 & 101,3 & 24,0 \\
21,824 & 7,79 & 107,7 & 21,822 & 14,22 & 102,0 & 24,0
\end{tabular}




\begin{tabular}{|c|c|c|c|c|c|c|}
\hline \multicolumn{3}{|c|}{ Proveta 01 (50 $\mathrm{ml}$ de solo $)$} & \multicolumn{3}{|c|}{ Proveta $02(250 \mathrm{ml}$ de solo $)$} & \multirow[b]{2}{*}{$\begin{array}{c}\text { Temperatura } \\
\left({ }^{0} \mathrm{C}\right)\end{array}$} \\
\hline $\begin{array}{l}\text { Tempo } \\
\text { (dias) }\end{array}$ & $\begin{array}{c}\text { Massa } \\
\text { (gramas) }\end{array}$ & $\begin{array}{l}\text { Concentra- } \\
\text { ção (ppm) }\end{array}$ & $\begin{array}{l}\text { Tempo } \\
\text { (dias) }\end{array}$ & $\begin{array}{c}\text { Massa } \\
\text { (gramas) }\end{array}$ & $\begin{array}{l}\text { Concentra- } \\
\text { ção (ppm) }\end{array}$ & \\
\hline 22,959 & 7,58 & 109,5 & 22,957 & 14,07 & 102,7 & 24,0 \\
\hline 23,957 & 7,37 & 125,3 & 23,956 & 13,89 & 105,8 & 25,0 \\
\hline 25,053 & 7,25 & 119,6 & 25,053 & 13,70 & 113,4 & 25,0 \\
\hline 26,188 & 7,11 & 115,4 & 26,188 & 13,53 & 102,8 & 25,5 \\
\hline 27,279 & 6,98 & 115,2 & 27,279 & 13,30 & 107,1 & 25,0 \\
\hline 28,054 & 6,90 & 114,5 & 28,054 & 13,17 & 106,5 & 27,5 \\
\hline 29,120 & 6,78 & 116,9 & 29,116 & 12,97 & 107,5 & 26,5 \\
\hline 30,086 & 6,71 & 113,2 & 30,080 & 12,85 & 100,5 & 25,0 \\
\hline 30,996 & 6,64 & 105,7 & 30,993 & 12,7 & 100,3 & 27,0 \\
\hline 31,989 & 6,56 & 113,4 & 31,981 & 12,54 & 100,6 & 28,0 \\
\hline 32,975 & 6,48 & 108,9 & 32,957 & 12,35 & 98,6 & 28,0 \\
\hline 34,048 & 6,37 & 106,8 & 34,044 & 12,14 & 96,6 & 29,0 \\
\hline 34,999 & 6,29 & 109,3 & 34,994 & 12,00 & 88,3 & 28,0 \\
\hline 36,054 & 6,22 & 109,5 & 36,052 & 11,86 & 96,3 & 29,0 \\
\hline 36,961 & 6,15 & 110,7 & 36,960 & 11,69 & 96,4 & 28,5 \\
\hline 37,970 & 6,08 & 107,8 & 37,968 & 11,56 & 95,5 & 28,5 \\
\hline 38,984 & 6,01 & 106,5 & 38,983 & 11,44 & 95,3 & 29,0 \\
\hline 39,876 & 5,97 & 106,5 & 39,873 & 11,36 & 84,7 & 27,0 \\
\hline 40,991 & 5,90 & 110,3 & 40,990 & 11,23 & 92,5 & 30,0 \\
\hline 41,994 & 5,84 & 109,9 & 41,993 & 11,12 & 88,2 & 29,0 \\
\hline 43,073 & 5,82 & 103,7 & 43,070 & 11,08 & 88,1 & 26,0 \\
\hline 44,004 & 5,78 & 103,3 & 44,003 & 11,03 & 82,4 & 28,0 \\
\hline 45,107 & 5,74 & 104,3 & 45,106 & 10,95 & 74,7 & 27,0 \\
\hline 46,074 & 5,70 & 106,4 & 46,074 & 10,90 & 70,6 & 28,0 \\
\hline 46,963 & 5,68 & 95,1 & 46,961 & 10,87 & 72,8 & 27,5 \\
\hline 48,159 & 5,63 & 96,9 & 48,157 & 10,79 & 76,0 & 27,5 \\
\hline 50,192 & 5,60 & 77,9 & 50,191 & 10,74 & 67,6 & 24,0 \\
\hline 50,980 & 5,58 & 71,6 & 50,979 & 10,72 & 64,1 & 24,5 \\
\hline 51,992 & 5,57 & 70,6 & 51,991 & 10,71 & 60,3 & 24,0 \\
\hline 53,141 & 5,57 & 60,9 & 53,139 & 10,71 & 60,4 & 25,0 \\
\hline 54,048 & 5,55 & 88,0 & 54,046 & 10,68 & 50,7 & 27,5 \\
\hline 55,014 & 5,49 & 79,6 & 55,012 & 10,59 & 66,6 & 28,5 \\
\hline 56,020 & 5,42 & 83,4 & 56,019 & 10,47 & 67,8 & 29,0 \\
\hline 57,016 & 5,36 & 80,7 & 57,015 & 10,38 & 73,9 & 29,0 \\
\hline 57,976 & 5,29 & 78,3 & 57,974 & 10,28 & 65,9 & 30,0 \\
\hline 58,818 & 5,25 & 77,3 & 58,817 & 10,23 & 75,6 & 29,0 \\
\hline 153,761 & 3,90 & 20,6 & 153,761 & 9,22 & 12,7 & 27,0 \\
\hline 161,741 & 3,83 & 14,1 & 161,743 & 9,18 & 14,5 & 24,5 \\
\hline 168,775 & 3,73 & 13,7 & 168,778 & 9,09 & 13,5 & 24,0 \\
\hline 176,842 & 3,55 & 19,6 & 176,847 & 8,89 & 19,4 & 25,0 \\
\hline
\end{tabular}

Para facilitar a visualização dos resultados, à seguir são apresentados os gráficos referente ao experimento com duas provetas com solo. 


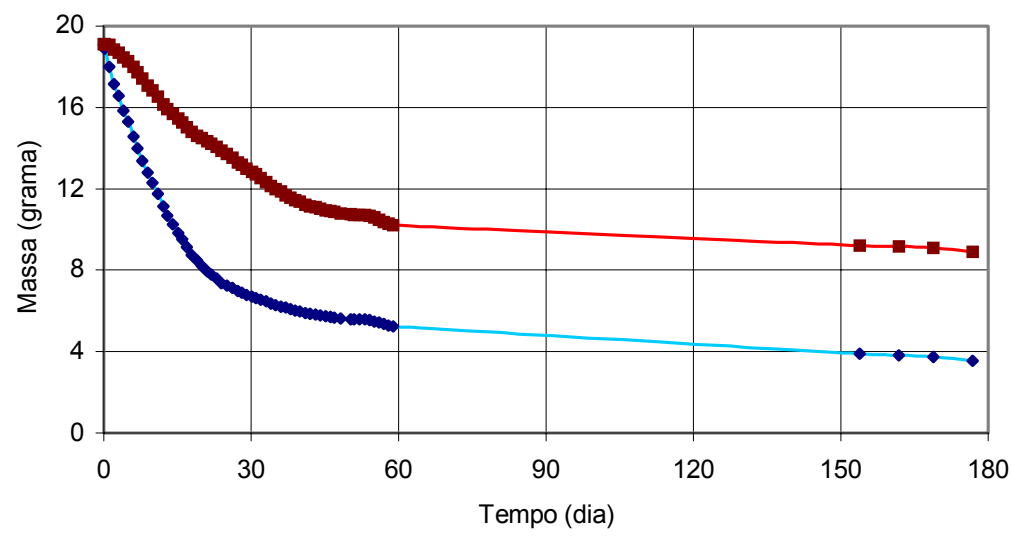

$\longrightarrow$ Proveta sem Recobrimento $\rightarrow$ Proveta com Recobrimento

Figura 5. 24- Representação gráfica dos resultados de massa em função do tempo.

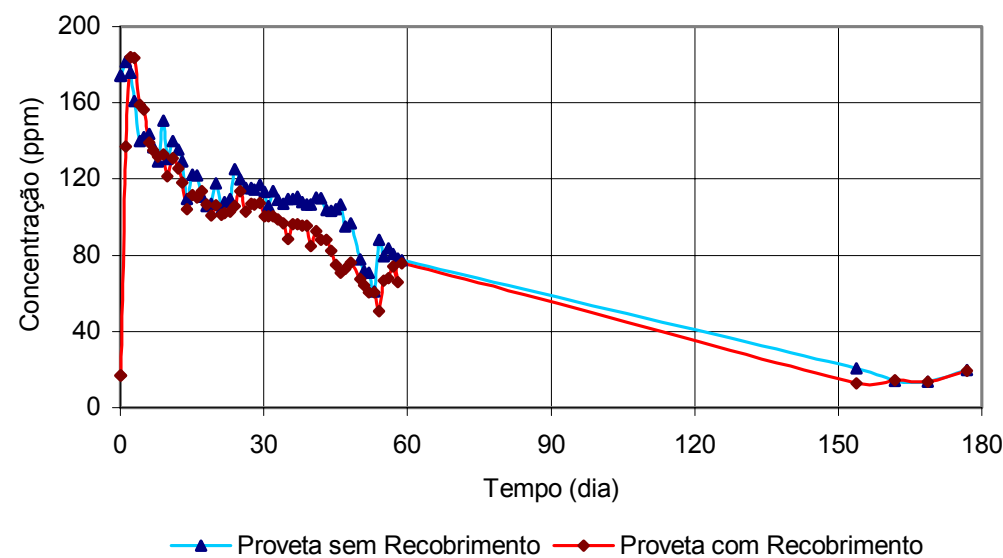

Figura 5. 25- Representação gráfica dos resultados de concentração em função do tempo. 


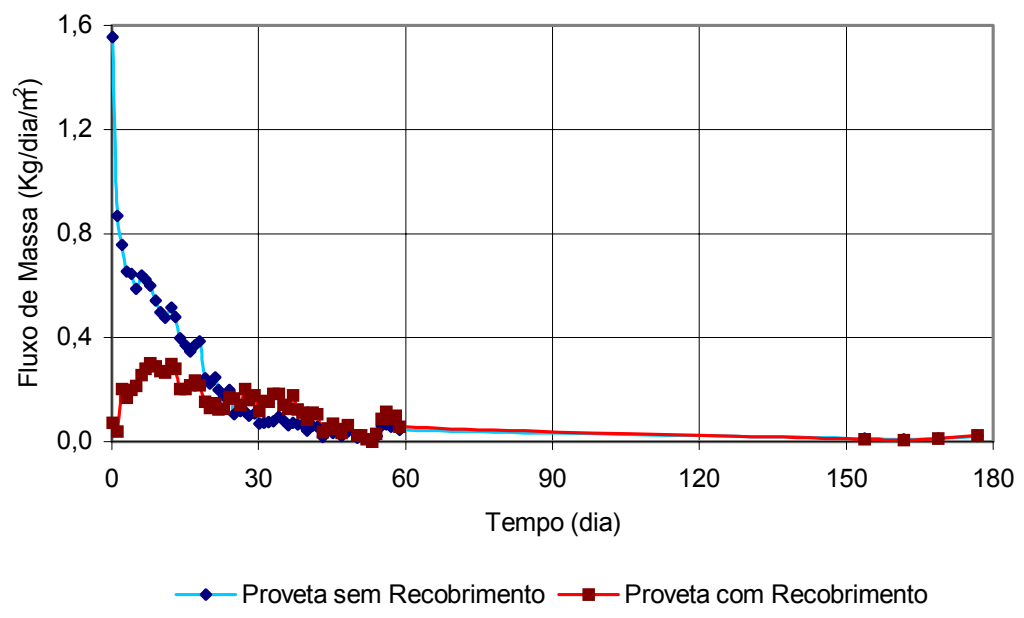

Figura 5. 26- Representação gráfica de fluxo de massa em função do tempo.

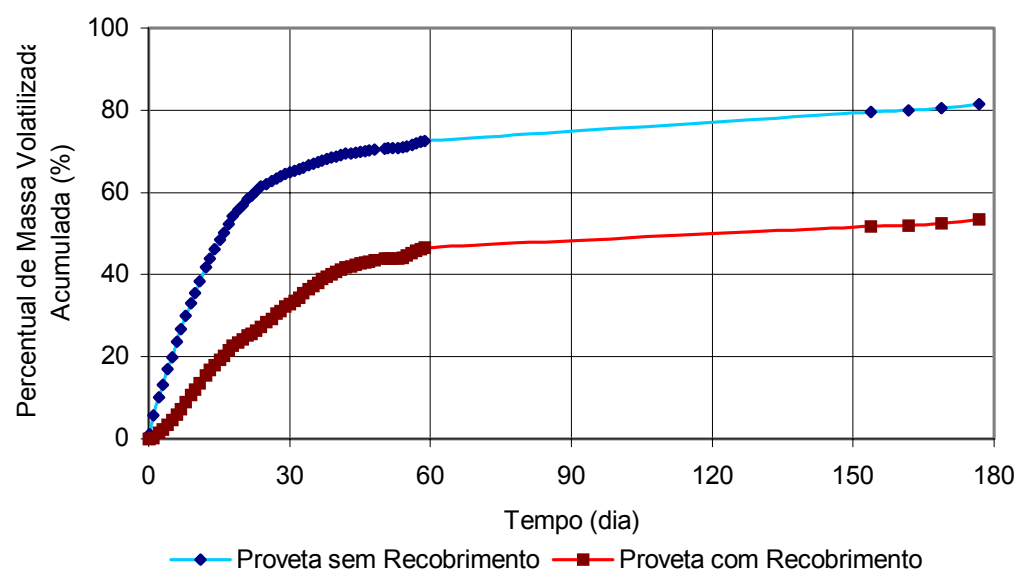

Figura 5. 27- Representação gráfica do percentual de massa acumulada volatilizada em função do tempo.

Pelas Figuras 5.24 e 5.27 percebe-se que a camada de solo adicionada acima da camada contaminada na Proveta02 funcionou como um "filtro" diminuindo os valores de massa volatilizada. Também é perceptível a mudança nas inclinações das curvas para as duas provetas. Para a Proveta01 a mudança ocorre em um tempo superior a 22 dias quando mais de $60 \%$ da massa inicial havia sido volatilizada e para a Proveta02 ocorre mais discretamente em um tempo superior a 58 dias quando mais de $46 \%$ da massa inicial havia sido volatilizada. Verificando-se a Figura 5.25 visualiza-se que mais uma vez a camada de recobrimento de solo adicionada à Proveta02 "filtrou" os resultados iniciais e somente a 
partir do segundo dia os valores das provetas 01 e 02 se equipararam, permanecendo assim até as últimas leituras realizadas. Na Figura 5.26 verifica-se ainda mais facilmente a influência da camada de recobrimento de solo adicionada à Proveta02. Para a Proveta01 o maior fluxo de massa verifica-se nos primeiros momentos do experimento com um decréscimo semelhante a uma exponencial; já para a Proveta02 o maior valor de fluxo de massa verificou-se após decorridos 7 dias do início do experimento, sendo que para as duas provetas os últimos resultados oscilam em valores próximos.

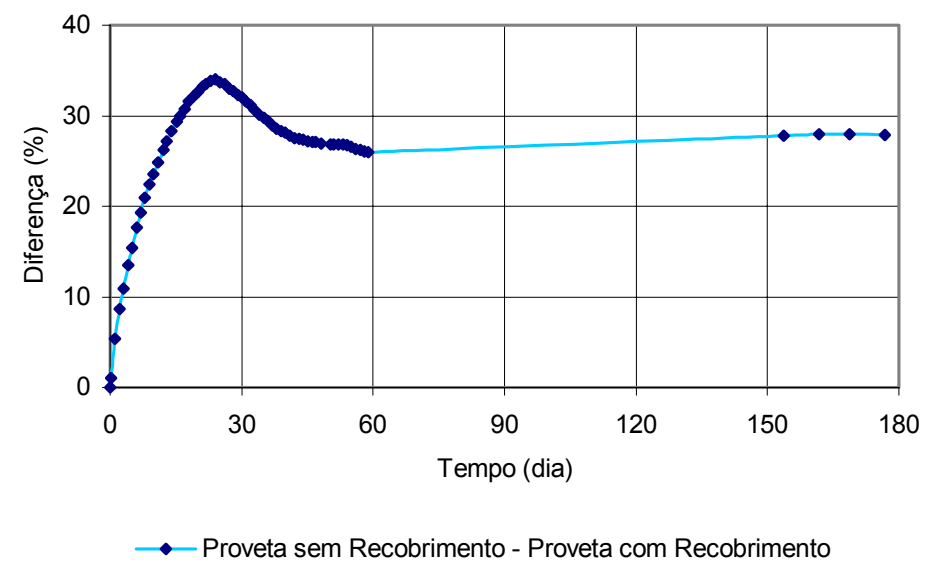

Figura 5. 28- Diferença entre os percentuais de massas volatilizadas para as Provetas 01 e 02.

Nota-se pela Figura 5.28 que após aproximadamente 60 dias, a diferença entre os percentuais das massas volatilizadas na Proveta01 sem recobrimento e Proveta02 com recobrimento manteve-se constante, no valor de aproximadamente $30 \%$ da massa inicial. Essa diferença corresponde à massa retida ou retardada pelo solo contido na Proveta02.

Um fato interessante pode ser observado na Figura 5.25, quando levados em conta os resultados da Figura 5.28. Embora tenha havido uma retenção significativa de massa na coluna de solo, a concentração medida com o detetor de fotoionização produziu resultados muito próximos, com ou sem coluna de recobrimento.

Outro fator relevante é que, mesmo após 180 dias, a concentração medida mostra um meio alterado (concentração em torno de 20ppm).

$\mathrm{Na}$ tentativa de desenvolver-se um modelo simples e de fácil aplicação para representar o fenômeno, seguiu-se os procedimentos tomados no experimento com quatro provetas e gasolina. Naquele caso partiu-se para aplicação de um equacionamento representativo para os resultados de concentração obtidos, em seguida com os demais resultados e com as informações anteriormente obtidas aplica-se a $1^{\text {a }}$ Lei de Fick. Para 
facilitar a compreensão do equacionamento proposto foi desenvolvida a Figura 5.29 com a finalidade de ilustrar o fenômeno.

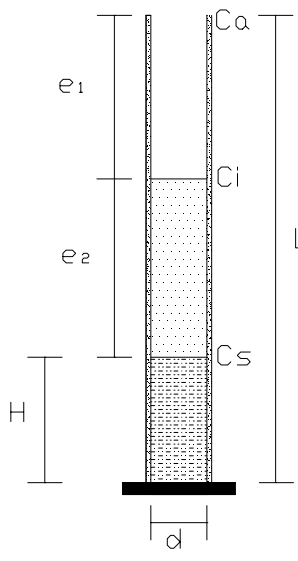

Figura 5. 29- Ilustração dos experimentos utilizando solo contaminado por gasolina em provetas de $250 \mathrm{ml}$. Vale ressaltar que para a Proveta01, no primeiro momento, a distância " $e_{2}$ " não existe.

Como dito anteriormente a Figura 5.25 representa os resultados de concentração obtidos com fotoionizador para as provetas 01 e 02 , sendo que foram aplicados aos resultados de cada proveta ajustes da forma $Y=\alpha \cdot \exp (-\beta \cdot t)$ calculando-se os melhores valores de " $\alpha$ " e " $\beta$ " pelo método dos mínimos quadrados para as mesmas. 


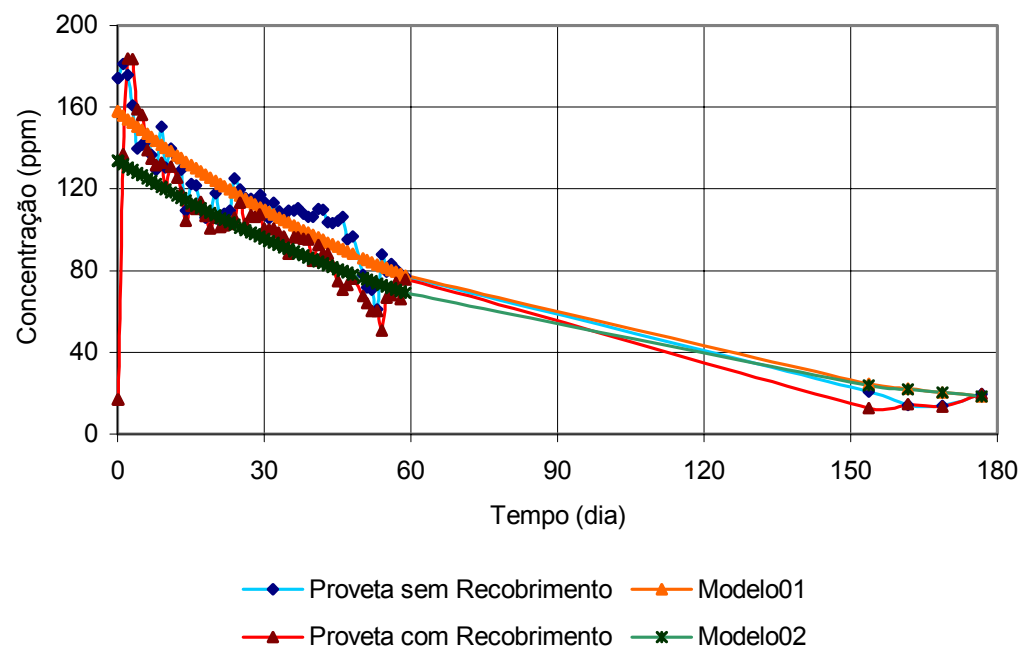

Figura 5. 30- Ajuste de modelo exponencial aos resultados de concentração obtidos com fotoionizador.

Como para as duas provetas contendo solo, a gasolina volatiliza e a camada de solo mantém-se constante, encontrou-se um novo resultado para a descarga de massa:

$$
\dot{M}=\frac{1}{\left(\frac{e_{1}}{D_{1}}+\frac{e_{2}}{D_{2}}\right)} \cdot A \cdot\left(C_{a}-C_{s}\right)
$$

Considerando-se:

$$
C_{a}=\alpha \cdot \exp (-\beta \cdot t)
$$

Tem-se:

$$
\rho \cdot \frac{\pi \cdot d^{2}}{4} \cdot \frac{d H}{d t}=\frac{1}{\left(\frac{e_{1}}{D_{1}}+\frac{e_{2}}{D_{2}}\right)} \cdot A \cdot\left(C_{a}-C_{s}\right)
$$

Para finalizar encontra-se: 
$\rho \cdot\left(\frac{e_{1}}{D_{1}}\right) \cdot\left(L-e_{1}-\frac{M}{\frac{\rho \cdot \pi \cdot d^{2} \cdot \eta}{4}}\right)+\frac{\rho \cdot\left(L-e_{1}-\frac{M}{\frac{\rho \cdot \pi \cdot d^{2} \cdot \eta}{4}}\right)^{2}}{2 \cdot D_{2}}=\frac{\alpha}{\beta} \cdot e^{-\beta \cdot t}-\frac{\alpha}{\beta}+C_{s} \cdot t \quad 5.21$

Onde:

$\eta=$ porosidade.

Ajustando-se os valores de $D_{1}, D_{2}, \eta$ e $C_{s}$ pelo método dos mínimos quadrados e comparando-se os lados direito e esquerdo da eq. 5.21 tem-se:

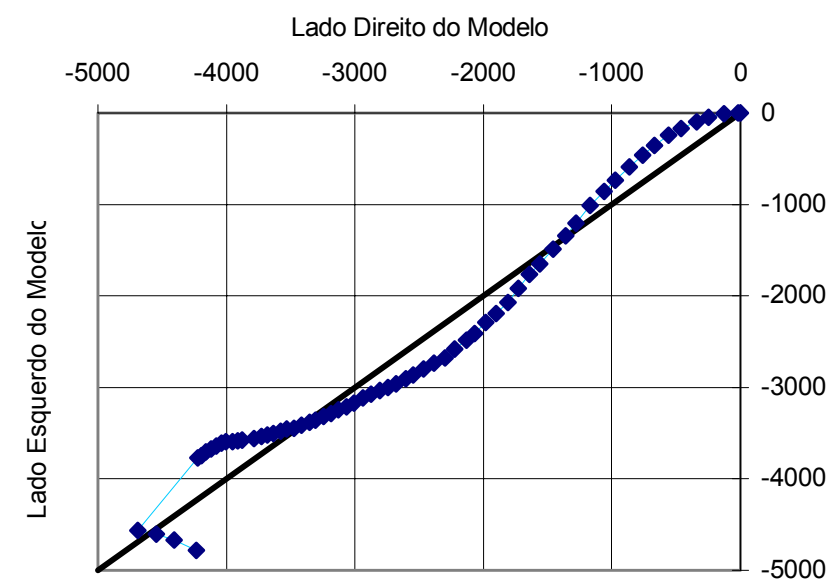

- Proveta sem Recobrimento — Referência

Figura 5. 31- Ajuste das constantes e comparação entre os dois lados do modelo proposto (Proveta01).

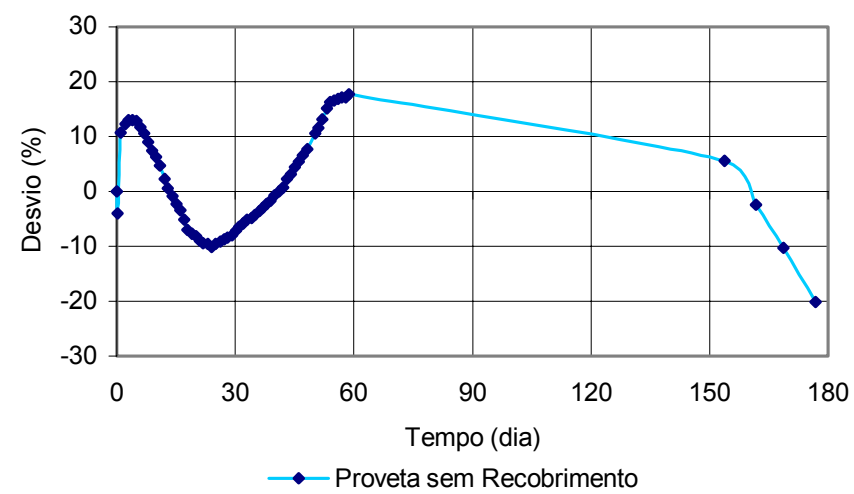

Figura 5. 32- Representação gráfica da variação do desvio percentual em função do tempo para a Proveta01. 
Nota-se pelas Figuras 5.30, 5.31 e 5.32 que o modelo proposto comportou-se bem de uma maneira geral, porém os três últimos valores apresentaram um desvio maior em relação à reta de referência. Este desvio pode ser justificado pelas limitações do detetor de fotoionização utilizado pois o mesmo mede apenas uma determinada gama de substâncias presentes na gasolina. Estas substâncias pertencem ao grupo das mais voláteis e com isso, nos primeiros momentos, os resultados fornecidos serão representativos. Com o decorrer do tempo, como as substâncias mais voláteis já estarão próximas de se esgotar, as leituras realizadas deixarão de ser representativas da massa volatilizada. Outros interferentes que não foram considerados no modelo se referem às condições ambientais como: temperatura, umidade, ventos, etc. Segundo SCHWARZENBACH et al. (1993), a transferência de produto para a fase de vapor é regida pela pressão de vapor do produto e quanto maior a pressão de vapor, mais volátil será a substância e maior será sua concentração na fase de vapor. Sendo assim, como a temperatura está diretamente ligada a pressão de vapor, estaria também influindo no fenômeno. Finalizando apesar de serem seguidos todos os passo descritos na metodologia, erros sistemáticos ou aleatórios podem ter ocorrido ao longo da fase experimental.

Para a Proveta02, a única diferença encontrada foi na equação final, pois os limites de integração são diferentes para os dois casos. Dessa maneira encontrou-se a eq. 5.22.

$$
\begin{gathered}
\rho \cdot\left(\frac{e_{1}}{D_{1}}\right) \cdot\left(L-e_{1}-\frac{M}{\frac{\rho \cdot \pi \cdot d^{2} \cdot \eta}{4}}\right)+\frac{\rho \cdot\left(L-e_{1}-\frac{M}{\frac{\rho \cdot \pi \cdot d^{2} \cdot \eta}{4}}\right)^{2}}{2 \cdot D_{2}}-\rho \cdot\left(\frac{e_{1}}{D_{1}}\right) \cdot\left(L-e_{1}-\frac{M_{i}}{\frac{\rho \cdot \pi \cdot d^{2} \cdot \eta}{4}}\right)+\frac{\rho \cdot\left(L-e_{1}-\frac{M_{i}}{\frac{\rho \cdot \pi \cdot d^{2} \cdot \eta}{4}}\right)^{2}}{2 \cdot D_{2}}= \\
=\frac{\alpha}{\beta} \cdot e^{-\beta \cdot t}-\frac{\alpha}{\beta}+C_{s} \cdot t
\end{gathered}
$$

Ajustando-se os valores de $\mathrm{D}_{1}, \mathrm{D}_{2}, \eta$ e $\mathrm{C}_{\mathrm{s}}$ pelo método de mínimos quadrados e comparando-se os lados direito e esquerdo da eq. 5.22 tem-se: 


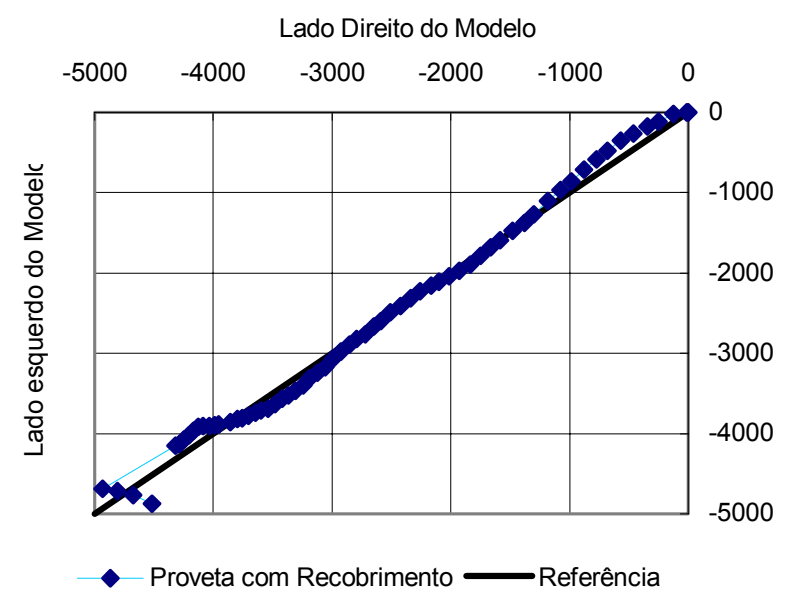

Figura 5. 33- Ajuste das constantes e comparação entre os dois lados do modelo proposto (Proveta02).

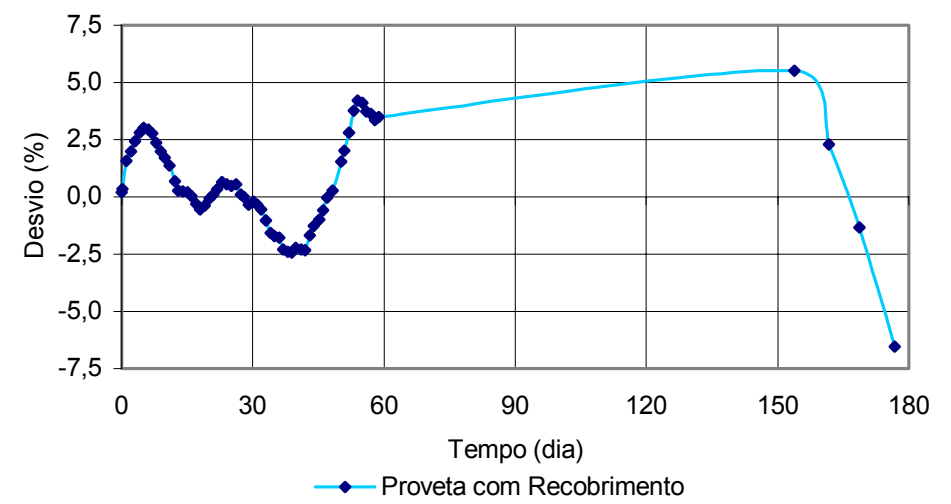

Figura 5. 34- Representação gráfica da variação do desvio percentual em função do tempo para a Proveta02.

Percebe-se pelas Figuras 5.30, 5.33 e 5.34 que modelo proposto para a Proveta02 apresentou melhores resultados do que o modelo proposto para Proveta01. Entretanto constata-se o mesmo desvio encontrado nos três últimos pontos do modelo anterior. Dessa forma podemos justificar da mesma maneira que o modelo anterior, ou seja, por limitações do detetor, por limitações do modelo utilizado e por erros experimentais.

As Figuras 5.35 a e b, mostram a comparação entre os resultados obtidos em laboratório, os resultados obtidos com a simulação do modelo JURY para as mesmas condições e resultados pelos modelos propostos nesta pesquisa. Nota-se que obtém-se valores de fluxo de mesma ordem de grandeza principalmente para tempos superiores a 100 
dias (pouco mais de 3 meses) os resultados obtidos pedem ser considerados satisfatórios. No caso da Proveta 02 o modelo JURY não reproduz a parte crescente do fluxo.
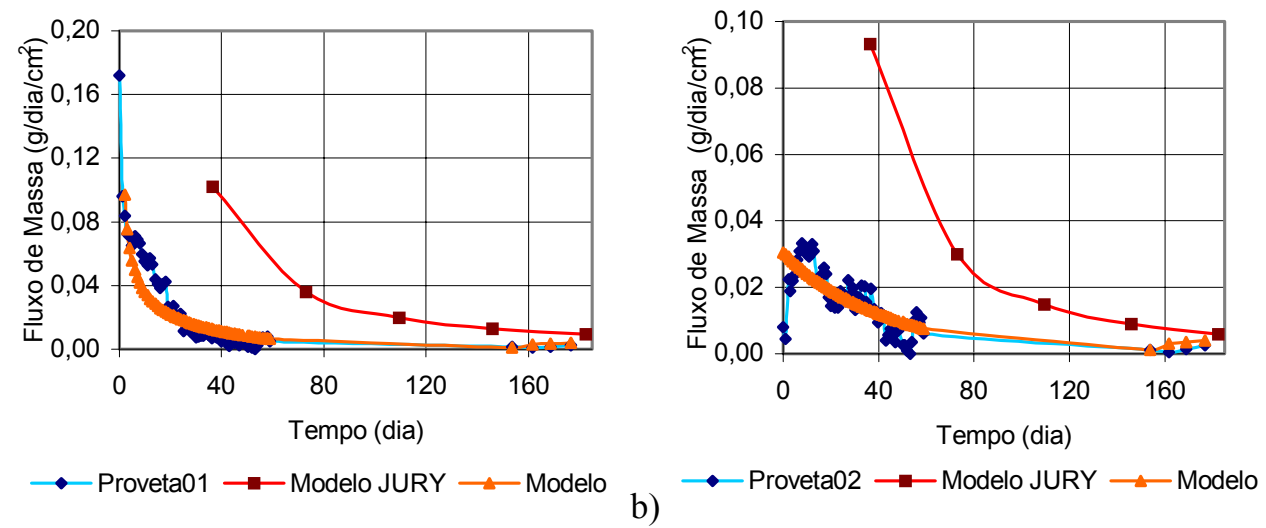

Figura 5. 35- Representação gráfica dos resultados obtidos simulando-se o modelo JURY para as condições do experimento. (a) para a Proveta sem Recobrimento e b) para a Proveta com Recobrimento\}.

\subsubsection{Ensaios de Difusão em Solo Não Saturado em Escala Maior}

Esta fase de ensaios foi realizada com a finalidade de compreender as respostas do detetor de fotoionização para casos de contaminação do solo por gasolina mais próximos da realidade, bem como comparar as informações obtidas neste experimento com as obtidas no experimento anterior. Os resultados do experimento utilizando duas colunas de acrílico podem ser visualizados na Tabela 5.7.

Tabela 5.7 - Resultados de concentração e temperatura medidos ao longo do tempo.

\begin{tabular}{cccc}
\hline $\begin{array}{c}\text { Tempo } \\
(\text { dia })\end{array}$ & $\begin{array}{c}\text { Coluna } 01 \\
\text { Concentração }\end{array}$ & $\begin{array}{c}\text { Coluna 02 } \\
\text { Concentração }\end{array}$ & $\begin{array}{c}\text { Temperatura } \\
(\text { ppm })\end{array}$ \\
\hline 0 & 11,5 & $(\mathrm{ppm})$ & \\
\hline 1 & 129,6 & 2,7 & 25,0 \\
2 & 145,7 & 9,8 & 25,5 \\
3 & 124,7 & 15,9 & 25,0 \\
4 & 135,6 & 36,3 & 27,5 \\
5 & 119,4 & 21,3 & 26,5 \\
& & 33,3 & 25,0
\end{tabular}




\begin{tabular}{|c|c|c|c|}
\hline $\begin{array}{l}\text { Tempo } \\
\text { (dia) }\end{array}$ & $\begin{array}{c}\text { Coluna } 01 \\
\text { Concentração } \\
\text { (ppm) }\end{array}$ & $\begin{array}{c}\text { Coluna } 02 \\
\text { Concentração } \\
\text { (ppm) }\end{array}$ & $\begin{array}{c}\text { Temperatura } \\
\left({ }^{0} \mathrm{C}\right)\end{array}$ \\
\hline 6 & 125,9 & 35,1 & 27,0 \\
\hline 7 & 128,8 & 62,6 & 28,0 \\
\hline 8 & 120,0 & 78,2 & 28,0 \\
\hline 9 & 117,4 & 77,1 & 29,0 \\
\hline 10 & 112,2 & 66,9 & 28,0 \\
\hline 11 & 124,1 & 78,9 & 29,0 \\
\hline 12 & 124,1 & 68,8 & 28,5 \\
\hline 13 & 119,4 & 63,8 & 28,5 \\
\hline 14 & 115,1 & 93,1 & 29,0 \\
\hline 15 & 109,5 & 68,0 & 27,0 \\
\hline 16 & 92,9 & 102,0 & 30,0 \\
\hline 17 & 107,9 & 101,8 & 29,0 \\
\hline 18 & 105,8 & 110,2 & 26,0 \\
\hline 19 & 107,5 & 102,0 & 28,0 \\
\hline 20 & 92,1 & 54,2 & 27,0 \\
\hline 21 & 87,5 & 39,3 & 28,0 \\
\hline 22 & 85,1 & 54,2 & 27,5 \\
\hline 23 & 78,0 & 52,3 & 27,5 \\
\hline 25 & 97,7 & 59,4 & 24,0 \\
\hline 26 & 59,8 & 38,3 & 24,5 \\
\hline 27 & 88,1 & 38,4 & 24,0 \\
\hline 28 & 79,7 & 50,3 & 25,0 \\
\hline 29 & 86,5 & 44,7 & 27,5 \\
\hline 30 & 101,4 & 56,6 & 28,5 \\
\hline 31 & 91,3 & 57,6 & 29,0 \\
\hline 32 & 52,8 & 51,7 & 29,0 \\
\hline 33 & 57,7 & 42,1 & 30,0 \\
\hline 34 & 84,4 & 64,2 & 29,0 \\
\hline 38 & 61,7 & 52,0 & 28,0 \\
\hline 41 & 79,5 & 52,7 & 29,0 \\
\hline 44 & 48,1 & 38,8 & 27,0 \\
\hline 48 & 69,1 & 53,0 & 28,0 \\
\hline 52 & 55,3 & 40,5 & 27,0 \\
\hline 55 & 69,6 & 44,7 & 28,0 \\
\hline 56 & 82,9 & 66,1 & 28,0 \\
\hline 57 & 56,8 & 28,9 & 28,5 \\
\hline 58 & 53,5 & 67,5 & 27,5 \\
\hline 59 & 44,3 & 39,8 & 29,5 \\
\hline 60 & 79,8 & 35,5 & 27,5 \\
\hline 64 & 24,4 & 27,6 & 31,0 \\
\hline 65 & 68,9 & 70,6 & 25,5 \\
\hline 66 & 31,4 & 36,2 & 30,0 \\
\hline 67 & 44,7 & 28,0 & 29,0 \\
\hline 68 & 51,1 & 41,7 & 31,0 \\
\hline 69 & 63,6 & 35,6 & 32,0 \\
\hline 70 & 36,4 & 27,8 & 28,5 \\
\hline 71 & 36,2 & 27,4 & 23,5 \\
\hline
\end{tabular}




\begin{tabular}{cccc}
\hline $\begin{array}{c}\text { Tempo } \\
(\text { dia })\end{array}$ & $\begin{array}{c}\text { Coluna 01 } \\
\text { Concentração } \\
(\mathrm{ppm})\end{array}$ & $\begin{array}{c}\text { Coluna 02 } \\
\text { Concentração } \\
(\mathrm{ppm})\end{array}$ & $\begin{array}{c}\text { Temperatura } \\
\left({ }^{0} \mathrm{C}\right)\end{array}$ \\
\hline 72 & 77,2 & 51,1 & 24,5 \\
73 & 78,3 & 31,2 & 27,0 \\
74 & 61,9 & 41,1 & 27,0 \\
75 & 52,7 & 45,4 & 27,5 \\
76 & 45,6 & 40,1 & 28,0 \\
129 & 21,2 & 12,5 & 27,0 \\
137 & 16,8 & 13,3 & 24,5 \\
144 & 16,2 & 25,2 & 24,0 \\
152 & 34,2 & 13,3 & 25,0 \\
166 & 25,6 & 14,5 & 25,0 \\
\hline
\end{tabular}

A seguir serão apresentadas duas representações gráficas dos resultados, a primeira representa os resultados referentes às colunas em função do tempo e a segunda representa a diferença entre as concentrações tomando com referência a coluna sem recobrimento.

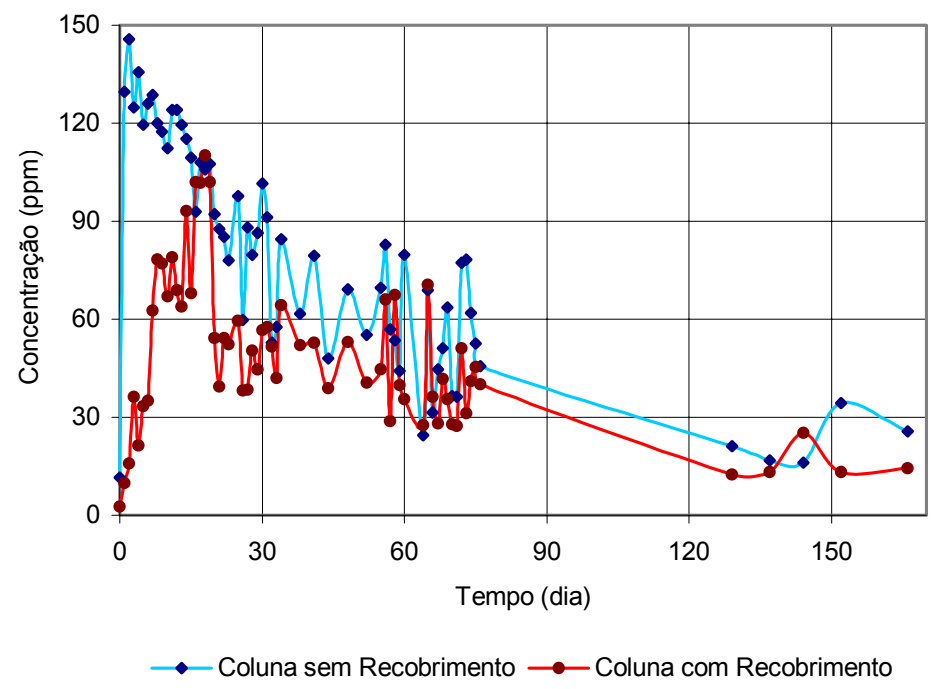

Figura 5. 36- Representação gráfica dos resultados de concentração ao longo do tempo. 


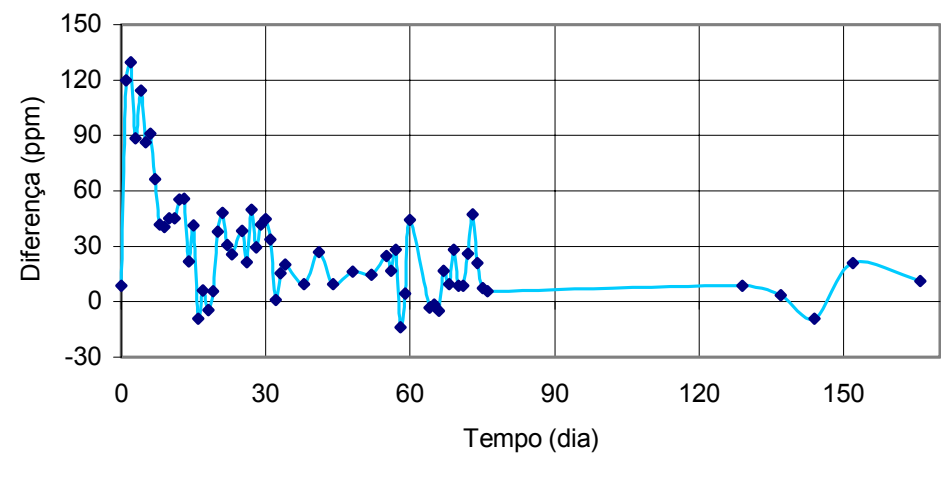

- Coluna sem Recobrimento - Coluna com Recobrimento

Figura 5. 37- Representação gráfica da diferença entre os resultados de concentração, tomando como referência a coluna sem recobrimento.

Algumas considerações podem ser feitas com relação as Figuras 5.36 e 5.37:

- Para a Coluna01 a concentração atingiu um máximo em dois dias, após o que apresentou um decaimento oscilante;

- A Coluna02 apresentou um pico de concentração por volta de 18 dias;

- A máxima concentração obtida na Coluna02 foi igual 76\% da máxima atingida para a Coluna01;

- Levando-se em consideração as oscilações observadas nos valores medidos, pode-se afirmar que as concentrações correspondentes à Coluna01 foram maiores que para a Coluna02. Em 61 valores medidos apenas 7 não satisfizeram esta constatação;

- Embora as concentrações na Coluna01 sejam quase sempre maiores que na Coluna02, as diferenças entre elas diminui com o tempo, tendendo então para se igualarem, como pode ser observado na Figura 5.37.

- O valor da concentração para um tempo de 150 dias (5 meses) após a aplicação da gasolina, está em torno de 20 ppm, valor nitidamente indicativo de alteração no ambiente.

- Para a Coluna01 os resultados de concentração obtidos apresentaram uma tendência semelhante à ocorrida com a Proveta01 do experimento anterior, os quais eram esperados. Para a Coluna02 os resultados de concentração obtidos apresentam tendência pouco semelhante a ocorrida com a Proveta02 do experimento anterior. Essa diferença pode ser explicada pelo aumento nas proporções do experimento sendo que a camada de recobrimento adicionada a Coluna02 não é proporcional a adicionada a Proveta02. 
Para concluir a fase de apresentação de resultados e discussões, são expostos e analisados os resultados do experimento utilizando cinco recipientes cilíndricos com capacidade aproximada de 20 litros cada. Sendo as leituras somente realizadas com detetor de fotoionização.

Tabela 5.8 - Valores de concentração e temperatura medidos ao longo do tempo para o experimento utilizando cinco recipientes cilíndricos.

\begin{tabular}{|c|c|c|c|c|c|c|}
\hline $\begin{array}{l}\text { Tempo } \\
\text { (dia) }\end{array}$ & $\begin{array}{c}\text { Recipiente } \\
01\end{array}$ & $\begin{array}{c}\text { Recipiente } \\
02\end{array}$ & $\begin{array}{c}\text { Recipiente } \\
03\end{array}$ & $\begin{array}{c}\text { Recipiente } \\
04\end{array}$ & $\begin{array}{c}\text { Recipiente } \\
05\end{array}$ & $\begin{array}{c}\text { Temperatura } \\
\left({ }^{\circ} \mathrm{C}\right)\end{array}$ \\
\hline 0 & 85,7 & 84,8 & 81,9 & 79,7 & 72,2 & 24,0 \\
\hline 1 & 100,6 & 88,8 & 94,8 & 101,4 & 89,1 & 24,5 \\
\hline 2 & 95,8 & 100,6 & 89,8 & 98,0 & 93,8 & 24,0 \\
\hline 3 & 116,6 & 90,3 & 92,0 & 97,4 & 93,9 & 25,0 \\
\hline 4 & 100,0 & 96,6 & 89,3 & 87,8 & 79,5 & 27,5 \\
\hline 5 & 106,7 & 100,9 & 99,6 & 93,7 & 72,4 & 28,5 \\
\hline 6 & 98,0 & 95,1 & 102,5 & 92,3 & 64,8 & 29,0 \\
\hline 7 & 87,3 & 93,1 & 98,0 & 73,7 & 50,0 & 29,0 \\
\hline 8 & 114,0 & 90,8 & 95,7 & 89,3 & 54,3 & 30,0 \\
\hline 9 & 91,2 & 92,7 & 88,0 & 78,4 & 53,6 & 29,0 \\
\hline 13 & 85,6 & 84,0 & 77,4 & 65,2 & 46,9 & 28,0 \\
\hline 16 & 96,5 & 92,4 & 79,7 & 67,8 & 50,4 & 29,0 \\
\hline 19 & 83,8 & 80,7 & 70,6 & 54,3 & 40,4 & 27,0 \\
\hline 23 & 93,1 & 89,7 & 78,5 & 63,9 & 46,2 & 28,0 \\
\hline 27 & 88,2 & 83,1 & 71,8 & 50,6 & 30,9 & 27,0 \\
\hline 30 & 98,0 & 92,0 & 84,3 & 48,2 & 27,5 & 28,0 \\
\hline 31 & 96,1 & 88,2 & 79,5 & 44,3 & 30,6 & 28,0 \\
\hline 32 & 92,7 & 84,1 & 75,7 & 43,0 & 33,6 & 28,5 \\
\hline 33 & 88,6 & 73,4 & 71,4 & 43,2 & 26,9 & 27,5 \\
\hline 34 & 94,7 & 83,5 & 76,4 & 40,8 & 27,6 & 29,5 \\
\hline 35 & 95,8 & 85,1 & 73,8 & 43,0 & 26,4 & 27,5 \\
\hline 39 & 72,9 & 72,2 & 65,1 & 42,3 & 20,9 & 31,0 \\
\hline 40 & 77,9 & 71,0 & 37,8 & 22,6 & 31,7 & 25,5 \\
\hline 41 & 83,2 & 82,3 & 72,5 & 47,9 & 19,5 & 30,0 \\
\hline 42 & 73,5 & 70,1 & 48,3 & 33,4 & 22,3 & 29,0 \\
\hline 43 & 77,3 & 72,8 & 54,6 & 40,3 & 24,9 & 31,0 \\
\hline 44 & 75,1 & 68,4 & 55,7 & 40,1 & 15,4 & 32,0 \\
\hline 45 & 72,6 & 63,1 & 50,2 & 38,2 & 16,7 & 28,5 \\
\hline 46 & 68,9 & 59,9 & 44,5 & 35,1 & 17,4 & 23,5 \\
\hline 47 & 69,8 & 59,7 & 43,4 & 30,8 & 24,8 & 24,5 \\
\hline 48 & 73,3 & 67,4 & 52,5 & 41,1 & 21,5 & 27,0 \\
\hline 49 & 68,2 & 60,4 & 41,9 & 32,2 & 26,1 & 27,0 \\
\hline 50 & 66,0 & 58,1 & 45,5 & 40,7 & 26,1 & 27,5 \\
\hline 51 & 69,0 & 60,4 & 44,7 & 40,1 & 25,6 & 28,0 \\
\hline 104 & 13,3 & 9,8 & 5,8 & 7,0 & 4,4 & 27,0 \\
\hline 112 & 10,9 & 10,0 & 7,5 & 6,9 & 5,4 & 24,5 \\
\hline 119 & 11,0 & 9,9 & 7,7 & 6,8 & 5,6 & 24,0 \\
\hline 127 & 12,3 & 10,2 & 9,2 & 7,8 & 2,9 & 25,0 \\
\hline 141 & 7,5 & 6,3 & 5,9 & 4,2 & 3,4 & 25,0 \\
\hline
\end{tabular}

A partir dos resultados apresentados foi criada uma representação gráfica dos mesmos para cada recipiente ao longo do tempo, que pode ser visualizada na Figura 5.38. 


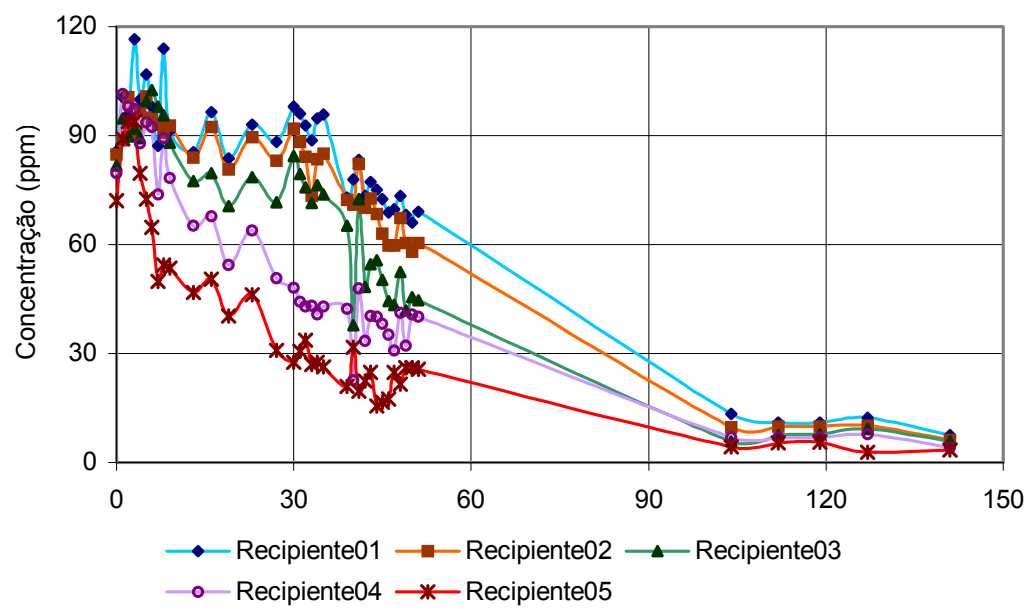

Figura 5. 38- Representação gráfica dos resultados de concentração medidos ao longo do tempo para o experimento que utilizou cinco recipientes cilíndricos.

Com este experimento simulou-se vários derramamentos superficiais. Verifica-se que a concentração máxima foi atingida após três dias do início do experimento. Fica claro que a relação gasolina aplicada em função da concentração é atenuada. Tomando-se como referência os casos extremos (Recipiente01 X Recipiente05) a relação de massas introduzidas foi de 5:1 e a relação entre as concentrações finais foi de 2,2:1.

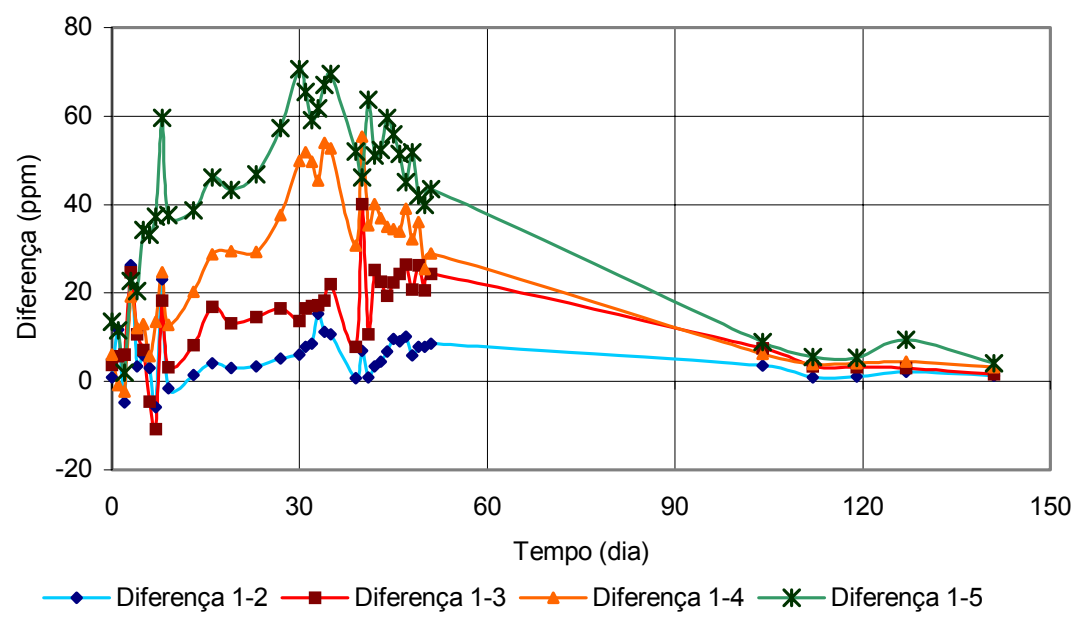

Figura 5. 39- Representação gráfica das diferenças entre as concentrações, tomando-se como referência o Recipiente01. 
O gráfico da Figura 5.39 mostra as diferenças entre as concentrações tomando como referência o Recipiente01. Nota-se que praticamente em todo o intervalo de tempo, os recipientes que têm a maior aplicação de gasolina apresentam maiores concentrações.

Na porção inicial de tempo até 10 dias aconteceram 7 ocorrências com concentração maior que a do Recipiente01, no restante do intervalo manteve-se a correlação: maior aplicação de contaminante acarreta maior concentração.

$\mathrm{Na}$ porção final do experimento (tempo maior que 100 dias) as diferenças nas concentrações oscilaram em valores absolutos de $1 \mathrm{ppm}$ a $12 \mathrm{ppm}$; em valores relativos de $8 \%$ a $76 \%$ (com base na maior concentração) sempre obedecendo a tendência: maior aplicação de contaminante implicando em maior concentração. 


\section{CONCLUSÕES}

Como item final desta pesquisa, este capítulo tem como finalidade expor as principais conclusões obtidas a partir da realização dos experimentos laboratoriais, análise de resultados e simulação computacional realizada.

$>\mathrm{O}$ modelo físico-matemático, implementado computacionalmente, mostrou-se satisfatório quando se considera o contexto do experimento, como pode ser verificado no Quadro01 no Anexo III.

O método desenvolvido pode ser aplicado para casos de dimensões mais compatíveis com as encontradas na prática da engenharia ambiental, através do ajuste dos parâmetros como foi apresentado neste trabalho.

$>$ Os gráficos que apresentaram os resultados referentes ao detetor de fotoionização mostraram claramente a existência de duas fases: a primeira com concentrações crescentes (seguida de um máximo) e a segunda com concentrações decrescentes. Os Quadro 02, Quadro 03 e Quadro 04 presentes no Anexo IV, mostram o tempo em que ocorreram os valores máximos de concentração. Esses resultados são úteis no planejamento de experimentos ou campanhas de medições em campo.

A Figura01 contida no Anexo III, mostra a influência da altura da coluna livre no fluxo. Isto tem importância prática. Em uma campanha de avaliação de contaminação através de medidas em piezômetros fica claro que a variação desse parâmetro deve ser considerada. Os resultados mostraram que quanto maior a coluna de ar livre menor é o fluxo inicial.

Como já relatado nas "discussões" não existe uma proporcionalidade entre quantidade de gasolina aplicada e valor de concentração medida com o detetor de fotoionização. Dessa maneira se em uma aplicação do equipamento for encontrada uma medida $20 \%$ maior que outra não se poderá concluir que foi introduzida uma massa $20 \%$ superior.

$>$ Os ensaios em colunas com cobertura de solo, tanto nas provetas quanto nas colunas de acrílico, que simulam um vazamento subterrâneo, mostraram claramente a influência da 
camada de recobrimento. Para as provetas, a quantidade de gasolina retida ou retardada pela camada de cobertura foi de aproximadamente $30 \%$ da massa inicial. Para as colunas de acrílico, a influência da cobertura pode ser notada pela defasagem no tempo decorrido até se atingir o pico de concentração e também pelo próprio valor do pico que foi menor quando existia recobrimento.

No experimento utilizando duas colunas de acrílico, embora tenha sido aplicada uma coluna de recobrimento de $1,25 \mathrm{~m}$ e $700 \mathrm{ml}$ de gasolina, é notável que, após 166 dias, ainda se consiga uma concentração de 14,5ppm para o caso com recobrimento. Esse é um dado de importância prática que mostra que esse equipamento pode detectar um vazamento mesmo após 5 meses da ocorrência do mesmo.

Para os ensaios que simulam um derramamento na superfície, fica mais claro o fato de o detetor de fotoionização não conseguir diferenciar a quantidade derramada, porém, os resultados demonstram a capacidade do aparelho em detectar a presença de vapores na atmosfera circundante, mesmo após decorridos 141 dias (4,7 meses) do evento. Nessa ocasião, a concentração variou de 7,5 a 3,4 ppm. Esse último valor, quando encontrado em centros urbanos de alta densidade de tráfego pode ser confundido com a poluição atmosférica.

Nos experimentos que simulam derramento superficial, as quantidades aplicadas foram equivalentes a no mínimo 100.000 e no máximo 500.000 litros de gasolina em uma área de aproximadamente $6.000 \mathrm{~m}^{2}(77 \mathrm{~m} \times 77 \mathrm{~m})$. Esses valores são razoavelmente compatíveis com valores usuais na área de transporte de combustíveis.

$>$ O trabalho mostrou que o detetor de fotoionização é equipamento útil na caracterização preliminar em um estudo de caso. Sua praticidade, baixo custo e fácil utilização o tornam um auxiliar importante na avaliação dos pontos de amostragem minimizando os altos custos de uma rede de monitoramento. 


\section{REFERÊNCIAS BIBLIOGRÁFICAS}

Agência Nacional do Petróleo, (2000). Alguns números do “donwstream” no Brasil. http://www.anp.gov.br/documentos/Apresentacao/QualiCombs/sld002.htm

American Petroleum Institute, (1999). API's Decision Support System for Exposure and Risk Assessment, Washington, D.C., EUA.

American Petroleum Institute, (1993). Guide for Assessing and Remediating Petroleum Hydrocarbons in Soils, Washington, D.C., EUA.

BANERJEE, S., YALKOWSKY, S. H. (1988). Cosolvent Induced Solubilzation of Hydrophobic Compounds into Water. Analytical Chemistry, v. 60, p. 2153 - 2155.

BAEHR, A.L.; BRUELL, C.J. (1990). Application of the Stefan-Maxwell equations to determine limitations of Fick's law when modeling organic vapor transport in sand columns. Water Resources Research, v.26, n.4, p. 1155-1163.

BAEHR, A.L.; CORAPCIOGLU, M.Y. (1987). A Compositional Multiphase Model for Groundwater Contamination by Petroleum Products 2. Numerical Solution. Water Resources Research, v. 23, n. 1, p. 201-213, Jan.

BRASIL, Leis, etc. (1999). Portaria n. 197, de 28 de dezembro de 1999. Estabelece as especificações de qualidade mínima a serem observadas para comercialização de gasolinas automotivas em todo o território nacional e define responsabilidades dos diversos agentes de cadeia logística. Lex: Coletânea de Legislação e Jurisprudência, São Paulo, v. 62, p. 1.965.

BRASIL, Leis, etc. (1998). Decreto n. 2.607 de 28 de maio de 1998. Dispõe sobre a adição de álcool etílico anidro combustível à gasolina. Lex: Coletânea de Legislação e Jurisprudência, São Paulo, v. 62, p. 1.965.

BRASIL, Leis, etc. (1990). Portaria n. 36 de 19 de janeiro de 1990. Lex: Coletânea de Legislação e Jurisprudência, São Paulo, v. 32, p. 153. 
CORAPCIOGLU, M.Y.; BAEHR, A.L. (1987). A Compositional Multiphase Model for Groundwater Contamination by Petroleum Products 1. Theoretical Considerations. Water Resources Research, v. 23, n. 1, p. 191-200, Jan.

FINOTTI, A.R.; CORSEUIL, H.X. (1997). Uso da Ação Corretiva Baseada no Risco RBCA - Nos Casos de Contaminação de Solos e Águas Subterrâneas por Gasolina no Brasil. In: CONGRESSO BRASILEIRO DE ENGENHARIA SANITÁRIA E AMBIENTAL, 19., Foz do Iguaçu, 1997. Anais. CD-ROM.

FERNANDES, M.; CORSEUIL, H.X. (1997). Contaminação de Águas Subterrâneas por Derramamento de Gasolina - Efeito Cossolvência. In: CONGRESSO BRASILEIRO DE ENGENHARIA SANITÁRIA E AMBIENTAL, 19., Foz do Iguaçu, 1997. Anais. CDROM.

FERREIRA, S.B. (2000). Estudos laboratoriais para avaliação do potencial de contaminação de água e de solo por gasolina oxigenada. São Carlos. 216p. Tese (Doutorado) - Escola de Engenharia de São Carlos, Universidade de São Paulo.

FETTER, C.W.J. (1993). Contaminant Hydrogeology, New York, Macmillan Publishing Co., $458 \mathrm{p}$.

GUIGUER, N. (1994?). Poluição das Águas Subterrâneas e do Solo Causada por Vazamentos em Postos de Abastecimento. Waterloo Hydrogeologic.

HIRATA, R.C.A. (1990). Amostragem de vapores do solo (AVS): desenvolvimento de uma técnica para a detecção de águas subterrâneas contaminadas por solventes orgânicos voláteis. Estudo de caso de Porto Feliz - São Paulo. São Paulo. 113p. Dissertação (Mestrado) - Instituto de Geociências, Universidade de São Paulo.

HIRSCHFELDER, J.O.; CURTISS, C.F.; BIRD, R.B. (1964). Molecular theory of gases and liquids. John Wiley \& Sons, New York.

HULING, S.G.; WEAVER, J.W. (1991). Dense nonaqueous phase liquids. USEPA Ground Water Issue. USEPA/540/4-91-0002. U.S. Gov. Print Office, Washington, DC. 
JAYNES, D.B.; ROGOWSKI, A.S. (1983). Applicability of Fick's law to gas diffusion. Soil Sci. Soc. American Journal, v.47, p. 425-430.

JOHNSON, P.C.; STANLEY, C.C.; KEMBLOWSKI, M.W.; BYERS, D.L.; COLTHART, J.D. (1990). A Practical Approach to the Design, Operation and Monitoring of In Situ Soil-Venting Systems. Groundwater Monitoring Review, p. 159-178.

JURY, W.A.; RUSSO, D.; STREILE, G.; EL ABD, H. (1990). Evaluation of Volatilization by Organic Chemicals Residing Below the Soil Surface. Water Resources Research, v. 26, n. 1, p. 13-20, Jan.

JURY, W.A.; GARDNER, W.R.; GARDNER, W.H. (1991). Soil Physics. $5^{\text {th }}$ Ed. (Wiley), $328 \mathrm{p}$.

KREAMER, D.K.; STETZENBACH, K.J. (1990). Development of a Standard. PureCompound Base Gasoline Mixture for Use as a Reference in Field and Laboratory Experiments. Groundwater Monitoring Review. p. 135-145.

MASON, E.A.; MALINAUSKAS, A.P. (1983). Gas transport in porous media: the dusty gas model. Elsevier Sic. Publ. Co., New York.

OLIVEIRA, E. (1992). Contaminação de aqüíferos por hidrocarbonetos provenientes de vazamentos de tanques de armazenamento subterrâneo. São Paulo. 112p. Dissertação (Mestrado) - Instituto de Geociências, Universidade de São Paulo.

OLIVEIRA, E.; CLEARY, R.W.; CUNHA, R.C.A.; PACHECO, A. (1990). Gasoline Hydrocarbons Groundwater Pollution Potential in Metropolitan São Paulo, Protection and Control of Ground Water. IAWPRC-ABAS. Porto Alegre, RS.

PETROBRÁS (1997). Relatório Anual. Acesso via Internet pelo endereço: http://www.petrobras.com.br

PINAL, R.; RAO, S. C.; LEE, L. S.; CLINE, P.V. (1990). Cosolvency of Partially Miscible Organic Solvents on the Solubility of Hydrophobic Organic Chemicals. Environmental Science and Technology. v. 24, p. 639 - 647. 
REGGiANI, L. (1999). Postos têm dívida ambiental de R\$ 3 bi. Folha de São Paulo, $2^{0}$ caderno, p. 1, São Paulo, 29 de agosto de 1999.

SCHWARZENBACH, R.P.; GSCHWEND, P.M.; IMBODEN, D.I. (1993). Environmental Organic Chemistry. New York, John Wiley \& Sons, 681p.

SCHWILLE, F. (1984). Migration of organic fluids immiscible with water in the unsaturated zone. In: Pollutants in porous media - B. Yaron et al. (ed.). Ecol. Stud. 47. SpringerVerlag, New York, p. 27-47.

SCHWILLE, F. (1988). Dense chlorinated solvents in porous and fractured media: Model experiments. Lewis Publ., Chelsea, MI.

SHONNARD, D.R.; BELL, R.L. (1993). Benzene Emissions Contaminated Air-Dry Soil with Fluctuations of Soil Temperature or Relative Humidity. Environ. Sci. Technol., v. 27, n. 13, p. 2909-2913.

SLEEP, B.E.; SYKES, J.F. (1989). Modeling the transport of volatile organics in variably saturated media, Water Resour. Res., v. 25, n. 1, p. 81-92, Jan.

TESTA, S.M.; PACZKOWSKI, M.T. (1989). Volume Determination and Recoverability of Free Hydrocarbon. Groundwater Monitoring Review. p. 120-128.

THORSTENSON, D.C.; POLLOCK, D.W. (1989). The adequacy of Fick's law. Ver. Geophys., v. 27, p. 61-78.

UNITED STATE ENVIRONMENTAL PROTECTION AGENCY, (1999). Office of Underground Storage Tanks, Markets and Technology Trends. EPA-510-B99-007, May 1999.

UNITED STATE ENVIRONMENTAL PROTECTION AGENCY, (1997). Office of Underground Storage Tanks, Expedited Site Assessment Tools for USTs: A Guide for Regulators, EPA-510-B97-001, March 1997. 
VAN DER WAARDEN, M.; BRIDIE, A.L.M.; GROENEWOUD, W.M. (1971). Transport of mineral oil components to groundwater: I. Model experiments on the transfer of hydrocarbons from a residual oil zone to trickling water. Water Res. v. 5, p. 213-226.

VAN DER WAARDEN, M.; BRIDIE, A.L.M.; GROENEWOUD, W.M. (1977). Transport of mineral oil components to groundwater: II. Water Res. v. 11, p. 359-365. 


\section{OBRAS CONSULTADAS}

ABRIOLA, L.M.; PINDER, G.F. (1985a). A Multiphase Approach to the Modeling of Porous Media Contamination by Organic Compounds 1. Equation Development. Water Resources Research, v. 21, n. 1, p. 11-18, Jan.

ABRIOLA, L.M.; PINDER, G.F. (1985b). A Multiphase Approach to the Modeling of Porous Media Contamination by Organic Compounds 2. Numerical Simulation. Water Resources Research, v. 21, n. 1, p. 19-26, Jan.

BENSON, D.A.; HUNTLEY, D.; JHONSON, P.C. (1993). Modeling Vapor Extraction and General Transport in the Presence of NAPL Mixtures and Nonideal Conditions. Ground Water, v. 31, n. 3, p. 437-445, May-June.

CHAPELLE, F.H. (1999). Bioremediation of Petroleum Hydrocarbon-Contaminated Ground Water: The Perspectives of History and Hydrology. Ground Water, v. 37, n. 1, p. 122132, January-February.

CLEARY, R.W. (1991). Qualidade da Água Subterrânea. Capítulo 3, Hidrologia Ambiental, v. III, Coleção ABRH de Recursos Hídricos, Rio de Janeiro, Brasil, Editora da UFRJ, $441 \mathrm{p}$.

CORSEUIL, H.X.; FERNANDES, M. (1999). Efeito do etanol no aumento da solubilidade de compostos aromáticos presentes na gasolina brasileira. Engenharia Sanitária e Ambiental, v. 4, n. 1 - Jan/Mar e n. 2 - Abr/Jun, p. 71-75.

FEITOSA, A.C.F.; FILHO, J.M., orgs. (1997). Hidrogeologia, Conceitos e Aplicações. Fortaleza, CPRM, LABHID-UFPE.

FELS, J.B. (1999). Source-identification investigations of petroleum contaminated groundwater in the Missouri Ozarks. Engineering Geology. p. 3-13. 
HUNT, J.R.; SITAR, N.; UDELL, K.S. (1988). Nonaqueous Phase Liquid Transport and Cleanup 1. Analysis of Mechanisms. Water Resources Research, v. 24, n. 8, p. 12471258 , Aug.

KOZIEL, J.; JIA, M.; KHALED, A.; NOAH, J.; PAWLISZYN, J. (1999). Field air analysis with SPME device. Analytica Chimica Acta, p. 153-162.

LIANG, H.C.; UDELL, K.S. (1999). Experimental and theoretical investigation of vaporization of liquid hydrocarbon mixtures in water-wetted porous media. Water Resources Research, v. 35, n. 3, p. 635-649, Mar.

MICHELSOM, R.W.; DURGIN, P.B. (1993). Field results of hydrocarbon vapor monitoring to detect leaking tanks. ASTM-Special Technical Publication, n. 1161. Publ. by ASTM, Philadelphia, PA, USA. p. 115-122.

NOBLE, R.A.; LAMBIER, P.E. (1990). Enhanced in-situ volatilization of hydrocarbon contaminated soils. Annu Symp Eng Geol Geotech Eng. Publ by Idaho State University, Pocatello, ID, USA. p 17.1-17.7.

OLIVEIRA, E. (2000). Transferência de fases. Boletim da Associação Brasileira de Águas Subterrâneas, n. 100, p. 8, Mar.

PETROBRÁS (1998a). A Companhia - Mapas. Acesso via Internet pelo endereço: http://www.petrobras.com.br.

PETROBRÁS (1998b). Relatório Anual. Acesso via Internet pelo endereço: http://www.petrobras.com.br

PREVEDELLO, C.L. (1996). Física do Solo (com problemas resolvidos). Curitiba, SAEAFS.

POWERS, E.S.; ABRIOLA, L.M.; Jr WEBER, W.J. (1992). An Experimental Investigation of Nonaqueous Phase Liquid Dissolution in Saturated Subsurface Systems: Steady State Mass Transfer Rates. Water Resources Research, v. 28, n. 10, p. 2691-2705, Oct. 
RAMERT, P.C.; EBERHARDT, W.L. (1996). Petroleum hydrocarbon removal via volatilization and biodegradation at McGrath, Alaska. Proceedings of the International Conference on Cold Regions Engineering, New York, NY, USA. p 94-105.

RIGHETTO, A.M. (1998). Hidrologia e Recursos Hídricos. São Carlos, Escola de Engenharia de São Carlos - Universidade de São Paulo.

YAMAMOTO, N.; OKAYASU, H.; HIRAIWA, T.; MURAYAMA, S.; MAEDA, T.; MORITA, M.; SUZUKI, K. (1998). Continuous determination of volatile organic compounds in the atmosphere by an automated gas chromatographic system. Jornal of Chromatography A, p. 177-186. 


\section{ANEXO I}

- Calibração da Balança Analítica 
Tabela - Resultados das calibrações realizadas para a balança QUIMIS (ESL 1000).

\begin{tabular}{cr}
$28 / 04 / 1999$ & \\
\hline Peso $(\mathrm{g})$ & Tara $(\mathrm{g})$ \\
\hline 2,00 & 2,00 \\
2,00 & 2,00 \\
5,00 & 5,00 \\
10,00 & 10,00 \\
10,00 & 10,00 \\
20,00 & 20,00 \\
50,00 & 50,00 \\
100,00 & 100,01 \\
100,00 & 100,01 \\
200,00 & 200,06 \\
500,00 & 500,09 \\
1000,00 & 1000,49 \\
\hline
\end{tabular}

Pelo critério de rejeição de pontos experimentais proposto por Chauvent, o último resultado encontrado para a primeira calibração poderia ser rejeitada. Para a segunda calibração realizada os dois últimos resultados poderiam ser rejeitados. Porém como dito anteriormente este método é muito criticado por vários pesquisadores pela facilidade de exclusão de resultados.

\begin{tabular}{|c|c|}
\hline Peso (g) & Tara $(\mathrm{g})$ \\
\hline 0,01 & 0,01 \\
\hline 0,02 & 0,02 \\
\hline 0,03 & 0,03 \\
\hline 0,04 & 0,04 \\
\hline 0,05 & 0,05 \\
\hline 0,06 & 0,06 \\
\hline 0,07 & 0,07 \\
\hline 0,08 & 0,08 \\
\hline 0,08 & 0,08 \\
\hline 0,10 & 0,10 \\
\hline 0,10 & 0,10 \\
\hline 0,15 & 0,15 \\
\hline 0,20 & 0,20 \\
\hline 0,30 & 0,30 \\
\hline 0,35 & 0,35 \\
\hline 0,40 & 0,40 \\
\hline 0,50 & 0,50 \\
\hline 0,60 & 0,60 \\
\hline 0,70 & 0,70 \\
\hline 0,80 & 0,80 \\
\hline 0,90 & 0,90 \\
\hline 0,95 & 0,95 \\
\hline 1,00 & 1,00 \\
\hline 2,00 & 2,00 \\
\hline 2,00 & 2,00 \\
\hline 4,00 & 4,00 \\
\hline 5,00 & 5,01 \\
\hline 7,00 & 7,00 \\
\hline 9,00 & 9,00 \\
\hline 10,00 & 10,00 \\
\hline 10,00 & 10,00 \\
\hline 12,00 & 12,00 \\
\hline 14,00 & 14,00 \\
\hline 15,00 & 15,00 \\
\hline 20,00 & 20,00 \\
\hline 30,00 & 30,00 \\
\hline 40,00 & 40,00 \\
\hline 50,00 & 50,00 \\
\hline 60,00 & 60,00 \\
\hline 70,00 & 70,00 \\
\hline 80,00 & 80,00 \\
\hline 90,00 & 90,01 \\
\hline 100,00 & 100,01 \\
\hline 100,00 & 100,01 \\
\hline 200,00 & 200,06 \\
\hline 500,00 & 500,08 \\
\hline 1000,00 & 100,47 \\
\hline
\end{tabular}




\section{ANEXO II}

- Tabela com as substâncias que estão contidas na gasolina Brasileira e são detectáveis pelo detetor de fotoionização, com seus referidos potenciais de ionização em elétron volt (ev). 
Tabela - Relação das substâncias presentes na gasolina brasileira e detectáveis pelo detetor de fotoionização, com lâmpada de 11,7 ev.

\begin{tabular}{lr}
\hline Substância & Potencial de Ionização (ev) \\
\hline Benzeno & 9,245 \\
n-butano & 10,63 \\
Etanol & 10,21 \\
Etilbenzeno & 8,87 \\
n-heptano & 10,07 \\
n-hexano & 10,18 \\
1-hexeno & 9,46 \\
Metanol & 10,85 \\
Naftaleno & 8,12 \\
n-nonano & 10,21 \\
n-octano & 10,24 \\
1-octeno & 9,52 \\
n-pentano & 10,34 \\
i-pentano & 10,32 \\
1-penteno & 9,50 \\
Propano & 11,07 \\
Tolueno & 8,82 \\
o-xileno & 8,56 \\
m-xileno & 8,56 \\
p-xileno & 8,445 \\
\hline
\end{tabular}




\section{ANEXO III}

- VALORES DE MÉdIA DOS DESVIOS E DESVIO PADRÃO PARA AOS MODELOS DESENVOLVIDOS.

- REPRESENTAÇÃO GRÁFICA dOS RESULTADOS DE FLUXO INICIAL EM FUNÇÃO DA COLUNA DE AR LIVRE EM CADA PROVETA, PARA O EXPERIMENTO QUE UTILIZOU QUATRO PROVETAS E GASOLINA PURA. 
Quadro 01- Desvio médio percentual e desvio padrão percentual para os modelos desenvolvidos para o experimento com quatro provetas e gasolina pura e para experimento com duas provetas e solo.

\begin{tabular}{lcccc|cc}
\hline & \multicolumn{4}{c|}{ 4 Provetas Gasolina Pura } & \multicolumn{2}{c}{ 2 Provetas com Solo } \\
\cline { 2 - 7 } & Prov.01 & Prov.02 & Prov.03 & Prov.04 & Prov.01 & Prov.02 \\
\hline Desvios Médios (\%) & 3,9 & 3,3 & 8,4 & 26,8 & 7,8 & 1,7 \\
Desvio Padrão (\%) & 2,5 & 2,9 & 8,5 & 13,8 & 5,0 & 1,4 \\
\hline
\end{tabular}

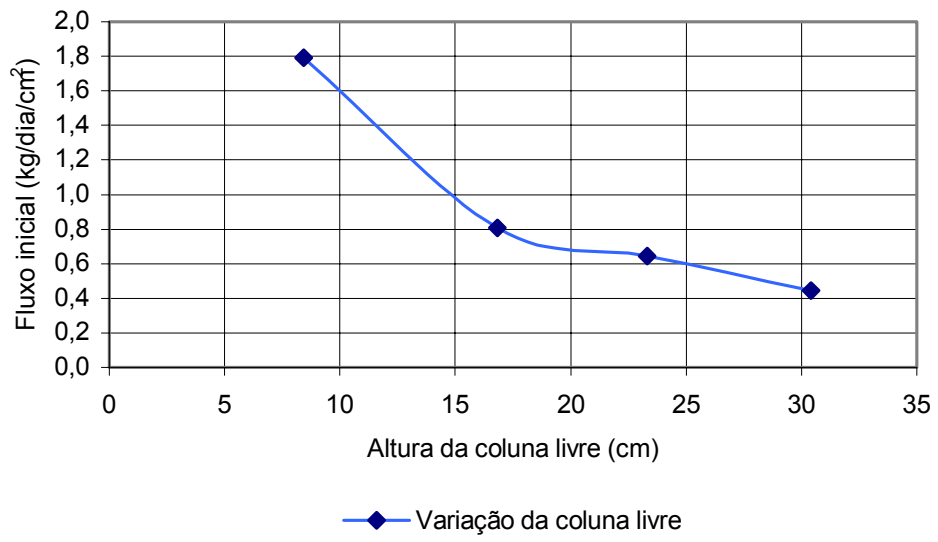

Figura01- Representação gráfica dos resultados de fluxo inicial em função dos comprimentos das respectivas colunas de ar livre para cada proveta, referente ao experimento que utilizou quatro provetas e gasolina pura. 


\section{ANEXO IV}

- RESULTADOS DAS MÁXIMAS CONCENTRAÇÕES OBTIDAS COM DETETOR DE FOTOIONIZAÇÃO E OS RESPECTIVOS TEMPOS ONDE FORAM OBTIDAS. 
Quadro 02- Máximos valores de concentração obtidos para o experimento com quatro provetas utilizando gasolina pura.

\begin{tabular}{ccccc}
\hline & \multicolumn{4}{c}{ 4 Provetas } \\
\cline { 2 - 5 } & Proveta 01 & Proveta 02 & Proveta 03 & Proveta 04 \\
\hline $\begin{array}{c}\text { Máxima Concentração } \\
\text { (ppm) }\end{array}$ & 336,3 & 343,5 & 315,4 & 291,9 \\
Tempo (dia) & 14,2 & 14,2 & 12,0 & 12,0 \\
\hline
\end{tabular}

Quadro 03- Máximos valores de concentração obtidos para os experimentos com duas provetas e duas colunas de acrílico e solo.

\begin{tabular}{ccccc}
\hline & \multicolumn{2}{c}{ 2 Provetas } & \multicolumn{2}{c}{ 2 Colunas } \\
\cline { 2 - 5 } & Proveta 01 & Proveta 02 & Coluna 01 & Coluna 02 \\
\hline $\begin{array}{c}\text { Máxima } \\
\text { Concentração (ppm) }\end{array}$ & 181,3 & 183,8 & 145,7 & 110,2 \\
Tempo (dia) & 1,1 & 2,2 & 2,0 & 18,0 \\
\hline
\end{tabular}

Quadro 04- Máximos valores de concentração obtidos para o experimento com cinco recipientes cilíndricos com capacidade para 20 litros .

\begin{tabular}{cccccc}
\hline & \multicolumn{5}{c}{ 5 Recipientes de 20 litros } \\
\cline { 2 - 6 } & Recipiente 01 & Recipiente 02 & Recipiente 03 & Recipiente 04 & Recipiente 05 \\
\hline $\begin{array}{c}\text { Máxima } \\
\text { Concentração } \\
(\mathbf{p p m )}\end{array}$ & 116,6 & 100,9 & 102,5 & 101,4 & 93,9 \\
\begin{tabular}{c} 
Tempo (dia) \\
\hline
\end{tabular} & 3,0 & 5,0 & 6,0 & 1,0 & 3,0 \\
\hline
\end{tabular}

